\title{
Débora Morais Cardoso
}

Impacto do uso de técnicas microbiológicas para o estreptococo beta hemolítico do grupo A no diagnóstico e tratamento das faringotonsilites

\footnotetext{
Tese apresentada à Faculdade de Medicina da Universidade de São Paulo para obtenção do título de Doutora em Ciências

Programa de Pediatria

Orientador: Prof. Dr. Alfredo Elias Gilio
}

(Versão corrigida. Resolução CoPGr 5890, de 20 de dezembro de 2010

A versão original está disponível na Biblioteca FMUSP)

\section{São Paulo}

2015 
DEDICATÓRIAS 
Dedico essa obra a minha família, meu bem mais precioso

Ao meu marido, Rodrigo, meu primeiro e grande amor! Meu companheiro e incentivador de todas as horas.

Aos meus filhos, Beatriz e Tiago, que me tornaram uma pessoa melhor e me apresentaram ao sentimento mais pleno que existe, o AMOR incondicional. Para eles e por eles busco sempre ser melhor...

Aos meus pais, Ana Maria e Flávio, sempre incentivadores do meu trabalho! Pessoas maravilhosas que investiram na formação dos meus valores morais e éticos, além de sempre terem valorizado a minha educação e terem investido na minha formação. Sempre com muito amor! Graças a esses valores concluo essa etapa tão importante de minha vida...

Aos meus irmãos, Andrea e Flávio, por sua amizade e companheirismo, e por sempre me admirarem e confiarem a mim os cuidados aos seus grandes tesouros, Rafael, Isabella e Gabriella. 
AGRADECIMENTOS 
Acabo de alcançar, através da conclusão dessa Tese de Doutorado, uma grande conquista na minha vida profissional e científica. Tenho plena consciência de que nada teria sido possível sem o apoio de muitas pessoas que me influenciaram direta ou indiretamente e ajudaram a realizar e concluir esse SONHO!

Gostaria, então, de fazer alguns agradecimentos de forma especial.

Inicialmente, a Deus por me prover da capacidade de cuidar do próximo, solidarizando-me pelo sofrimento alheio e trazendo-me grande satisfação em poder exercer essa minha paixão tão intensa que é a Medicina.

Ao meu marido Rodrigo, filhos Beatriz e Tiago, pais Ana Maria e Flávio, irmãos Andrea e Flávio, sobrinhos, Isabella, Rafael, Luis Felipe e Gabriella, e a toda minha família, por acreditarem em mim e me incentivarem de forma tão intensa!!!

Ao Dr. Alfredo Elias Gilio, meu orientador, que me propiciou a descoberta do caminho para a vida científica e acadêmica, sempre de maneira serena, respeitando as minhas idéias e valores! Um verdadeiro Professor e um exemplo a ser seguido...

À Natalina que mais do que uma funcionária, é uma amiga! Meu braço direito de todos os momentos...

Às minhas grandes amigas do PSI-HU, Milena De Paulis, Beatriz Marcondes e Eloísa Correia, sempre dispostas a ajudar, com palavras de apoio ou conhecimentos técnicos, incentivando-me de forma incessante até nos momentos mais difíceis...

À minha querida amiga Eliane Barreira, minha confidente das alegrias e dificuldades da vida...

Ao meu grande amigo João Paulo Becker Lotufo, grande conselheiro e excelente pessoa! O primeiro a incentivar a minha entrada na vida científica. 
Aos meus queridos amigos Maki e Angela, tão presentes na minha vida acadêmica, sempre muito compreensivos e prestativos diante das agruras desse período turbulento.

Ao meu colega Shieh, excelente matemático, que me ajudou muito a entender a incompreensível ciência estatística.

Ao meu colega do Pronto-Socorro Infantil Rodrigo (Caco) que me auxiliou todas as vezes que solicitei sua ajuda, principalmente, no momento da formatação dessa obra.

Gostaria, enfim, de agradecer a todos os que estiveram envolvidos nessa etapa da minha vida e galgaram comigo os difíceis caminhos da vida científica.

O meu MUITO OBRIGADA a todos os membros do Pronto-Socorro Infantil, colegas médicos companheiros de trabalho, enfermeiros, técnicos de enfermagem, alunos do quinto ano, residentes do primeiro ano, farmacêutica (Mônica), bibliotecária (Maria Alice), equipe do Laboratório Clínico do HU. Sem o auxílio e compreensão dessas pessoas a tarefa teria sido muito árdua! 
"Eu me curvo em admiração àqueles que como eu tiveram a oportunidade de viver situações tão extraordinárias o que faz com que eu sinta que cada minuto da minha trajetória profissional tem valido a pena". 
Esta tese está de acordo com as seguintes normas, em vigor no momento desta publicação:

Referências: adaptado de International Committee of Medical Journals Editors (Vancouver).

Universidade de São Paulo. Faculdade de Medicina. Divisão de Biblioteca e Documentação. Guia de apresentação de dissertações, teses e monografias. Elaborado por Anneliese Carneiro da Cunha, Maria Julia de A. L. Freddi, Maria F. Crestana, Marinalva de Souza Aragão, Suely Campos Cardoso, Valéria Vilhena. 3a ed. São Paulo: Divisão de Biblioteca e Documentação; 2011. 


\section{SUMÁRIO}

Lista de abreviaturas, símbolos e siglas

Lista de gráficos

Resumo

Abstract

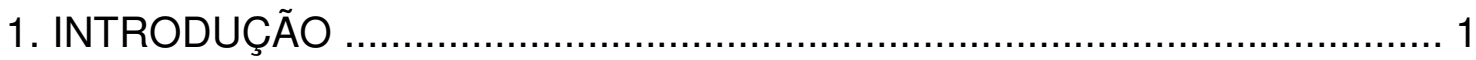

$1.1 \mathrm{O}$ estreptococo beta-hemolítico do grupo A ……................................... 3

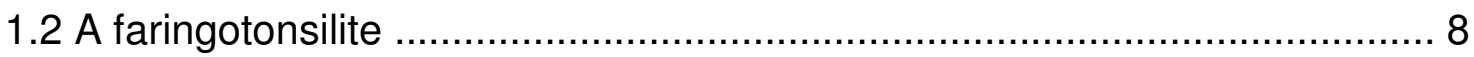

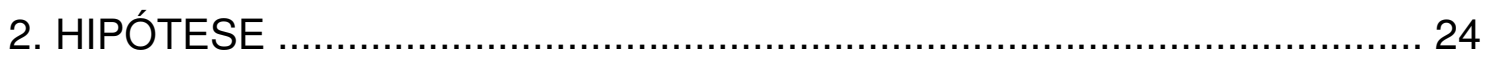

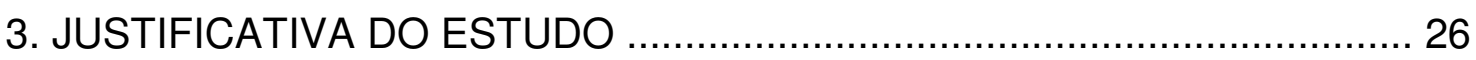

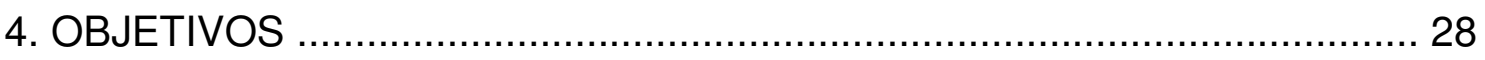

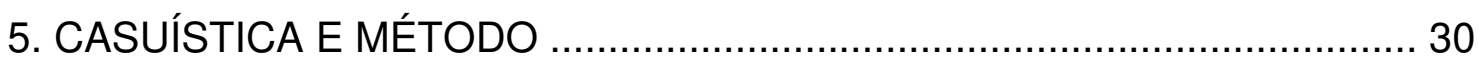

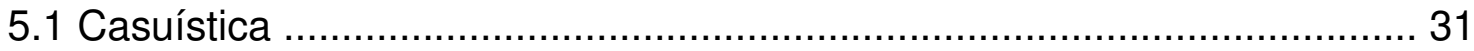

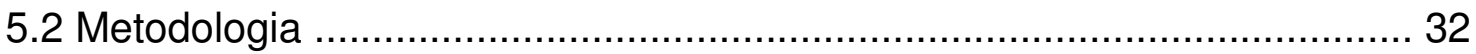

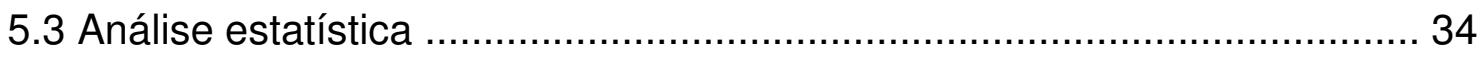

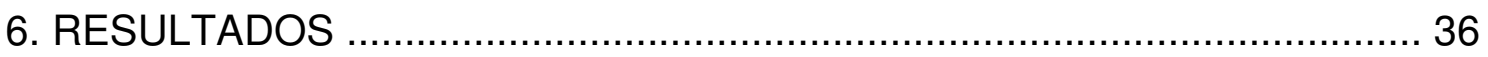

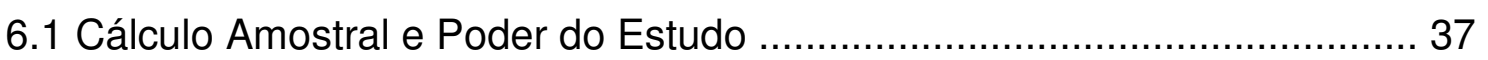

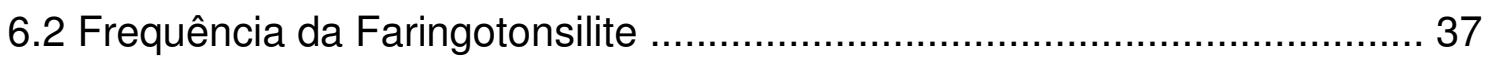

6.3 Distribuição por faixa etária e gênero das crianças atendidas com

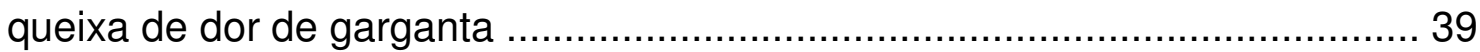

6.4 Intenção de prescrever antibiótico baseado no quadro clínico ................... 39

6.5 Frequência da infecção pelo EBHGA …………................................. 40

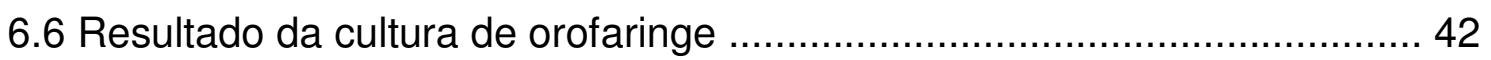

6.7 Diagnóstico clínico: sensibilidade, especificidade, VPN e VPP ................ 42

6.8 Mudança de conduta após a realização da PRE ....................................... 44

6.9 Médicos responsáveis pelo atendimento ............................................... 45

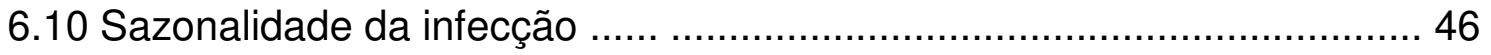

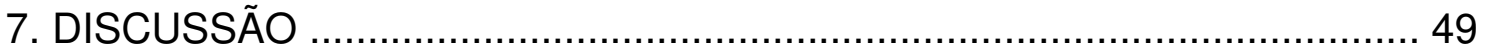

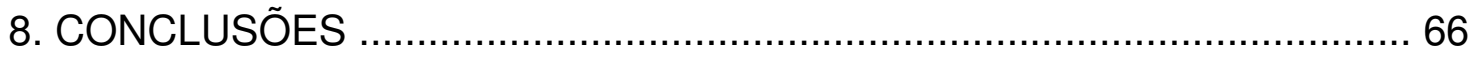

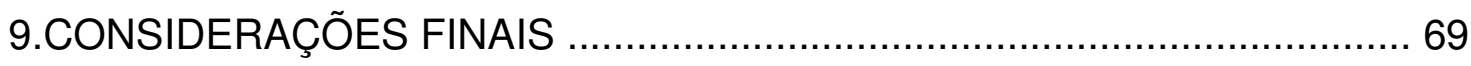

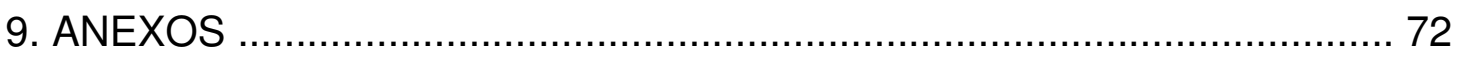

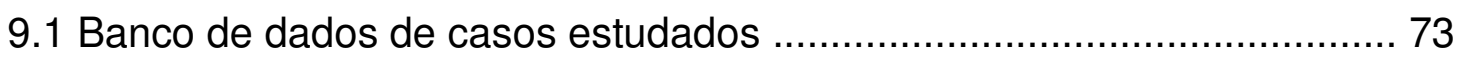


9.2 Artigo publicado na Revista Paulista de Pediatria ................................. 93

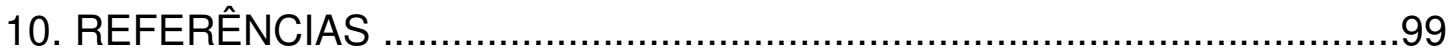




\section{LISTA DE FIGURAS}

Figura 1 - Sensibilidade e Especificidade dos escores clínicos.

10

Figura 2 - Sensibilidade e Especificidade da PRE em comparação à cultura de orofaringe.

Figura 3 - Valor Preditivo Positivo e Valor Preditivo Negativo da PRE em comparação à cultura de orofaringe

Figura 4 - Fluxograma dos pacientes atendidos.

\section{LISTAS DE GRÁFICOS}

Gráfico1 - Casos de EBHGA definidos pela PRE durante o período estudado.

Gráfico 2 - Relação entre o número de casos de faringotonsilite e temperaturas médias diárias......

Gráfico 3 - Relação entre o número de casos de faringotonsilite e a amplitude de temperaturas diárias. 


\section{LISTA DE TABELAS}

Tabela 1 - Sensibilidade e Especificidade dos Escores Clínicos

Tabela 2 - Distribuição dos pacientes estudados segundo idade (em anos) e gênero

Tabela 3 - Intenção do médico de prescrever antibiótico baseado no quadro clínico

Tabela 4 - Resultados da PRE na amostra estudada............................. 40

Tabela 5 - Frequência da infecção pelo EBHGA.................................... 40

Tabela 6 - Positividade de EBHGA com base nos resultados da PRE e cultura de acordo com a faixa etária (em anos).

Tabela 7 - Positividade de EBHGA com base nos resultados da PRE de acordo com a faixa etária (em anos)

Tabela 8 - Relação entre intenção do médico em dar antibiótico pelo quadro clínico e infecção pelo EBHGA

Tabela 9 - Conduta final após realização da PRE.

Tabela 10 - Redução do uso de antibiótico com o uso de técnicas microbiológicas (PRE e/ou cultura de orofaringe).

Tabela 11 - Diagnóstico clínico de acordo com o responsável pelo atendimento.

Tabela 12 - Distribuição dos casos de EBHGA definidos pela PRE durante o período estudado. 


\section{LISTA DE SIGLAS}

EBHGA Estreptococo beta hemolítico do grupo A de Lancefield

PCR Reação de cadeia polimerase

LTA Ácido lipoteicóico

IVAS Infecção de vias aéreas superiores

PRE Prova Rápida para detecção do Estreptococo Beta-hemolítico do grupo A

VPP Valor Preditivo Positivo

VPN Valor Preditivo Negativo

RADT Rapid Antigen Detection Test

DRC Doença Reumática do Coração

FR $\quad$ Febre Reumática

USP Universidade de São Paulo

ABNT Associação Brasileira de Normas e Técnicas 
RESUMO 
Cardoso DM. Impacto do uso de técnicas microbiológicas para estreptococo beta hemolítico do grupo $A$ no diagnóstico e tratamento das faringotonsilites [Tese]: São Paulo: Faculdade de Medicina, Universidade de São Paulo; 2015.

INTRODUÇÃO: A Faringotonsilite é doença comum nos consultórios e prontosocorros de pediatria. OBJETIVOS: Avaliar o impacto da realização rotineira da prova rápida para pesquisa de estreptococo do grupo $A(P R E)$ no diagnóstico e tratamento da faringotonsilite aguda em crianças e adolescentes atendidos em um Hospital Geral. MÉTODOS: Trata-se de um estudo prospectivo, observacional, de protocolo de atendimento, instituído no Pronto-Socorro do Hospital Universitário da Universidade de São Paulo para o atendimento de crianças e adolescentes com diagnóstico de faringotonsilite aguda. RESULTADOS: Foram estudadas 1039 crianças e adolescentes. Com base no quadro clínico, antibiótico seria prescrito em 530 pacientes (51\%), e com o uso da PRE e/ou cultura de orofaringe foi prescrito em 268 (25,8\%) pacientes. Das 509 crianças que não receberiam antibiótico pelo quadro clínico, 157 tiveram PRE e/ou cultura de orofaringe positiva. O diagnóstico baseado no quadro clínico apresentou sensibilidade de 63,06\% (IC-95\%:62,95-63,17\%); especificidade de 57,33\% (IC-95\%:57,25-57,41\%); valor preditivo positivo de 50,57\% (IC-95\%:50,47-50,66\%) e valor preditivo negativo de 69,16\% (IC-95\%: 50,47-50,66\%). CONCLUSÕES: Neste estudo o diagnóstico clínico da faringotonsilite estreptocócica mostrou baixa sensibilidade e especificidade. $O$ uso rotineiro da prova rápida para pesquisa de estreptococo permitiu uma redução do uso de antibiótico e a identificação de crianças e adolescentes com faringotonsilite estreptocócicas que não receberiam antibiótico e estariam sob o risco das complicações da infecção estreptocócica.

Descritores: Sensibilidade e especificidade, Febre reumática, Antibacterianos, Infecções estreptocócicas, Faringite, Streptococcus pyogenes, Adolescente, Criança. 
ABSTRACT 
Cardoso DM. Impact of the use of microbiological techniques for Group A Streptococcus in the diagnosis and treatment of sore throats [Thesis]: São Paulo: Faculdade de Medicina, Universidade de São Paulo; 2015.

BACKGROUND: Sore throat is a common disease in the pediatric emergency room. OBJECTIVES: The objective of this study was to evaluate the impact of routine performance of rapid antigen detection test (RADT) in the diagnosis and treatment of acute pharyngitis in children treated at an academic hospital. METHODS: This is a prospective, observational, protocol compliance, established at the Emergency of Hospital Universitário - Universidade de São Paulo for the care of children and adolescents diagnosed with acute pharyngitis. RESULTS: We studied 1039 children and adolescents. Based on clinical findings, antibiotic would be prescribed in 530 patients $(51 \%)$ and using the RADT or sore throat culture was prescribed in 268 patients. Of the 509 children who did not receive antibiotics for the clinical, 157 had positive RADT or sore throat culture. The diagnosis based on clinical sensitivity was 63,06\% (IC 95\% $62,95-63,17 \%$ ), specificity $57,3 \%$ (IC $95 \% 57,25-57,41 \%$ ), positive predictive value of $50,57 \%$ (IC $95 \% 50,47-50,66 \%$ ) and negative predictive value of $69,16 \%$ (IC 95\% 50,47-50,66\%). CONCLUSIONS: In this study the clinical diagnosis of streptococcal pharyngitis had low sensitivity and specificity. The routine use of rapid test for streptococcal research led to a reduction of antibiotic use and the identification of a risk group for complication of streptococcal infection.

Descriptors: Sensitivity and specificity, Rheumatic fever, Anti-bacterial agents, Streptococcal infections, Pharyngitis, Streptococcus pyogenes, Adolescent, Child. 
1 INTRODUÇÃO 
A faringotonsilite aguda é definida como uma infecção da faringe e/ou tonsilas. Dentre as infecções de vias aéreas superiores, é queixa freqüente na faixa etária pediátrica (Ayanruoh et al., 2009; Giraldez-Garcia et al., 2011; Regoli et al., 2011; Le Marechal et al., 2013). Em todo o mundo, é responsável por cerca de 5 a $20 \%$ dos atendimentos em serviços de emergência pediátrica (Pichichero, 1995; Atlas et al., 2005; Ayanruoh et al., 2009; Giraldez-Garcia et al., 2011; Regoli et al., 2011).

É causada por vários agentes etiológicos, e a frequência de cada agente etiológico varia de acordo com a idade da criança, a estação do ano e a área geográfica (Wald, 2007). Os vírus são os agentes etiológicos mais comuns e podem agir diretamente na faringe causando o processo inflamatório, como por exemplo, vírus Epstein Baar, citomegalovírus, adenovírus, herpes simples, influenza, e enterovirus. Outros vírus causam faringite como parte de uma síndrome respiratória de via aérea superior, como rinovírus, coronavírus, vírus sincicial respiratório e parainfluenza (Wald, 2007; Regoli et al., 2011; Van Brusselen et al., 2014; Weber, 2014). Dentre os agentes bacterianos, o estreptococo beta-hemolítico do grupo A de Lancefield (EBHGA), Streptococcus pyogenes, é responsável por 15 a 30\% dos casos (Needham et al., 1998; Schwartz et al., 1998; Ebell, 2003; Atlas et al., 2005; Santos et al., 2005; Wald, 2007; Ayanruoh et al., 2009; Cardoso et al., 2009, 2013; GiraldezGarcia et al., 2011; Regoli et al., 2011; Weber, 2014). 


\subsection{0 estreptococo beta hemolítico}

O termo estreptococo foi utilizado, pela primeira vez, por Rosenbach, em 1884, para descrever um microrganismo esférico que crescia em cadeias e que foi isolado de lesões supurativas no homem.

A descrição da existência de diferentes tipos de estreptococos data de 1900 . Um trabalho fundamentado na definição do tipo de hemólise que os estreptococos exibiram na placa de ágar-sangue culminou com a classificação em alfa-hemolíticos ( $\alpha$ hemolíticos ou hemólise parcial) e beta-hemolíticos ( $\beta$ hemolíticos ou hemólise completa). Em 1933, Rebecca Lancefield descreveu a reação de precipitação dos estreptococos beta-hemolíticos diferenciando-os em vários grupos, de acordo com a expressão do carboidrato na membrana. Os estreptococos beta-hemolíticos foram, então, classificados em grupos A, B, C, D, F, G (Lancefield, 1933).

O EBHGA apresenta em sua membrana o carboidrato $\mathrm{N}$-acetil-glucosamina (carboidrato A). Com o passar dos anos a classificação do EBHGA tornou-se mais específica e, descreveu-se mais de 150 tipos de EBHGA, baseando-se na expressão de diferentes proteínas em sua membrana, as proteínas M e T (Henningham, 2012).

A proteína $\mathrm{M}$ consiste de uma estrutura espiralada composta por quatro regiões de repetição de aminoácidos (A-D). Há uma região rica em prolina / glicina, que permite a introdução da proteína dentro da parede celular bacteriana, e uma região hidrofóbica, que atua como uma "âncora" na membrana. A porção $\mathrm{N}$ terminal da proteína é muito variável. Utilizando-se técnicas de reação de 
cadeia polimerase $(\mathrm{PCR})$ é possível realizar o sequenciamento dos genes (genes emm) que codificam tais proteínas. Isso permite definir com exatidão os genes emm correspondentes aos sorotipos de proteínas M. Foram descritas mais de 80 tipos de proteína M presentes na membrana do EBHGA o que confere variabilidade antigênica ao EBHGA (Bisno et al., 2003; Henningham, 2012; Walker et al., 2014).

A proteína $T$ também confere variação antigênica ao EBHGA, porém há menos proteínas T conhecidas e acredita-se ser uma proteína mais estável. Em algumas situações, para a definição sorológica do EBHGA pode ser, então, preferível a tipagem através da proteína T (Henningham, 2012).

A faringotonsilite é uma doença superficial causada pelo EBHGA. Acredita-se que existam três fases na patogênese da tonsilite estreptocócica: 1) adesão ao tecido epitelial das tonsilas do hospedeiro, seguida de invasão e persistência no interior das células; 2) aquisição de nutrientes e condições que permitam a proliferação no hospedeiro; 3) evasão à resposta imune do hospedeiro (Bisno et al., 2003; Henningham, 2012).

A patogênese dessas doenças é determinada por um extenso repertório de fatores de virulência da bactéria. Esses fatores de virulência são regulados de acordo com a resposta imunológica do hospedeiro à infecção.

Os principais fatores de virulência do EBHGA relacionados à tonsilite são:

1) Cápsula - O EBHGA possui uma cápsula espessa composta por ácido hialurônico, que é quimicamente semelhante ao tecido conjuntivo do hospedeiro. Portanto, não é reconhecida como antigênica pelo sistema imunológico do hospedeiro, o que permite que a bactéria esconda seus antígenos no interior dessa cápsula. A cápsula de ácido hialurônico também 
impede a opsonização e fagocitose pelos neutrófilos e macrófagos do hospedeiro (Bisno et al., 2003; Henningham, 2012).

2) Parede celular - A parede celular do EBHGA é composta por peptideoglicanos com componentes de ácido lipoteicóico (LTA). A principal função destes componentes é manter a estabilidade estrutural da bactéria. 0 LTA facilita a aderência do EBHGA nas células epiteliais das tonsilas. Os peptideoglicanos funcionam como endotoxina capaz de ativar a via alternativa do complemento.

3) Adesinas - O EBHGA, assim como outras bactérias, produz adesinas para promover sua fixação e invasão nas células epiteliais do hospedeiro. São alguns exemplos o ácido lipoteicóico da parede celular, proteína M, pili, proteínas de ligação de fibronectina (proteína F).

Proteína M - A proteína M está claramente associada aos fatores de virulência do EBHGA, pois favorece a colonização e aumenta a resistência à fagocitose. Além disso, fornece variabilidade antigênica ao EBHGA dificultando a formação de memória imunológica a esse agente bacteriano.

Pili - Atua na patogênese do EBHGA ao favorecer a adesão da proteína $M$ ao epitélio tonsilar do hospedeiro (Walker et al., 2014).

Proteína de Ligação da Fibronectina (Proteina F) - A ligação do EBHGA à fibronectina do hospedeiro aumenta sua aderência às células epiteliais (Bisno et al., 2003; Henningham, 2012; Walker et al., 2014).

Apesar dos fatores de virulência, a doença superficial causada pelo EBHGA, quando ocorre, é autolimitada na maioria dos casos. O curso natural da faringotonsilite causada pelo EBHGA é uma infecção com resolução espontânea dos sinais e sintomas em 2 a 5 dias, podendo perdurar por 8 a 10 
dias. O indivíduo permanece infectado, transmitindo o EBHGA por até uma semana após resolução dos sintomas, se não tratado com antibiótico adequadamente (Ebell, 2003).

Essa evolução benigna ocorre em função das defesas do hospedeiro. Em indivíduos normais, mecanismos de defesa inespecíficos (movimento mucociliar, tosse, espirros e reflexos da epiglote) impedem que as bactérias penetrem além do epitélio superficial do trato respiratório superior (tonsilas faríngeas). Nas situações em que há falha nesse sistema de proteção, ocorre a ativação do sistema fagocítico do hospedeiro, segunda linha de defesa contra a invasão estreptocócica. A bactéria é opsonizada pela ativação das vias clássica ou alternativa do complemento e através de anticorpos específicos produzidos no soro. Os fagócitos são células que atuam através da produção de metabólitos do oxigênio, como o peróxido de hidrogênio e superóxido, que são "tóxicos" às bactérias. Após a fagocitose, o EBHGA não é capaz de produzir catalase ou superóxido dismutase em quantidades suficientes para inativar esses metabólitos produzidos, o que, então, causa sua morte.

Indivíduos que tenham tido uma infecção prévia pelo EBHGA apresentam anticorpos $\lg \mathrm{G}$ e $\lg \mathrm{A}$ específicos contra a proteína $\mathrm{M}$, armazenados de forma duradoura nos linfócitos B, o que, também, favorece a fagocitose (Henningham, 2012).

Entretanto, apesar da evolução autolimitada, o EBHGA merece destaque entre as causas bacterianas de faringotonsilite por se tratar do único agente etiológico com indicação de tratamento (Ebell, 2003). A antibioticoterapia precoce na faringotonsilite causada pelo EBHGA está indicada com a finalidade de: 
Diminuição do tempo de doença, reduzindo sua morbidade, com retorno às atividades mais precocemente (Pichichero, 1995; American Academy of Pediatrics, 2000; Ebell, 2003; Shulman et al., 2012);

Prevenção das complicações supurativas: abscesso peritonsilar, mastoidite, abscesso retrofaríngeo, linfadenite supurativa cervical, otite média e sinusite (Pichichero, 1995; Needham et al., 1998; Schwartz et al., 1998; American Academy of Pediatrics, 2000; Dingle et al., 2014; Van Brusselen et al., 2014); Prevenção de transmissão do EBHGA, pois, após 24 horas de antibioticoterapia não há transmissão do agente bacteriano (Pichichero, 1995; Needham et al., 1998; Schwartz et al., 1998; American Academy of Pediatrics, 2000; Shulman et al., 2012; Van Brusselen et al., 2014);

Prevenção de complicações não supurativas, especialmente, febre reumática (Pichichero, 1995; Needham et al., 1998; Schwartz et al., 1998; American Academy of Pediatrics, 2000; Dingle et al., 2014; Van Brusselen et al., 2014).

Outras bactérias podem causar a faringotonsilite, mas são raras e esporádicas, e, usualmente, há achados epidemiológicos e de anamnese que auxiliam na identificação dos pacientes acometidos por essas bactérias. Neisseria gonorrhoeae e Corynebacterium diphteriae podem causar a tonsilite, entretanto, uma anamnese cuidadosa pode confirmar o risco desses agentes etiológicos. Arcanobacterium haemolyticum é um agente etiológico que pode causar tonsilite com exantema escarlatiniforme, mas ocorre em menos de $0,1 \%$ dos casos, especialmente, em adultos jovens. Mycoplasma pneumoniae também pode ser causa de tonsilite, entretanto, esses pacientes, habitualmente, apresentam tosse e outros sinais e sintomas de infecção de trato respiratório baixo. Outras bactérias beta-hemolíticas como os 
Estreptococos dos grupos C, G, B e F também podem causar tonsilite, porém, o quadro clínico pode ser indistinguível daquele causado pelo EBHGA (Pichichero, 1995; Wald, 1998; American Academy of Pediatrics, 2000; Cardoso et al., 2009; Weber, 2014).

\subsection{A faringotonsilite}

Apenas pelos sinais e sintomas clínicos é difícil diferenciar os quadros virais dos bacterianos (Wald, 1998; American Academy of Pediatrics, 2000; Bisno et al., 2003; Gerber et al., 2009; Regoli et al., 2011; Piñeiro-Pérez et al., 2011; Cardoso et al., 2013; Le Marechal et al., 2013). A faringotonsilite causada pelo EBHGA tem um pico de incidência entre as crianças em idade escolar, acima de 5 anos, sendo incomum nos menores de 3 anos (Regoli et al., 2011; Weber, 2014) e muito rara em menores de 2 anos (Piñeiro-Pérez et al., 2011). A maioria dos autores descreve a faringotonsilite estreptocócica como mais freqüente durante as estações mais frias do ano (Pichichero, 1995; Wald et al., 1998; American Academy of Pediatrics, 2000; Regoli et al., 2011; Weber, 2014). Classicamente, são descritos achados clínicos sugestivos de doença bacteriana: 1) febre, odinofagia de início súbito, cefaléia, vômitos e dor abdominal; 2) hiperemia, hipertrofia e exsudato purulento em tonsilas; 3) adenopatia cervical anterior dolorosa; 4) petéquias em palato; 5) ausência de sinais e sintomas sugestivos de infecções de vias aéreas superiores (IVAS), como tosse, coriza, lacrimejamento ocular, obstrução de vias aéreas superiores (Gerber et al., 2009; Weber, 2014). Entretanto, os dados clínicos e epidemiológicos não são específicos ou sensíveis para o diagnóstico de faringotonsilite causada pelo EBHGA. Dessa forma, desde a década de 70, 
vários autores em diversos países, têm tentado estabelecer um escore clínico com especificidade e sensibilidade altas para a detecção de faringotonsilite estreptocócica, porém sem sucesso.

Walsh e Bookheim em 1975 foram os primeiros autores a propor que o diagnóstico da tonsilite causada pelo EBHGA poderia ser determinado através de alguns sinais e sintomas. Em estudo realizado nos Estados Unidos com 478 pacientes adultos, os autores propuseram um escore clínico que se baseava na história de exposição recente ao EBHGA, presença de febre, além de linfonodomegalia cervical e exsudato tonsilar. $\mathrm{Na}$ presença de todas as variáveis clínicas, o paciente era considerado com alto risco de infecção pelo EBHGA. O escore apresentava sensibilidade de 55\% e especificidade de $74 \%$ para a detecção do EBHGA em tonsilas (Walsh, 1975).

Breese, em 1977, estabeleceu um escore clínica que avaliou a presença de variáveis clínicas (idade, contagem de leucócitos, febre, ausência de tosse, adenomegalia cervical dolorosa e exsudato tonsilar) e epidemiológica (estação do ano). A sensibilidade e especificidade desse escore para a identificação da tonsilite causada pelo EBHGA foram, respectivamente, 91\% e 38\% (Breese, 1977).

Em 1981, Centor et al. propuseram um modelo clínico para determinar a probabilidade de infecção estreptocócica ocorrer em pacientes adultos que procuravam um serviço de emergência com história de dor de garganta e febre. O modelo consistia na avaliação de quatro variáveis clínicas (exsudato tonsilar, linfonodomegalia cervical dolorosa, febre e ausência de tosse). Pacientes com as quatro variáveis presentes apresentaram probabilidade de $56 \%$ de cultura de orofaringe positiva para EBHGA, três variáveis 32\%; duas variáveis 15\%; 
uma variável $6,5 \%$ e zero variável $2,5 \%$. Ao longo dos anos, diversos autores adotaram sistemas de pontuação como o critério diagnóstico de escolha para diagnóstico e tratamento da faringotonsilite aguda (Centor et al., 1981).

Os critérios de Centor et al. (1981) passaram a ser modificados e utilizados como base para a definição de novos escores clínicos para o diagnóstico da faringotonsilite, especialmente na faixa etária pediátrica. Entretanto, os escores descritos apresentam variação de sensibilidade de 12 a 93\% e especificidade de 30 a 93\% (Breese, 1977; Steinhoff et al., 1997; Mclsaac et al., 1998; Wald et al., 1998; Bisno et al., 2002; Ebell, 2003; Rimoin et al., 2005; Santos et al., 2005; Smeesters et al., 2006) (Figura 1).

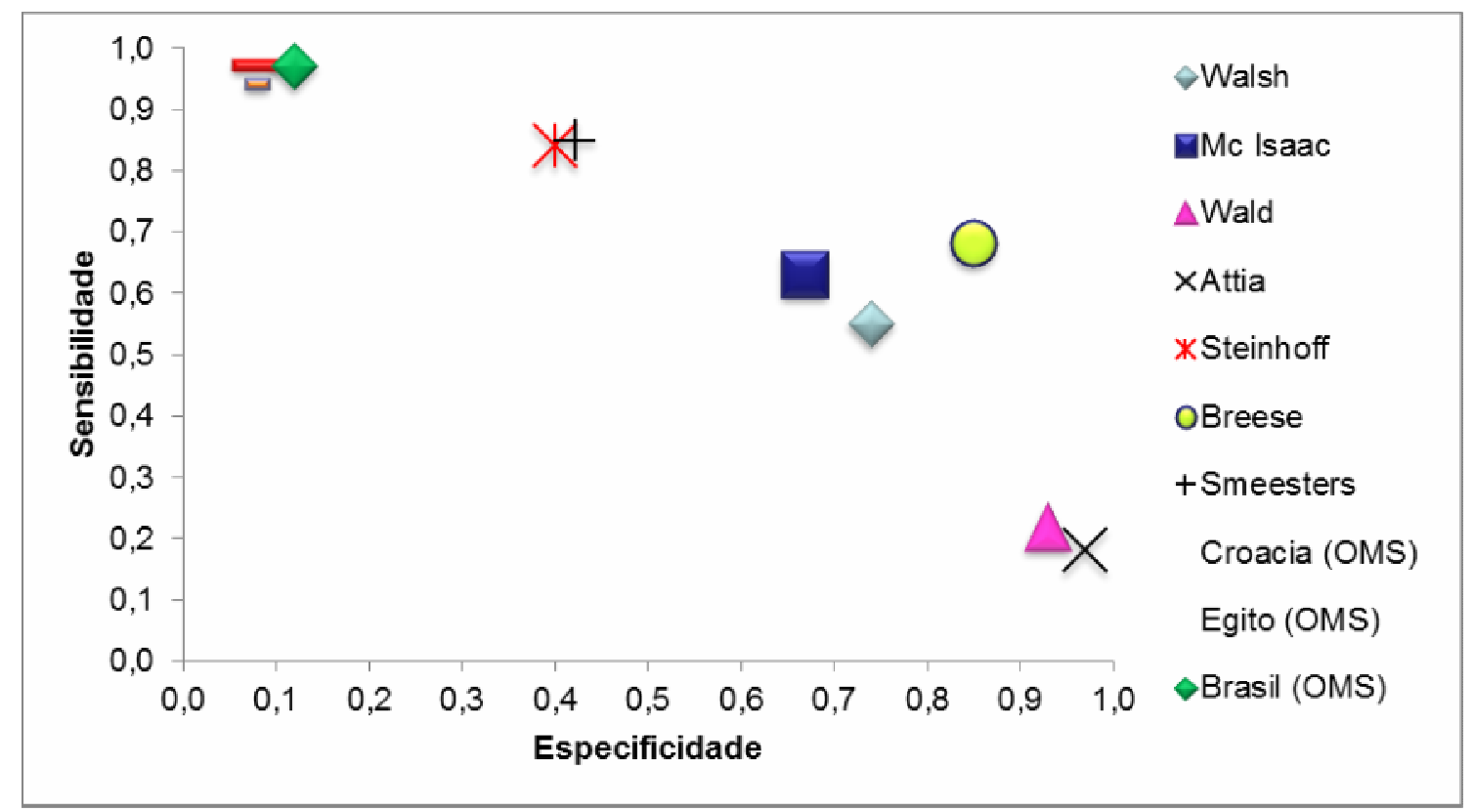

Figura 1: Sensibilidade e Especificidade dos escores clínicos

Steinhoff et al., em 1997 nos Estados Unidos, fizeram um estudo com 451 pacientes e apresentou um escore clínico ponderando a presença de linfonodomegalia cervical anterior dolorosa e exsudato tonsilar. A presença 
dessas variáveis clínicas mostraram sensibilidade de $84 \%$ e especificidade de 40\% para a tonsilite pelo EBHGA (Steinhoff et al., 1997).

Mclsaac et al., em 1998 realizaram um estudo em Toronto envolvendo 521 pacientes pediátricos e adultos. Os autores realizaram a revisão dos critérios de Centor et al. (1981) e sugeriram um escore clínico com as quatro variáveis clínicas previamente propostas (febre, exsudato tonsilar, linfonodomegalia cervical dolorosa e ausência de tosse) e a idade para a avaliação de crianças. Nesse modelo, a cada uma das variáveis clínicas presentes, foram atribuídos pontos. Na variável idade: 3 a 15 anos recebeu 1 ponto; 15 a 44 anos - 0 pontos e maiores de 45 anos - 1 ponto. A presença de febre maior que $38^{\circ} \mathrm{C}$, ausência de tosse, presença de linfonodomegalia cervical anterior dolorosa, presença de exsudato tonsilar, receberam 1 ponto cada, respectivamente. Dessa forma, os resultados demonstraram que indivíduos com escore de 0-1 apresentavam 2-6\% de probabilidade de EBHGA na cultura de orofaringe, naqueles com pontuação de $2-3,10-28 \%$ de probabilidade de infecção pelo EBHGA e no escore de 4 pontos, a chance de a tonsilite ser causada pelo EBHGA foi de 38-63\%. Esse escore mostrou sensibilidade de $63 \%$ e especificidade de 67\% (Mclsaac et al., 1998).

Wald et al., em 1998, propuseram um escore clínico epidemiológico com 6 variáveis (estação do ano, idade, linfonodomegalia cervical anterior dolorosa, hipertrofia ou exsudato tonsilar e ausência de tosse, rinite ou conjuntivite). Esse escore apresenta sensibilidade de $22 \%$ e especificidade de $93 \%$, e, quando presentes as 6 variáveis, seu Valor Preditivo Positivo é de 85\%, porém na ausência de qualquer variável, esse valor cai para 50\% (Wald et al., 1998). 
Em 2001, Attia et al., nos Estados Unidos, ao estudarem 587 pacientes, determinaram um modelo clínico com sensibilidade de $18 \%$ e especificidade de 97\%, respectivamente, para a determinação da infecção pelo EBHGA. Para isso, utilizaram as seguintes variáveis clínicas: hipertofia tonsilar, linfonodomegalia cervical, ausência de tosse e/ou coriza, febre escarlatiniforme (Attia et al., 2001).

A Organização Mundial de Saúde realizou um estudo em três países distintos (Brasil, Egito e Croácia) para propor um escore clínico a ser aplicado em países em desenvolvimento. Nesse estudo, determinou-se que a presença de exsudato em tonsilas e adenopatia cervical anterior dolorosa em crianças acima de cinco anos consiste em caso sugestivo de faringotonsilite por EBHGA e, portanto, recomenda-se a antibioticoterapia empírica. Tal escore apresenta sensibilidade de $93 \%$ e especificidade de 12\% (Rimoin et al., 2005).

Ebell, em 2003, numa revisão comentada de diversos estudos, concluiu que não foi possível identificar um sinal/sintoma e/ou escore clínico capaz de determinar o diagnóstico da faringotonsilite causada pelo EBHGA (Ebell, 2003). Le Marechal et al., em 2013, realizou metanálise para avaliar a eficiência do diagnóstico clinico da faringotonsilite. Com a inclusão de 9560 pacientes, em 16 estudos, concluiu que não é possível a realização do diagnóstico preciso com a utilização dos sinais e sintomas (Le Marechal et al., 2013).

No Brasil, estudos foram realizados com intuito de se verificar se o diagnóstico clínico pode prever o diagnóstico etiológico de forma precisa. Porém, os resultados foram conflitantes, demonstrando que o diagnóstico clínico pode não ser uma forma segura de se conduzir o tratamento da faringotonsilite na infância (Santos et al., 2005; Cardoso et al., 2009). Cillo et al., em 1999, 
avaliaram o quadro clínico de 51 crianças com faringotonsilite aguda e não encontrou significância estatística para qualquer sinal ou sintoma. Sugerindo, então, que o diagnóstico clínico de faringotonsilite causada pelo EBHGA fundamentado, apenas, em sinais e sintomas foi ineficiente para a realização de um diagnóstico preciso (Cillo et al., 1999). Santos, em 2005, analisando sinais e sintomas, isoladamente, em 376 pacientes mostrou que a presença de petéquias em palato, exsudato e adenopatia cervical anterior dolorosa foram mais frequentes naquelas crianças que apresentavam cultura positiva para o EBHGA (Santos et al., 2005). Entretanto, os próprios autores referem que, mesmo em amostras semelhantes, os sinais e sintomas variam de estudo para estudo.

Smeesters et al., em 2006, propuseram um escore clínico que se baseou em um estudo com 220 pacientes realizado em três hospitais públicos em Brasília. As crianças com idade de 0 a 15 anos foram avaliadas quanto à idade, presença de sinais sugestivos de infecção viral (conjuntivite, tosse, coriza, diarréia e exantema) e sinais sugestivos de infecção bacteriana (febre $>38,5^{\circ} \mathrm{C}$, linfonodos cervicais, cefaleia, petéquias em palato, dor abdominal e início súbito < 48 h). Na variável idade, as crianças $\leq 35$ meses recebiam pontuação de 20; 36 a 59 meses, 6 pontos e $\geq 60$ meses, 2 pontos. Quanto aos sinais virais, na ausência desses, 0 pontos; se 1 sinal, 7 pontos; se $\geq 2$ sinais, 10 pontos. Os sinais bacterianos, na ausência, 10 pontos, 1 sinal -2 pontos, e $\geq 2$ sinais -4 pontos. Naqueles em que a soma dos pontos atribuídos às variáveis tinha valor $\geq 8$, o quadro foi considerado viral e, portanto, indicou-se sintomáticos. Naqueles com valor $<8$, considerou-se o quadro sugestivo de infecção bacteriana, e portanto, indicou-se a antibioticoterapia. A sensibilidade 
desse escore foi de $41 \%$ e a especificidade de $84 \%$, em comparação ao padrão-ouro para o diagnóstico, a cultura de orofaringe (Smeesters et al., 2006).

Cardoso et al. (2013) em estudo com 650 crianças que avaliou a acurácia do diagnóstico clínico como preditor da etiologia da infecção, observaram que a sensibilidade e especificidade do diagnóstico clínico foram de 61,1\% e 47,7\%, respectivamente, ao se avaliar idade superior a 2 anos, história de febre e dor de garganta e ausência de sinais sugestivos de infecção de vias aéreas superiores, como tosse, coriza, lacrimejamento ocular.

Tabela 1: Sensibilidade e Especificidade dos Escores Clínicos

\begin{tabular}{l|l|l}
\hline Escore Clínico & Sensibilidade & Especificidade \\
\hline Walsh,1975 & $55 \%$ & $74 \%$ \\
\hline Breese,1977 & $91 \%$ & $38 \%$ \\
\hline Steinhoff,1997 & $84 \%$ & $40 \%$ \\
\hline Mc Isaac,1998 & $63 \%$ & $67 \%$ \\
\hline Wald,1998 & $22 \%$ & $93 \%$ \\
\hline Attia,2001 & $18 \%$ & $97 \%$ \\
\hline Rimoin, 2005 OMS & $93 \%$ & $12 \%$ \\
\hline Smeesters,2006 & $41 \%$ & $84 \%$ \\
\hline Cardoso,2013 & $61,1 \%$ & $47,7 \%$ \\
\hline
\end{tabular}

Assim, em função dessa dificuldade em se determinar o diagnóstico etiológico confiável, os comitês norte-americanos, como o Comitê de Febre Reumática, Endocardite e Doença de Kawasaki da Associação Americana de Cardiologia, a Academia Americana de Pediatria, a Sociedade Americana de Pediatria (American Academy of Pediatrics, 2000), comitês de especialistas europeus, na 
França, Espanha, Portugal, Itália e Finlândia (Buchbinder et al., 2007; Morais et al., 2009; Chiappini et al., 2011; Giraldez-Garcia et al., 2011; Piñeiro-Pérez et al., 2011; Regoli et al., 2011), e mais recentemente, a Sociedade Brasileira de Pediatria (Nascimento-Carvalho; Marques, 2006) recomendam que o diagnóstico de faringotonsilite estreptocócica do grupo $A$, em pacientes com suspeita clínica e epidemiológica, seja estabelecido através do uso de técnicas microbiológicas. Em contrapartida, sociedades médicas no Reino Unido, Escócia, Holanda e Bélgica, consideram a faringotonsilite, ainda que causada pelo EBHGA, uma infecção benigna e autolimitada e, portanto, não necessitaria ser tratada, empiricamente com antibióticos. O principal argumento dos autores é que em função da baixa incidência de febre reumática nesses países, assim como em outros países desenvolvidos, a antibioticoterapia empírica e a investigação etiológica não são necessárias. A posição assumida por esses países busca indicar o uso de antibióticos em casos bem selecionados, de forma, a conduzir seu uso de maneira mais prudente, evitando, assim, o surgimento e a propagação de cepas de bactérias resistentes aos antibióticos, assim como evitar os eventos adversos causados pelo uso do antibiótico (Chiappini et al., 2011; Regoli et al., 2011; Weber, 2014).

Dentre os métodos microbiológicos disponíveis, a cultura de orofaringe semeada em ágar sangue é o padrão-ouro para o diagnóstico da faringotonsilite estreptocócica do grupo A (Pichichero, 1995; Needham et al., 1998; Schwartz et al., 1998; Webb, 1998; American Academy of Pediatrics, 2000; Bisno et al., 2002; Giesseker et al., 2002; Santos et al., 2005; Wald, 2007; Ayanruoh et al., 2009; Cardoso et al., 2009; Gerber et al., 2009; Morais et al., 2009; Tanz et al., 2009; Giraldez-Garcia et al., 2011; Piñeiro-Pérez et al., 
2011; Regoli et al., 2011; Shulman et al., 2012; Cardoso et al., 2013). Vários fatores podem interferir na eficácia diagnóstica da cultura de orofaringe, como a técnica de coleta, a capacidade técnica do indivíduo que realiza o exame, assim como a capacidade técnica do laboratório em que é realizada. Outro fator que altera a sensibilidade da cultura de orofaringe é o tempo de semeadura da secreção que deve ser superior a 24 horas, com leitura do resultado entre 24 e 48 horas (Webb, 1998; Giesseker et al., 2002). Quando a leitura é realizada nas primeiras 24 horas há a chance de resultados falsos negativos em 40\% dos casos (Webb, 1998).

A Prova Rápida para Estreptococo beta-hemolítico do grupo A (PRE) é um imunoensaio para a detecção de antígenos do carboidrato do grupo A do agente etiológico na orofaringe. Apresenta especificidade em torno de $95 \%$ quando comparado à cultura de orofaringe (Santos et al., 2005; Camurdan et al., 2008; Cardoso et al., 2009; Lasseter et al., 2009; Tanz et al., 2009; Gurol et al., 2010; Rogo et al., 2010; Ruiz-Aragón et al., 2010; Cohen et al., 2012; Cardoso et al., 2013), e por essa razão, preconiza-se que nos casos em que a PRE for positiva não se realize cultura de orofaringe concomitante (Armengol et al., 2004; Edmonson; Farwell, 2005; Weber, 2014). Resultados de PRE falso positivo são raros, porém podem ocorrer quando há a presença de outros estreptocococos na orofaringe, como Streptococcus milleri, alfa-hemolíticos, que expressam em sua membrana o antígeno do carboidrato do grupo $A$. Estreptococos beta-hemolíticos inviáveis também podem causar PRE positiva, sem correlação com a cultura de orofaringe (Rubin; Mirkin, 2000; Gerber; Shulman, 2004). 
Por outro lado, a sensibilidade é variável em função da intensidade da doença, técnica de coleta, quantidade de antígenos e tipo de kit utilizado (Armengol et al., 2004; Rimoin et al., 2005; Camurdan et al., 2008; Gerber et al., 2009; Tanz et al., 2009). Dessa forma, recomenda-se que frente a uma prova rápida negativa proceda-se a coleta de cultura de orofaringe (Webb, 1998; Woods, 1999; Linder et al., 2005; Fontes et al., 2007; Morais et al., 2009). Vários estudos foram realizados para comparar a PRE e a cultura de orofaringe, observando-se que a sensibilidade da PRE varia de $62 \%$ a $96,7 \%$, a especificidade varia de 95,1 a $100 \%$, o valor preditivo positivo de $84,9 \%$ a $95 \%$ e o valor preditivo negativo de 93,8\% a 98,9\% (Santos et al., 2005; Camurdan et al., 2008; Lasseter et al., 2009; Tanz et al., 2009; Gurol et al., 2010; Rogo et al., 2010; Ruiz-Aragón et al., 2010; Cohen et al., 2012) (Figuras 2 e 3).

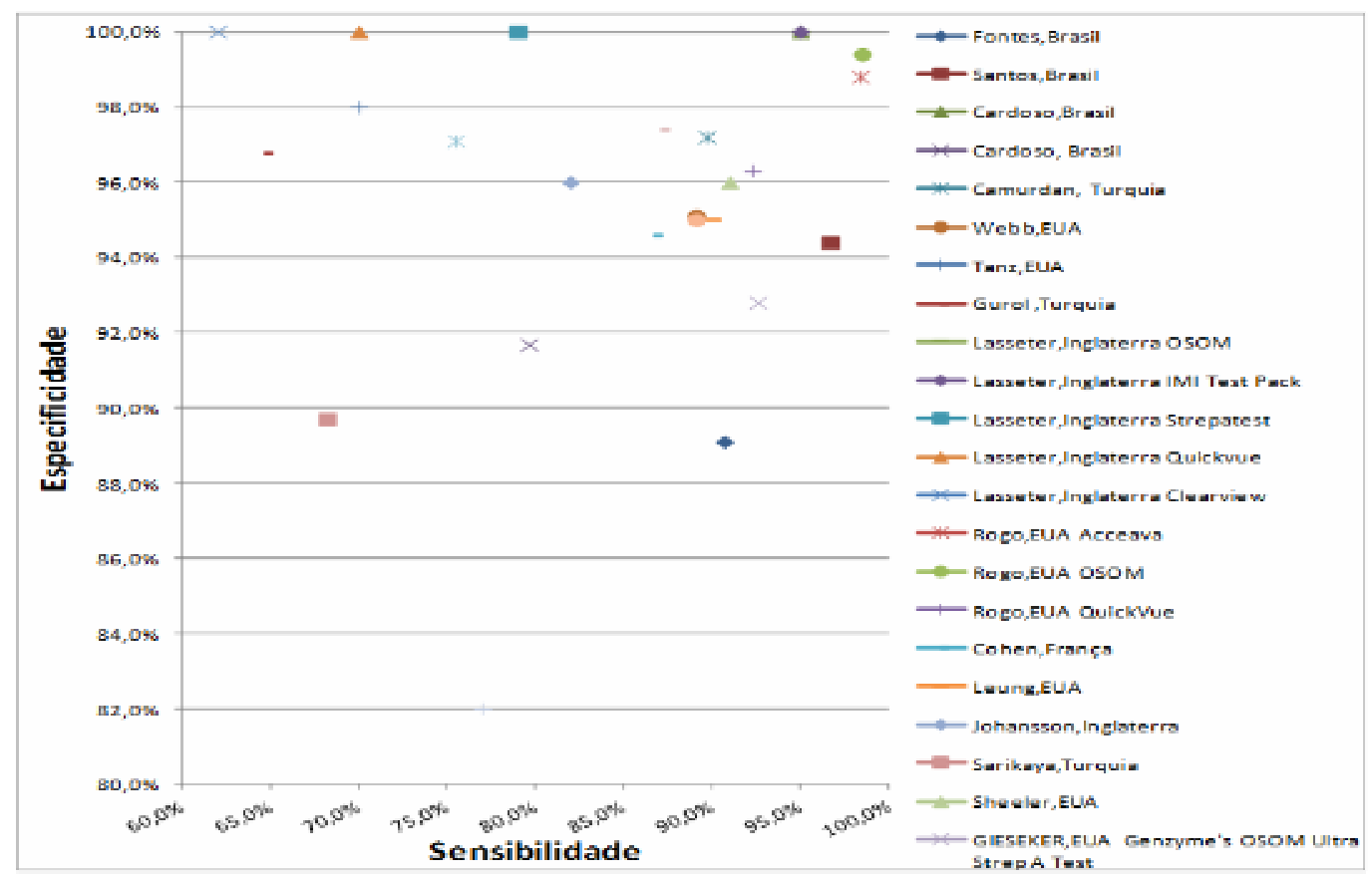

Figura 2: Sensibilidade e Especificidade da PRE em comparação à cultura de orofaringe 


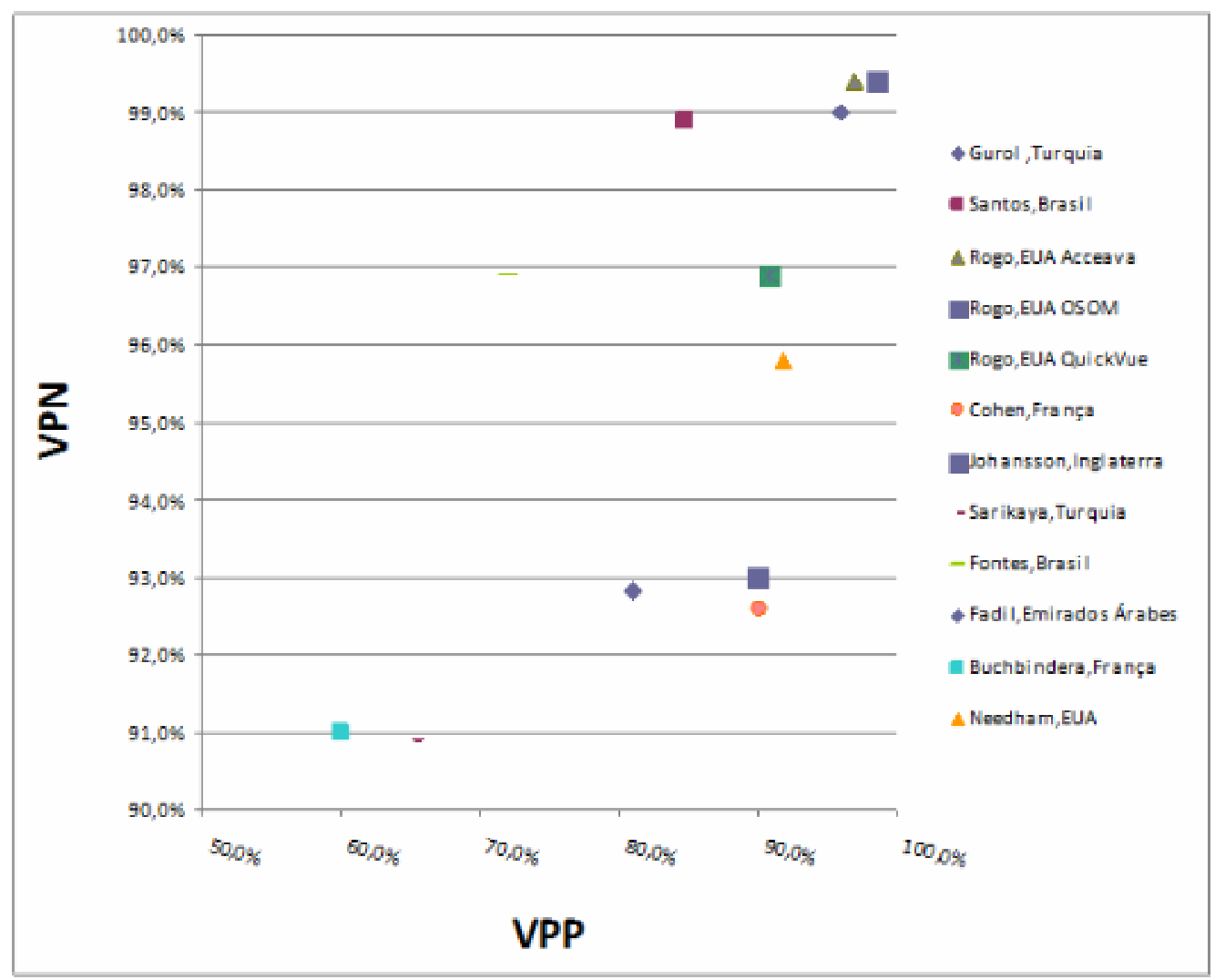

Figura 3: Valor Preditivo Positivo e Valor Preditivo Negativo da PRE em comparação à cultura de orofaringe

Fontes et al. (2007), no período de 1997-2001, em um estudo com 220 crianças, demonstrou que a sensibilidade, especificidade, VPP e VPN da PRE em comparação com a cultura de orofaringe foram, respectivamente, $90,7 \%$, $89,1 \%, 72,1 \%$ e $96,9 \%$.

Santos e Berezin (2005), em 2000-2001, ao avaliar a sensibilidade, especificidade, VPP e VPN da PRE em comparação com a cultura de orofaringe, numa amostra com 376 crianças, observou valores de 96,7\%, $94,4 \%, 84,8 \%, 98,9 \%$, respectivamente.

Cardoso et al. $(2009,2013)$ realizou em São Paulo, no Hospital Universitário da USP, dois estudos para avaliar a aplicabilidade da PRE em um pronto-socorro infantil. Verificou, em 2006-2007, numa amostra com 122 crianças com idade de 2-14 anos completos que a sensibilidade e a especificidade da PRE em 
comparação com a cultura de orofaringe foram, respectivamente, 95\% e 100\%. No período de 2008 a 2009, após a introdução da PRE na rotina desse hospital, verificou que o VPN do teste foi de $94,8 \%$.

Webb (1998), em uma metanálise que incluiu 13 estudos, observou que a sensibilidade e especificidade da PRE foram $89,1 \%$ e $95 \%$, respectivamente. A sensibilidade e especificidade da cultura de orofaringe foram de $83,4 \%$ e $99 \%$, respectivamente.

Sheeler et al., nos Estados Unidos em estudo ocorrido em 2002, demonstrou especificidade de $96 \%$ e sensibilidade de $91 \%$ da PRE para o diagnóstico da tonsilite causada pelo EBHGA, quando comparada à cultura de orofaringe. Johansson e Mansson (2003), em estudo realizado na Suécia, demonstrou que a sensibilidade, especificidade, VPP e VPN da PRE foram $82 \%, 96 \%, 90 \%$ e $93 \%$, respectivamente.

Camurdan et al. (2008), em estudo realizado no período de 1998-2001, com 1248 crianças incluídas, observou que a sensibilidade da PRE foi de $89,7 \%$, a especificidade de $97,2 \%$, o VPP de $95 \%$ e o VPN de $93,8 \%$, ao se comparar com a cultura de orofaringe.

Tanz et al. (2009) demonstrou que a sensibilidade e a especificidade da PRE foram $70 \%$ e $98 \%$, respectivamente, quando comparadas com o padrão-ouro, a cultura de orofaringe.

Sarikaya et al. (2010), em estudo realizado na Turquia, encontrou valores menores de sensibilidade, especificidade, VPP e VPN da PRE, 68,2\%, 89,7\%, $90,9 \%$ e $65,2 \%$.

Gurol et al. (2010) demonstrou baixos valores de sensibilidade para a PRE quando comparou com o padrão-ouro, cultura de orofaringe. Os valores de 
sensibilidade, especificidade, VPP e VPN foram, respectivamente, $64,6 \%$, $96,79 \%, 80,95 \%$ e $92,82 \%$.

Em um estudo realizado na França, por Cohen et al. (2012), encontrou-se valores altos de sensibilidade, especificidade, VPP e VPN da PRE, 86,7\%, $94,6 \%, 90,1 \%$ e $92,6 \%$, respectivamente.

Em função dos resultados preliminares dos trabalhos que estudaram a PRE, comparando a sua sensibilidade e especificidade com a cultura de orofaringe, alguns autores passaram, então, a fazer estudos com as diferentes variedades de PRE com o intuito de se definir qual o melhor teste a se indicar. A partir dos anos 2000, começaram a ser publicados os resultados desses estudos.

Giesseker et al. (2002), ao comparar dois testes verificou que a sensibilidade variou de 75,5 a $92,2 \%$ e que a especificidade variou entre os 2 testes de $92,8 \%$ a $97,1 \%$. A conclusão da autora foi que há necessidade de se realizar cultura de orofaringe concomitante para se atingir um valor maior do que $95 \%$ de sensibilidade para a detecção do EBHGA

Lasseter et al. (2009) fez um estudo para comparar a sensibilidade e especificidade de cinco diferentes testes rápidos em relação à cultura de orofaringe. A variação da sensibilidade dos testes foi de $62 \%$ a $95 \%$, e a especificidade foi de $100 \%$.

Rogo et al. (2010) também estudou três diferentes testes rápidos e o que pôde observar foi que tanto a sensibilidade quanto a especificidade foram superiores a $98 \%$ para a identificação do EBHGA.

Em metanálise realizada na Austrália, em 2014, os autores estudaram diferentes testes rápidos e observaram que a sensibilidade e a especificidade da PRE foram $86 \%$ e 96\%, respectivamente (Lean et al., 2014). 
Portanto, o que se vem observando, nos últimos anos, é o surgimento de testes rápidos não só muito específicos, como também, com sensibilidade bastante elevada. Esses são instrumentos que se mostram importantes auxiliares para a definição do diagnóstico etiológico das faringotonsilites de forma precisa e precoce. Dessa forma, evita-se a transmissão de EBHGA; diminui-se o risco de complicações supurativas e não supurativas, como a febre reumática; melhorase a sintomatologia, diminuindo a morbidade da infecção; e, enfim, evita-se o uso desnecessário de antibióticos.

O uso criterioso de antibiótico desempenha um papel importante na prevenção da resistência bacteriana aos antimicrobianos, na redução dos custos de cuidados na saúde, e na melhora do atendimento individual ao paciente (Deuster et al., 2010).

Entretanto, o uso de antibióticos para o tratamento de Infecções respiratórias agudas de vias aéreas superiores, de etiologia viral, é bastante comum, tanto em países desenvolvidos como naqueles em desenvolvimento (Bricks, 2003). As taxas de uso inadequado de antibióticos, nos Estados Unidos, foram estimadas em cerca 25 a 50\% das prescrições (Deuster et al., 2010). Em estudo realizado na cidade de São Paulo, verificou-se que $68 \%$ dos antibióticos prescritos para crianças menores de sete anos com infecções respiratórias agudas, dentre elas a faringotonsilite, eram inadequados (Bricks, 2003).

Isto se deve a uma multiplicidade de fatores, dentre eles, a dificuldades para diferenciar clinicamente infecções de etiologia viral das bacterianas, o desconhecimento sobre os possíveis eventos adversos associados ao uso inadequado de antibióticos e, especialmente, o impacto que o uso inadequado 
de antibiótico causa sobre o aumento da resistência bacteriana (Schwartz et al., 1998; Bricks, 2003; Samore et al., 2005; Deuster et al., 2010).

A emergência e disseminação de cepas de bactérias resistentes aos antimicrobianos são problemas de saúde pública que acometem tanto os países desenvolvidos como aqueles em desenvolvimento (Samore et al., 2005; Smeester et al., 2006; Werner; Deasy, 2009; Deuster et al., 2010; Llor et al., 2011; Pulcini et al., 2012). Infecções resistentes causam maior morbidade e mortalidade, geram custos mais elevados e aumentam o tempo de evolução da doença com persistência mais prolongada dos sinais e sintomas (Samore et al., 2005; Smeesters et al., 2006; Ayanruoh et al., 2009; Werner; Deasy, 2009; Deuster et al., 2010). Intervenções para diminuir a prescrição inadvertida de antibióticos devem ser providenciadas, de forma urgente, devido, também, ao declínio da produção e criação de novos antimicrobianos, em especial, para bactérias multi-resistentes (Werner; Deasy, 2009; Deuster et al., 2010). Essas intervenções devem ocorrer levando-se em consideração o país e os recursos disponíveis, e podem variar desde uma modificação no comportamento da classe médica até o uso de técnicas diagnósticas complementares (Samore et al., 2005; Buchbinder et al., 2007; Al-Najjar; Uduman, 2008; Sabuncu et al., 2009; Werner; Deasy, 2009; Deuster et al., 2010; Llor et al., 2011; Pulcini et al., 2012; Litvin et al., 2012; Regueras De Lorenzo et al., 2012), como a PRE.

Outra realidade existente é o risco de ocorrerem eventos adversos graves em função do uso de antibióticos. Reação anafilática ao uso da penicilina ocorre em $0,015 \%$ com taxa de mortalidade por choque em $0,002 \%$. Em geral, 0 tratamento com 10 dias de antibiótico pode apresentar alguma morbidade em cerca de $10 \%$ dos casos (Weber, 2014). 
Estudos demonstraram que com o uso de técnicas diagnósticas complementares, como a PRE, a prescrição adequada de antibióticos ocorre na maioria dos casos (Needham et al., 1998; Ayanruoh et al., 2009; Choby, 2009; Cardoso et al., 2013).

Cardoso et al. (2009) realizou um trabalho prospectivo no Pronto-Socorro do Hospital Universitário da USP para comparação dos diagnósticos clínico e microbiológico nas crianças com faringotonsilites. A conclusão dos autores foi que o exame clínico sem o uso de técnicas microbiológicas é insuficiente para detecção da faringotonsilite causada pelo EBHGA (Cardoso et al., 2009).

A partir de abril de 2008, instituiu-se no Hospital Universitário da Universidade de São Paulo, como rotina, um protocolo de atendimento aos pacientes com suspeita de faringotonsilite aguda, baseado nas recomendações da Sociedade Brasileira de Pediatria. Todas as crianças com mais de dois anos de idade, com queixa de dor de garganta, febre e ausência de sinais de infecções virais, passaram a ser submetidas à coleta da prova rápida para EBHGA. Nas crianças em que a PRE é negativa, colhe-se novo swab para a realização de cultura de orofaringe, e aguarda-se o resultado sem a introdução de antibióticos. Nos casos em que a PRE é positiva, inicia-se o tratamento com antibiótico. 
2 HIPÓTESE 
O uso de técnicas microbiológicas para o diagnóstico da faringotonsilites em crianças e adolescentes reduz o uso de antibióticos em Pronto-Socorro de Hospital Geral. 
3 JUSTIFICATIVA 
Apesar de o uso de técnicas microbiológicas para o diagnóstico e tratamento da faringotonsilite na infância ser recomendação da Sociedade Brasileira de Pediatria não há, em nosso meio, estudo que avalie a utilidade desta conduta em Pronto Socorro de Hospital Geral. 
4 OBJETIVOS 


\subsection{Objetivo principal}

Avaliar o impacto da utilização rotineira da prova rápida para pesquisa de estreptococo (PRE) na prescrição de antimicrobianos no atendimento a crianças e adolescentes com faringotonsilite aguda atendidas em um ProntoSocorro de Hospital Geral.

\subsection{Objetivos secundários}

Avaliar a sensibilidade, a especificidade, Valores Preditivo Positivo e Negativo (VPP, VPN) do diagnóstico clínico na população estudada.

Descrever a frequência de atendimentos motivados pela queixa de dor de garganta e febre.

Descrever a frequência da faringotonsilite por Estreptococo beta-hemolítico do grupo A em crianças e adolescentes atendidas em um Pronto-Socorro de Hospital Geral.

Avaliar o acerto no diagnóstico clínico de acordo com o responsável pelo atendimento (aluno do $5 \square$ ano de Graduação em Medicina, residente do $1 \square$ ano do Programa de Pediatria e médicos assistentes).

Descrever a sazonalidade do Estreptococo beta-hemolítico do grupo A, no período de um ano. 
5 CASUÍSTICA E MÉTODO 


\subsection{Casuística}

Foi realizado estudo prospectivo observacional de protocolo de atendimento, instituído no Pronto-Socorro do Hospital Universitário da Universidade de São Paulo, no período de 01 de novembro de 2009 a 30 de novembro de 2010 . 0 estudo foi aprovado pelo Comitê de Ética em Pesquisa do Hospital Universitário da USP CEP-HU/USP registro 996/10.

O Hospital Universitário da Universidade de São Paulo (HU-USP) é um hospital-escola, de nível de atenção secundário situado na região oeste da cidade de São Paulo, dentro do campus da Universidade de São Paulo (USP). Tem como característica o atendimento regionalizado à população residente no Distrito de Saúde do Butantã e a funcionários, alunos e docentes da Universidade e seus dependentes.

O setor de emergência da Pediatria presta atendimento a crianças de 0 a 15 anos incompletos, que são trazidas ao hospital espontaneamente ou encaminhadas por Unidades Básica de Saúde ou AMAs (Assistência Médica Ambulatorial) da região. O Pronto Socorro Infantil do Hospital Universitário (PSI-HU) conta com sete salas de atendimento, uma sala para medicação, uma para emergência e setor com onze leitos de observação, sendo dois de isolamento. A equipe de atendimento é formada por médicos assistentes, responsáveis pela atenção médica e pela supervisão de residentes do Departamento de Pediatria da Faculdade de Medicina da Universidade de São Paulo e alunos do $5^{\circ}$ ano da Graduação em Medicina da Faculdade de Medicina da Universidade de São Paulo, em regime de internato. 
São atendidas em média 200 crianças por dia (cálculo baseado nos dados estatísticos do HU-USP dos últimos 5 anos). No período do estudo foram atendidas 66661 crianças com média diária de 169,19.

A característica sócio-econômica da população atendida no HU-USP é predominantemente constituída por famílias de baixo nível sócioeconômico, sendo que $57 \%$ têm renda familiar inferior a 3 salários mínimos (relatórios do Hospital Universitário).

Foram considerados critérios de inclusão para análise do estudo, os atendimentos realizados a crianças e adolescentes com as seguintes características: idade de 2 a 15 anos incompletos, história de dor de garganta e febre, e ausência de sinais sugestivos de infecção viral (tosse, obstrução nasal, lacrimejamento ocular, diarréia). Foram considerados critérios de exclusão crianças que tivessem usado antibiótico nas últimas 24 horas.

\subsection{Método}

Foram avaliados os resultados da prova rápida para EBHGA (PRE).

O teste utilizado foi o QuickVue In-Line Strep A Test ${ }^{\circledR}$ (Quidel Corporation, San Diego, California, USA), que consiste em um imunoensaio rápido para a detecção qualitativa de antígenos de estreptococos do grupo A. O material examinado foi secreção de orofaringe. Utilizou-se um swab que foi introduzido na orofaringe com cuidado para não tocar em mucosa jugal, língua ou úvula. Com movimento vigoroso procedeu-se à coleta da secreção em tonsilas, e a prova rápida foi realizada imediatamente com metodologia de acordo com as recomendações do fabricante. O kit consiste de dois reagentes (A- nitrito de 
sódio e B- ácido acético), um tubo plástico para a solução formada pela mistura dos reagentes $A$ e $B$, um swab para a coleta da secreção, uma placa para a leitura do resultado. Antes da coleta da secreção, faz-se uma solução com 4 gotas de cada um dos reagentes no tubo. Após isso colhe-se a secreção com o swab e coloca-se esse swab no tubo com a solução, aguarda-se um minuto e após isso coloca-se 3 gotas da nova solução $(A+B+$ secreção de orofaringe) na placa para a leitura do resultado do teste. Aguarda-se cinco minutos e realizase a leitura do teste. O teste é considerado positivo quando há a coloração de 2 bandas (controle e teste) e negativo quando há a coloração de apenas 1 banda (controle).

Nos pacientes com PRE positiva, iniciou-se a antibioticoterapia. Nos pacientes em que a PRE apresentou resultado negativo foi colhida cultura de secreção de orofaringe. O material colhido foi encaminhado em meio de transporte Stuart (Oxoid). Foi semeado em ágar sangue de carneiro 5\% e em caldo Todd-Hewitt (Oxoid) e incubados em estufa com $5-10 \%$ de $\mathrm{CO}_{2}$ a $35 \pm 2 \square$ C. Após o período de incubação inicial de 18 a 24 horas, foi realizada a leitura da placa de ágar sangue. $\mathrm{Na}$ ausência de crescimento bacteriano, a placa foi incubada por mais 24 horas. Após esse período, foi feita a pesquisa da presença de colônias com características de EBHGA. As colônias beta-hemolíticas presentes no ágar sangue foram isoladas e posteriormente, identificadas pelo método automatizado Vitek (B) (Biomérieux) e se necessário foi realizado o teste de aglutinação em látex para a identificação dos grupos de estreptococos betahemolíticos Streptococcal Grouping Kiњ (Oxoid)

Os exames foram colhidos pelos médicos responsáveis pelo atendimento da criança, previamente treinados. Após a coleta dos exames, foram preenchidos 
os seguintes dados do paciente: nome (iniciais) da criança; idade; data do atendimento; número de matrícula do paciente; resultado da Prova Rápida para Estreptococo do grupo A. Duas perguntas foram direcionadas ao médico que atendeu a criança: Você indicaria antibiótico pelos dados clínicos? Você prescreveu antibiótico após o exame? A decisão de dar ou não dar o antibiótico baseou-se na impressão clínica inicial, em que o examinador ponderou a presença ou ausência de sinais e sintomas sugestivos de infecção bacteriana, como exsudato purulento, hipertrofia e hiperemia tonsilar, petéquias no palato, linfonodomegalia cervical dolorosa.

Foram avaliadas as características demográficas da população estudada (idade e gênero) e quais agentes etiológicos tiveram crescimento na cultura de orofaringe. Para determinar o desempenho do PRE nas diversas faixas etárias, os pacientes foram divididos em menores de 5 anos e idade igual ou maior 5 anos, pois já fora descrito um pico de incidência de faringotonsilite causada pelo EBHGA a partir dos 5 anos de idade.

A cultura de orofaringe foi considerada NEGATIVA, quando não houve identificação de qualquer agente etiológico, quando foram identificados agentes da microbiota habitual da orofaringe (Streptococcus viridans) ou quando identificados agentes etiológicos não causadores de tonsilite (Haemophilus sp, Neisseria sp, Streptococcus pneumoniae). A cultura de orofaringe foi considerada positiva quando identificados os seguintes agentes etiológicos: Streptococcus pyogenes, Estreptococo beta-hemolítico dos grupos G, F e C, Estreptococo beta-hemolítico inviável para identificação de sorogrupos ou Estreptococo beta-hemolítico não tipável. 


\subsection{Análise estatística}

Foi utilizada estatística descritiva básica para exploração dos dados na forma de tabelas de dupla entrada com frequências e proporções para as variáveis. As comparações entre as variáveis categóricas foram feitas pelo teste QuiQuadrado $\left(\mathrm{x}^{2}\right)$. O nível de significância considerado para os testes de hipóteses foi de $5 \%$ e o intervalo de confiança foi de $95 \%$. Foi utilizado o pacote estatístico R, versão 2.15.2, além do pacote Office - Excel e Word, versão 2007.

A avaliação da sazonalidade foi realizada através do cálculo do coeficiente de correlação $\left(R^{2}\right)$. 
6 RESULTADOS 


\section{Cálculo amostral e poder do estudo}

Considerando que o objetivo do teste é verificar se a PRE e a cultura mostramse positivas na mesma proporção do diagnóstico clínico, fez-se um cálculo de tamanho de amostra conservador, com margem de erro de $3 \%$ e nível de confiança de 95\%. Para isso, seria necessário estudar, no mínimo, 1068 indivíduos.

O poder desse estudo, ao comparar o impacto do uso da PRE para o diagnóstico e tratamento das faringotonsilites é de $77,5 \%$.

\section{Frequência da faringotonsilite}

Durante o período em que ocorreu o estudo, 66.661 crianças foram atendidas no Pronto Socorro da Divisão de Clínica Pediátrica do Hospital Universitário da USP. Dos atendimentos realizados, 6.706 foram motivados por queixas relacionadas a dor de garganta e febre (CID J03.8, J03.9, J03.0, J03, J00, J31, J31.1, J00). Portanto, a frequência da queixa de dor de garganta e febre na população atendida no período do estudo foi de $10,05 \%$. De todas as crianças com dor de garganta, 3.147 apresentavam idade de 2 anos a 4 anos 11 meses e 29 dias e 2789 tinham idade igual ou maior a 5 anos.

De acordo com os critérios de inclusão (idade de 2 a 15 anos incompletos, queixa de dor de garganta e febre, ausência de sinais sugestivos de infecções virais) foram incluídas no estudo 1.219 crianças atendidas. Em 3 os dados estavam incompletos e em 177 o protocolo de atendimento não foi seguido, pois a PRE teve resultado negativo e não foi colhida a cultura de orofaringe 
concomitantemente. Foram estudadas, portanto, 1.039 crianças atendidas, com perda de $14,7 \%$ dos pacientes da amostra inicial.

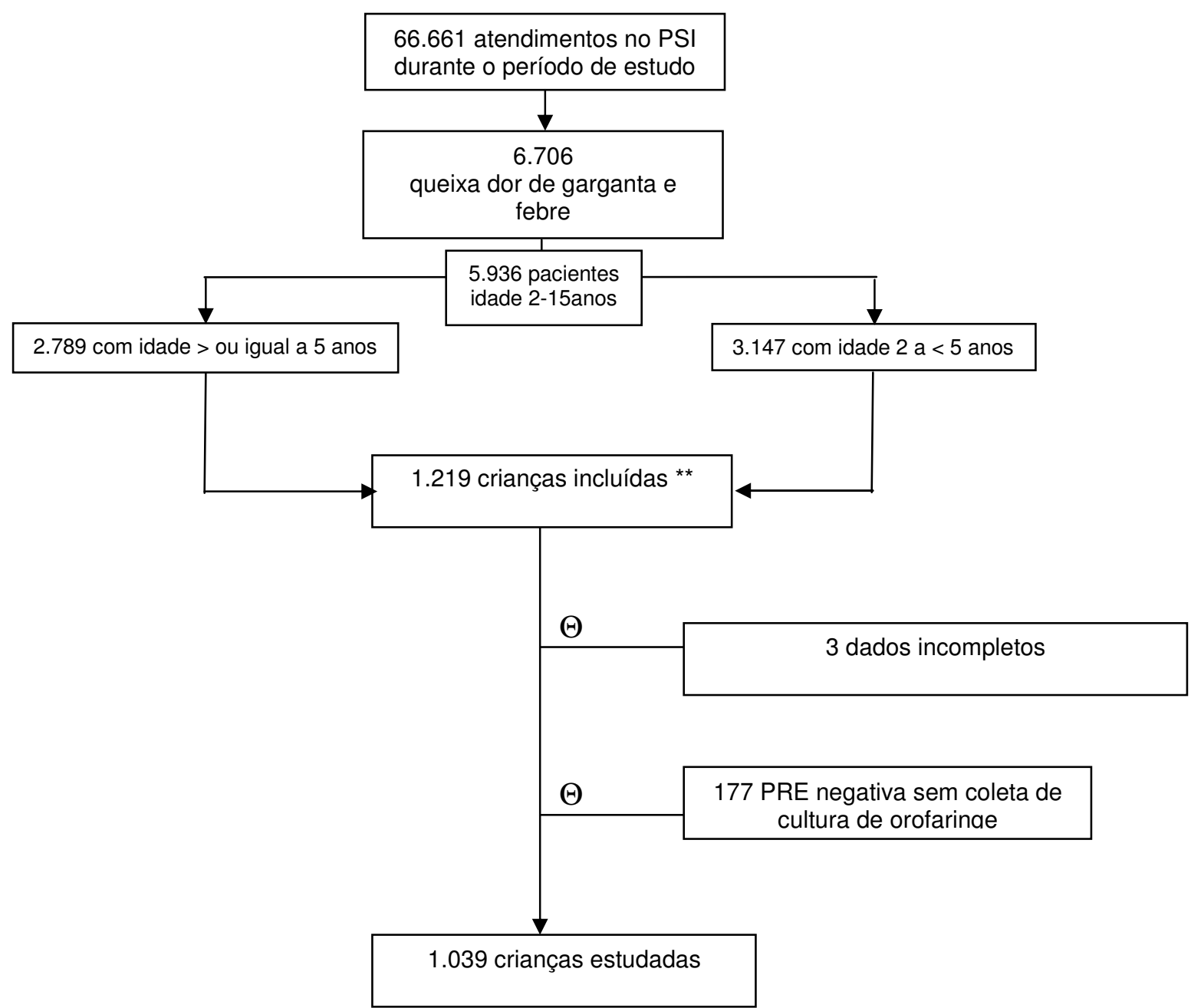

** Idade 2-15 anos incompletos, dor de garganta e febre, ausência de sinais sugestivos de infecção viral $\Theta$ perdas na amostra

\section{FIGURA 4: Fluxograma de crianças atendidas}




\subsection{Distribuição por faixa etária e gênero de crianças atendidas no pronto-} socorro com queixa de dor de garganta

De acordo com a Tabela 1, verifica-se que das crianças incluídas no estudo, $351(33,8 \%)$ apresentavam idade entre 2 e 5 anos, e $688(66,2 \%)$ tinham idade maior ou igual a 5 anos. E, em relação ao gênero, 50,8\% correspondiam ao feminino e $49,2 \%$ ao masculino.

Tabela 2: Distribuição dos Pacientes estudados segundo idade (em anos) e gênero

\begin{tabular}{lccc}
\hline Idade & Total & Sexo masculino & Sexo feminino \\
\hline $2-5$ anos & $351(33,7 \%)$ & 179 & 172 \\
\hline$\geq 5$ anos & $688(66,3 \%)$ & 332 & 356 \\
\hline Total & 1039 & 511 & 528 \\
\hline
\end{tabular}

Intenção de prescrever antibiótico baseado no quadro clínico

Em quinhentos e trinta (51\%) atendimentos os médicos afirmaram que, baseando-se no quadro clínico, prescreveriam antibióticos antes da realização da PRE e 509 (49\%) que não prescreveriam (Tabela 2).

Tabela 3: Intenção do médico de prescrever antibiótico baseado no quadro clínico

\begin{tabular}{lc}
\hline \multicolumn{2}{c}{ Prescreveria de Antibiótico } \\
\hline Prescreveria & \multicolumn{1}{c}{ Total } \\
\hline Sim & $530(51,0 \%)$ \\
Não & $509(49,0 \%)$ \\
\hline Total & $1039(100 \%)$ \\
\hline
\end{tabular}




\subsection{Frequência da infecção pelo EBHGA}

A frequência do EBHGA na amostra estudada foi determinada pelo resultado da PRE, quando positiva, e pelo resultado da cultura de orofaringe, quando a PRE teve resultado negativo. A PRE foi positiva em 409 crianças e negativa em 630 (Tabela 3). Dentre os 630 casos de PRE negativa, em 23 casos houve crescimento de EBHGA na cultura de orofaringe. Dessa forma, a frequência da infecção causada pelo EBHGA na amostra foi de 41,6\% (Tabela 4).

Tabela 4: Resultados da PRE na amostra estudada

\begin{tabular}{lc}
\hline \multicolumn{2}{c}{ Resultado da PRE } \\
\hline Resultado & Total \\
\hline Negativo & $630(60,5 \%)$ \\
Positivo & $409(39,5 \%)$ \\
\hline Total & $1039(100,0 \%)$ \\
\hline
\end{tabular}

PRE= Prova Rápida Estreptocócica

Tabela 5: Frequência da infecção pelo EBHGA ${ }^{\star *}$

\begin{tabular}{lc}
\hline \multicolumn{2}{c}{ EBHGA } \\
\hline Resultado & Total \\
\hline Negativo & $607(58,4 \%)$ \\
Positivo & $432(41,6 \%)$ \\
\hline Total & $1039(100,0 \%)$ \\
\hline EBHGA= Infecção pelo Estreptococo beta-hemolitico grupo A \\
$* *$ PRE positiva ou PRE negativa com cultura positiva
\end{tabular}


Para determinar o desempenho da PRE nas diversas faixas etárias, os pacientes foram divididos em: menores de 5 anos e com idade igual ou maior a 5 anos. A distribuição de casos EBHGA positivo e com PRE positiva em cada faixa etária e entre menores e maiores de 5 anos estão ilustradas nas Tabelas 5 e 6.

De acordo com as diferentes faixas etárias, verificamos que a positividade de infecção por EBHGA definida pelos resultados da cultura e PRE ocorre, predominantemente, no grupo de crianças com idade igual ou maior que 5 anos com $p=0,001$. (Tabela 5). O mesmo ocorre com o resultado da PRE que se mostra positivo, principalmente, na faixa etária igual ou maior de 5 anos, com $p=0,006$ (Tabela 6).

Tabela 6: Positividade de EBHGA baseado na PRE e cultura de acordo com a faixa etária (em anos)

\begin{tabular}{lcccc}
\hline Idade & \multicolumn{2}{c}{ EBHGA } & \multicolumn{2}{c}{ P valor } \\
\hline & Positivo & Negativo & Total & \\
\hline $2-5$ & $120(34,1 \%)$ & $231(65,8 \%)$ & 351 & 0,001 \\
$\geq 5$ & $312(45,3 \%)$ & $376(54,6 \%)$ & 688 & \\
\hline Total & 432 & 607 & 1039 & \\
\hline
\end{tabular}

Tabela 7: Positividade de EBHGA baseado nos resultados da PRE de acordo com a faixa etária (em anos)

\begin{tabular}{lcccc}
\hline Idade & \multicolumn{2}{c}{ PRE } & \multicolumn{2}{l}{ P valor } \\
\hline & Positivo & Negativo & Total & \\
\hline $2-4$ & $117(33,3 \%)$ & $234(66,7 \%)$ & 351 & 0,006 \\
$\geq 5$ & $292(42,4 \%)$ & $396(57,6 \%)$ & 688 & \\
\hline Total & 409 & 630 & 1039 & \\
\hline
\end{tabular}




\subsection{Resultado de cultura de orofaringe}

Foram colhidas cultura de orofaringe em 630 pacientes.

Dos 630 casos em que a PRE foi negativa, em 23 houve o crescimento de EBHGA (teste falso negativo). Entre os 23 casos em que o teste foi falso negativo, 3 ocorreram nas crianças com idade 2 a 5 anos e 20 naquelas com idade maior ou igual a 5 anos. Em 568 a cultura foi negativa e, em 39 houve crescimento de outras bactérias (Staphylococcus aureus, Estreptococos betahemolíticos dos grupos C, F e G). Dessa forma, o valor preditivo negativo da PRE para infecção pelo EBHGA foi de 96,39\%(IC 95\% 96,38- 96,41\%).

Nos 39 casos em que houve o crescimento de outras bactérias (outros estreptococos beta-hemolíticos e $S$. aureus), 15 voltaram e 3 receberam antibiótico por manutenção dos sintomas. Na cultura de orofaringe desses pacientes, houve o crescimento de Estreptococo beta-hemolítico do grupo $\mathrm{C}$ (2 casos) e Estreptococo beta-hemolítico do grupo $F$ (1 caso). Esses 3 pacientes teriam recebido antibiótico pela avaliação clínica.

\section{Diagnóstico clínico: sensibilidade, especificidade, valor preditivo negativo e valor preditivo positivo}

Pelo quadro clínico, os médicos teriam indicado antibiótico em 530 crianças (51\%) e não indicariam em 509 crianças (49\%) (Tabela 2).

Das crianças que receberiam antibiótico, pelo quadro clínico, 268 (50,6\%) tinham infecção pelo EBHGA (PRE positiva ou PRE negativa com cultura positiva) e em 262 (49,4\%) o EBHGA foi negativo (PRE negativa). Das crianças que não receberiam antibiótico pelo quadro clínico, $352(69,1 \%)$ não tinham 
infecção pelo EBHGA e em 157 (30,8\%) o EBHGA foi positivo. Dessa forma, o uso da avaliação clínica como único instrumento para a determinação do diagnóstico etiológico, acarretaria erro em $40,2 \%$ dos casos.

A prescrição de antibiótico, no primeiro momento aliada aos resultados da PRE e cultura, nos indica que $15,2 \%$ dos pacientes seriam privados do tratamento necessário, enquanto $25,0 \%$ deles teriam recebido antibióticos desnecessariamente se os exames microbiológicos não tivessem sido realizados para a determinação da conduta (Tabela 7).

A sensibilidade do diagnóstico clínico encontrada foi de 63,06\% (IC 95\% 62,9563,17\%), a especificidade foi de 57,33\% (IC 95\% 57,25-57,41\%). O Valor Preditivo Negativo encontrado foi de $69,16 \%$ (IC 95\% 69,07-69,24\%) e o Valor Preditivo Positivo de 50,57\% (IC 95\% 50,47-50,66\%).

Tabela 8: Relação entre intenção do médico em dar antibiótico pelo quadro clínico e infecção pelo EBHGA

Infecção pelo EBHGA**

\begin{tabular}{lccc}
\hline Daria ATB \EBHGA & Negativo & Positivo & Total \\
\hline Não & 352 & 157 & $509(49,0 \%)$ \\
Sim & 262 & 268 & $530(51,0 \%)$ \\
\hline Total & $614(59 \%)$ & $425(41 \%)$ & $1039(100,0 \%)$ \\
\hline
\end{tabular}

ATB=Antibiótico EBHGA= Estreptococo beta hemolítico grupo $A$

Acerto diagnóstico $=$ Daria ATB e EBHGA positivo ou Não daria ATB e EBHGA negativa

** Infecção pelo EBHGA = PRE positiva ou PRE negativa com cultura positiva 


\section{Mudança de conduta após a realização da PRE}

Analisando a conduta final após a realização da PRE, podemos verificar que $39,5 \%(24,8 \%+14,7 \%)$ das condutas iniciais foram alteradas após a finalização do atendimento que foi regido de acordo com o protocolo proposto, com valor de $p<0,001$ o que indica que há significância estatística na mudança de conduta quando se utiliza a PRE e a cultura de orofaringe para a definição do diagnóstico e tratamento da faringotonsilite (Tabela 8).

Tabela 9: Conduta final após realização da PRE

\begin{tabular}{lcccc}
\hline \multicolumn{5}{c}{ Manutenção da Prescrição do antibiótico } \\
\hline \multicolumn{5}{c}{ Prescreveria Antibiótico } \\
\hline Prescreveu & Não & Sim & Total & P \\
\hline Não & $353(33,9 \%)$ & $\mathbf{2 5 8 ( 2 4 , 8 \% )}$ & $611(58,8 \%)$ & $<0,01$ \\
Sim & $\mathbf{1 5 6 ( 1 4 , 7 \% )}$ & $272(26,1 \%)$ & $428(41,1 \%)$ & \\
\hline Total & $509(49,0 \%)$ & $530(51,0 \%)$ & $1039(100,0 \%)$ & \\
\hline
\end{tabular}

A prescrição de antibióticos ocorreu em $428(41,1 \%)$ pacientes da amostra estudada ao se utilizar métodos microbiológicos para a definição da conduta. Inicialmente, sem a utilização desses recursos para o diagnóstico, a prescrição teria ocorrido em 530 (51\%) dos pacientes. Dessa forma, observou-se uma redução de $10 \%$ das prescrições de antibióticos para o tratamento das faringotonsilites (Tabela 9). 
Tabela 10: Redução do uso de antibiótico com o uso de técnicas microbiológicas

\begin{tabular}{lccc}
\hline \multicolumn{4}{c}{ Uso de Antibióticos } \\
\hline $\begin{array}{l}\text { Métodos microbiológicos } \\
\text { Não }\end{array}$ & Sim & Total \\
\hline Não & 509 & $530(51 \%)$ & 1039 \\
Sim & 611 & $428(41,1 \%)$ & \\
\hline
\end{tabular}

** PRE ou cultura de orofaringe

\section{Médicos responsáveis pelo atendimento:}

As planilhas foram preenchidas pelos responsáveis pelo atendimento ao paciente. $\mathrm{O}$ atendimento foi feito pelo médico assistente ou médico residente assistido ou não pelo médico assistente, e aluno do $5 \square$ ano da graduação que sempre foi assistido por um assistente e/ou residente. Da amostra de pacientes incluídos que foram atendidos durante o período do estudo, 321 atendimentos foram realizados pelos assistentes (30,9\%), 530 (51\%) pelos residentes e 188 $(18,1 \%)$ pelos alunos assistidos pelo assistente e/ou residente. Entre os médicos assistentes, o diagnóstico clínico correto ocorreu em 192 casos $(59,8 \%)$ e em 129 casos $(40,2 \%)$ a conduta baseada na clínica teria sido equivocada. Os médicos residentes teriam realizado diagnóstico correto em 318 casos (60\%), porém em 212 casos (40\%) a conduta seria inadequada se não fossem utilizados métodos microbiológicos. Por fim, na opinião dos alunos do $5 \square$ ano da graduação, o diagnóstico baseado nos achados clínicos seria correto em 103 casos (54,7\%) e incorreto em 85 (45,3\%). Com p valor igual a 0,957, verificou-se que o diagnóstico clínico correto independe do responsável pelo atendimento (Tabela 10). 
Tabela 11: Diagnóstico clínico de acordo com o responsável pelo atendimento

\begin{tabular}{lllll}
\hline \multicolumn{5}{c}{ Diagnóstico Clínico } \\
\hline Responsável & Correto & Errado & Total & P \\
\hline Assistente & $192(59,8 \%)$ & $129(40,2 \%)$ & $321(30,9 \%)$ & 0,957 \\
Residente & $318(60 \%)$ & $212(40 \%)$ & $530(51 \%)$ & \\
Aluno & $104(54,7 \%)$ & $84(45,3 \%)$ & $188(18,1 \%)$ & \\
\hline Total & $614(59,1 \%)$ & $425(40,9 \%)$ & $1039(100 \%)$ & \\
\hline
\end{tabular}

\section{Sazonalidade da Infecção pelo EBHGA}

A ocorrência da infecção pelo EBHGA definida pelo resultado da PRE, durante o período estudado, está ilustrada na Tabela 11.

Tabela 12: Distribuição de casos de EBHGA definidos pela PRE durante o período estudado

\begin{tabular}{l|c|c|c}
\hline $\begin{array}{l}\text { Mês e ano de } \\
\text { atendimento }\end{array}$ & Exames no mês & $\begin{array}{c}\text { Pre /Cultura } \\
\text { positivas (EBHGA+) }\end{array}$ & Porcentagem \\
\hline Novembro/2009 & 80 & 26 & $32,5 \%$ \\
\hline Dezembro/2009 & 15 & 4 & $26,7 \%$ \\
\hline Janeiro/2010 & 30 & 10 & $33,3 \%$ \\
\hline Fevereiro/2010 & 85 & 31 & $36,4 \%$ \\
\hline Março/2010 & 85 & 39 & $45,8 \%$ \\
\hline Abril/2010 & 60 & 22 & $36,7 \%$ \\
\hline Maio/2010 & 87 & 38 & $43,6 \%$ \\
\hline Junho/2010 & 40 & 13 & $32,5 \%$ \\
\hline Julho/2010 & 82 & 38 & $46,3 \%$ \\
\hline Agosto/2010 & 140 & 56 & $40 \%$ \\
\hline Setembro/2010 & 52 & 24 & $46,1 \%$ \\
\hline Outubro/2010 & 100 & 49 & $49,0 \%$ \\
\hline Novembro/2010 & 159 & 73 & $45,9 \%$ \\
\hline
\end{tabular}


A proporção de exames positivos com os exames colhidos durante o mês, estão ilustrados no Gráfico 1.

Gráfico 1: Casos de EBHGA definidos pela PRE durante o período estudado

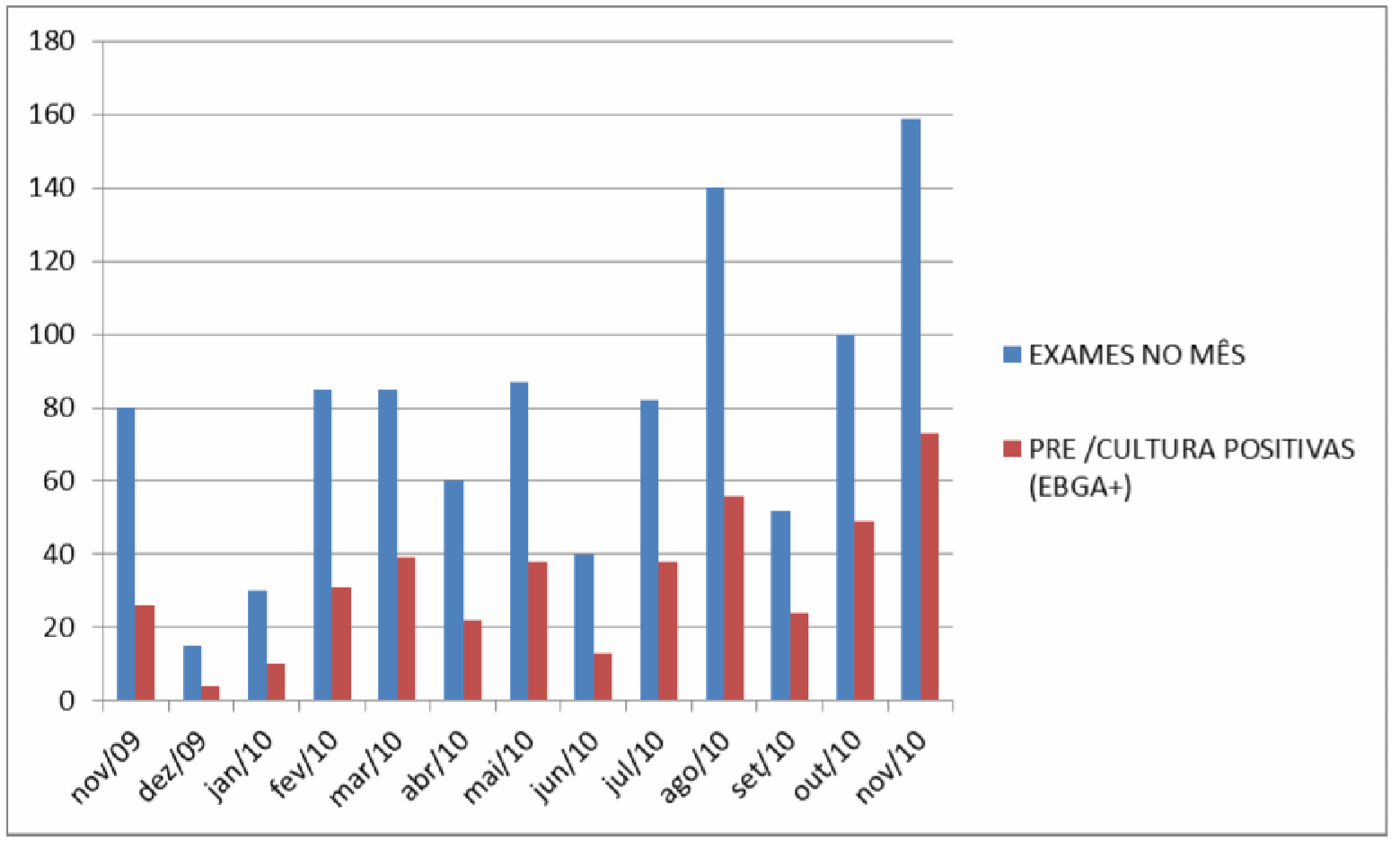

Conforme o Gráfico 2, observamos que não há indícios de correlação entre a incidência de faringotonsilite por EBHGA e as temperaturas médias diárias no período. O gráfico de dispersão em forma de nuvem é um forte indício deste fato; a correlação muito próxima de zero $\left(R^{2}-0,04\right)$ corrobora este fato. 
Gráfico 2: Relação entre o número de casos de faringotonsilite e temperaturas médias diárias

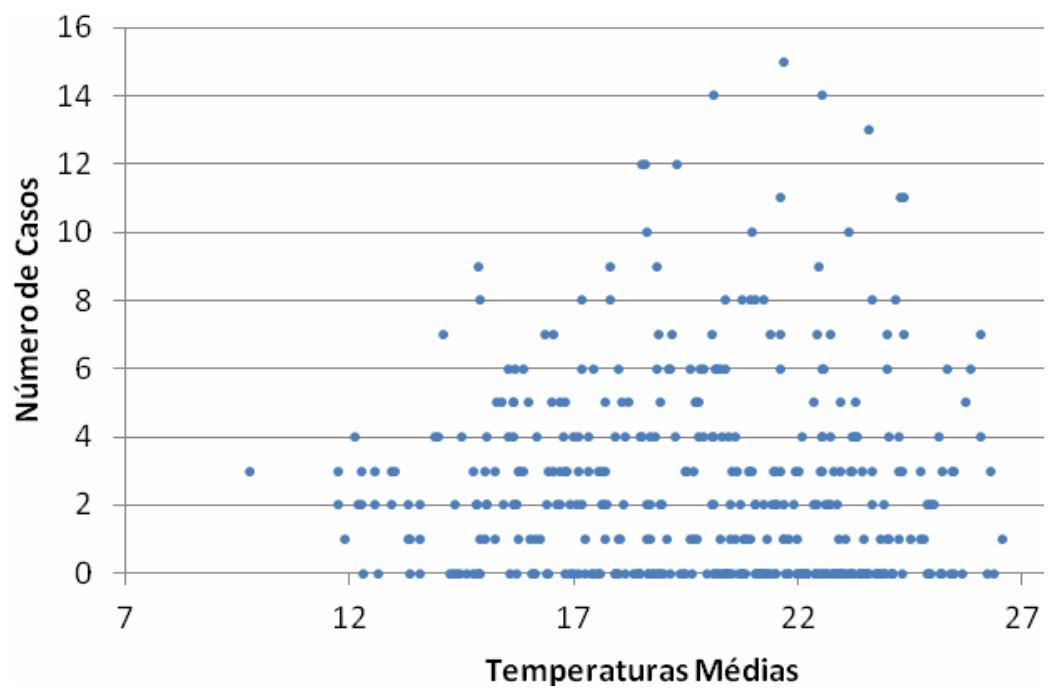

FONTE: Estação Metereológica IAG/ USP

O Gráfico 3 demonstra que não há correlação entre a incidência de faringotonsilites por EBHGA e variação de temperatura diária, medida através da amplitude de temperaturas. Para esta comparação, a correlação ainda é baixa $\left(R^{2} 0,17\right)$.

Gráfico 3: Relação entre o número de casos de faringotonsilite e a amplitude de temperaturas diárias

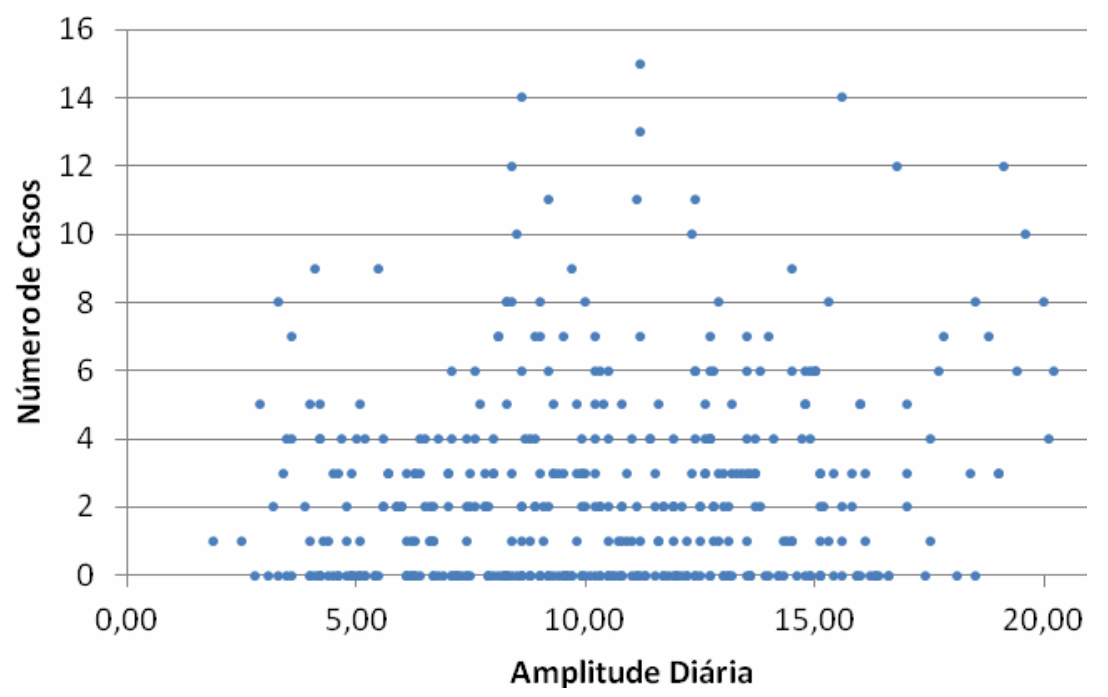

FONTE: Estação Metereológica IAG/ USP 
7 DISCUSSÃO 
A frequência da queixa da dor de garganta e febre na amostra estudada foi de $10,5 \%$ dos atendimentos realizados no Pronto-Socorro Infantil. Esses resultados corroboram os dados de literatura que apontam a faringotonsilite, dentre as IVAS, como causa frequente de consultas. Estima-se que, no mundo todo, os atendimentos pediátricos relacionados às faringotonsilites variem de 1,3\% a 20\% (Atlas et al., 2005; Ayanruoh et al., 2009; Choby, 2009; Chiappini et al., 2011; Giraldez-Garcia et al., 2011; Regoli et al., 2011; Wessels, 2011; Shulman et al., 2012). Dados norte-americanos mostram que 11 a 15 milhões de atendimentos/ano são realizados em função de dor de garganta (Choby, 2009; Shulman et al., 2012). E o custo da tonsilite causada pelo EBHGA, em crianças, é estimado em US\$224 a 539 milhões ao ano (Lean et al., 2014).

Assim como descrito anteriormente, verificou-se que a maior prevalência de queixas de faringotonsilite, e da tonsilite causada pelo EBHGA ocorre na faixa etária acima de 5 anos de idade (Breese, 1977; Wald et al., 1998; Wald, 2007; Choby, 2009; Morais et al., 2009; Shaikh et al., 2010; Chiappini et al., 2011; Regoli et al., 2011; Shulman et al., 2012).

A frequência de Estreptococo do grupo A encontrada na amostra desse estudo foi de $41,6 \%$, superior à descrita pela maior parte dos estudos que é de 15 a 30\% (Atlas et al., 2005; Armengol et al., 2004; Santos et al., 2005; Wald, 2007; Ayanruoh et al., 2009; Cardoso et al., 2009; Morais et al., 2009; Mateo et al., 2010; Shaikh et al., 2010; Giraldez-Garcia et al., 2011; Regoli et al., 2011; Cardoso et al., 2013). Entretanto, resultado semelhante foi descrito por Morais e Teles (2009) que descreveu prevalência de $43 \%$ de tonsilite por EBHGA em crianças. 
Uma possível explicação para essa ocorrência é que o uso das técnicas microbiológicas, ainda que adequadas, não distingue o indivíduo infectado do colonizado. A colonização de indivíduos saudáveis por EBHGA pode variar de 10 a 50\% (Martin et al., 2004; Smeester et al., 2006; Shaikh et al., 2010; Wessels, 2011; Roberts et al., 2012). Em metanálise realizada com 18 estudos, verificou-se que a prevalência de indivíduos colonizados pelo EBHGA variou de 3 a 26\% quando se avaliou crianças assintomáticas com idade de 0 a 18 anos. Ao se estratificar a idade, observou-se que a prevalência de colonizados nos menores de 5 anos foi de 24\% (Shaikh et al., 2010). O indivíduo é definido como colonizado quando há a presença persistente do EBHGA na orofaringe, porém sem sinais de infecção aguda ou resposta imunológica à inflamação pelo EBHGA (Pichichero, 1995; Choby, 2009; Gerber et al., 2009). Os pacientes podem permanecer colonizados pelo EBHGA até um ano apesar do uso de antibióticos (Choby, 2009; Roberts et al., 2012). A antibioticoterapia é indicada para o tratamento da tonsilite e para evitar a febre reumática, porém não é capaz de erradicar o EBHGA nos colonizados (Roberts et al., 2012). Os pacientes colonizados por EBHGA não apresentam risco de complicações supurativas ou não supurativas, assim como o risco de transmissão de cepas é bastante improvável (Pichichero, 1995; Choby, 2009; Gerber et al., 2009). Dessa forma, não há indicação de antibioticoterapia para os colonizados (Pichichero, 1995; Gerber et al., 2009). Exceção pode ser feita em situações em que os colonizados tenham contato com pacientes com história prévia de febre reumática, glomerulonefrite pós-estreptocócica, ou doença invasiva pelo EBHGA. Ou se, eventualmente, o indivíduo colonizado for profissional de saúde que trabalha em hospitais, clínicas ou casas de repouso (Choby, 2009). 
Há algumas hipóteses para justificar a ocorrência da colonização pelo EBHGA. Dentre elas acredita-se que: 1) possa ocorrer a sobrevivência intracelular do EBHGA no epitélio tonsilar e que permanece latente, sem provocar reação inflamatória ou resposta imune; 2) outros estreptococos não pertencentes ao grupo A produzem beta-lactamases conferindo ao EBHGA resistência "cruzada" aos antimicrobianos não pemitindo sua erradicação; 3) hipoteticamente, os colonizados seriam indivíduos com ausência de microbiota normal, o que impediria a inibição do crescimento do EBHGA e dificultaria sua erradicação (Shaikh et al., 2010). Diferenciar os indivíduos colonizados dos verdadeiramente infectados pode ser difícil, de tal forma, que se o paciente apresenta sintomatologia sugestiva de infecção viral (tosse, coriza, lacrimejamento ocular, obstrução nasal, conjuntivite, diarréia) com identificação microbiológica sugestiva de EBHGA (PRE e/ou cultura positivas), ou se permanece com exames laboratoriais positivos para EBHGA apesar da antibioticoterapia adequada, provavelmente, trata-se de colonização e não infecção (Pichichero, 1995; Schwartz et al., 1998; Martin et al., 2004; Smeester et al., 2006; Gerber et al., 2009; Shaikh et al., 2010; Roberts et al., 2012; Shulman et al., 2012; Weber, 2014). Entretanto, também não é remota a possibilidade de o indivíduo apresentar dor de garganta e febre sem concomitância com outros sinais de IVAS, com PRE e/ou cultura positivas, e não se tratar de um indivíduo infectado pelo EBHGA, mas, colonizado pelo EBHGA e infectado por vírus. Porém, nessa situação a diferenciação é mais difícil, sendo, então, necessária a evidência da reação imunológica à infecção, na forma de produção de anticorpos, como a anti-estreptolisina A (ASLO), que 
geralmente é tardia, aproximadamente 2 a 3 semanas após a infecção (Martin et al., 2004).

Ao se avaliar a frequência de faringotonsilite causada pelo EBHGA, definida por resultado positivo da PRE e/ou cultura de orofaringe, nas diferentes faixas etárias, verificou-se que houve significância estatística quando avaliados a positividade dos exames e a idade igual ou maior que 5 anos. Acredita-se que a tonsilite causada pelo EBHGA seja menos prevalente na faixa etária inferior aos 5 anos (Linder et al., 2005; Shulman et al., 2012), devido a alta incidência de infecções virais nessa faixa etária, além, da menor aderência da bactéria ao epitélio tonsilar (Peñalba Citores et al., 2007) o que dificulta a possibilidade de penetração nesse sítio e consequente infecção (Henningham, 2012). Neste estudo, a prevalência de infecção pelo EBHGA determinada pela PRE e cultura de orofaringe em menores de 5 anos, foi de 33,9\%. Outros autores também identificaram o EBHGA em 10 a $30 \%$ das tonsilites em crianças com idade inferior a 5 anos, especialmente nas idades de 2 a 3 anos (Woods, 1999; Peñalba Citores et al., 2007; Morais et al., 2009; Wessels, 2011; Tellechea et al., 2012). Dessa forma, apesar de maior prevalência nos maiores de 5 anos, os resultados demonstraram a necessidade de se realizar o exame também nos menores de 5 anos.

A avaliação clínica inicial realizada pelos médicos que atenderam às crianças gerou diagnóstico clínico inadequado em 40,2\% dos casos, o que corrobora os dados da literatura mundial que demonstram que a avaliação clínica, sem o uso de técnicas microbiológicas, é um instrumento diagnóstico impreciso para a identificação da faringotonsilite estreptocócica do grupo A (Schwartz et al., 1998; American Academy of Pediatrics, 2000; Atlas et al., 2005; Santos et al., 
2005; Wald, 2007; Ayanruoh et al., 2009; Cardoso et al., 2009, 2013; Gerber et al., 2009; Giraldez-Garcia et al., 2011; Regoli et al., 2011; Shulman et al., 2012).

Diversos autores já demonstraram que o diagnóstico clínico epidemiológico da faringotonsilite estreptocócica do grupo A apresenta sensibilidade, em geral, alta, porém, especificidade aquém da aceitável (Centor et al., 1981; Breese, 1977; Steinhoff et al., 1997; Schwartz et al., 1998; Mclsaac et al., 1998; Cillo et al., 1999; American Academy of Pediatrics, 2000; Bisno et al., 2002; Armengol et al., 2004; Atlas et al., 2005; Rimoin et al., 2005; Santos et al., 2005; Nascimento-Carvalho; Marques, 2006; Smeesters et al., 2006; Matthys et al., 2007; Wald, 2007; Ayanruoh et al., 2009; Cardoso et al., 2009, 2013; Gerber et al., 2009; Tanz et al., 2009; Chiappini et al., 2011; Giraldez-Garcia et al., 2011; Regoli et al., 2011; Shulman et al., 2012). Neste estudo, os resultados corroboram os dados da literatura, em que o diagnóstico clínico apresenta sensibilidade, especificidade, VPP e VPN baixos. Alguns escores clínicos demonstraram em determinadas situações que alguns sinais e sintomas podem apresentar maior sensibilidade, especificidade e valor preditivo positivo para a infecção pelo EBHGA (Edmonson; Farwell, 2005; Santos et al., 2005). Entretanto, como os resultados não são reprodutíveis por outros autores, a recomendação preconizada por comitês de especialidades médicas, em todo o mundo, é a utilização de técnicas microbiológicas com o intuito de identificar o agente etiológico da tonsilite (American Academy of Pediatrics, 2000; Bisno et al., 2002; Ebell, 2003; Rimoin et al., 2005; Santos et al., 2005; NascimentoCarvalho; Marques, 2006; Cardoso et al., 2009; Tanz et al., 2009; Regoli et al., 2011). Essas recomendações ditam que frente a uma suspeita clínica e 
epidemiológica de tonsilite causada pelo EBHGA sejam realizados métodos microbiológicos para a definição do agente etiológico e, consequente, conduta terapêutica. Diversos autores confrontam essa recomendação e sugerem que, talvez, o melhor custo benefício para a definição da conduta seja basear-se nos escores clínicos para definir se esse paciente tem a indicação de ser submetido à coleta de PRE e/ou cultura de orofaringe (Rosenberg et al., 2002; Edmonson; Farwell, 2005; Al-Najar, 2008; Tanz et al., 2009; Piñeiro-Pérez et al., 2011; Shulman et al., 2012). No presente estudo, os critérios de inclusão foram bastante amplos, porém se basearam na adaptação dos critérios de Centor et al. (1981) propostos por Mclsaac et al. (1998, 2000). Ao se incluir todas as crianças com idade entre 2 e 15 anos incompletos, com queixa de febre e dor de garganta e ausência de sinais de infecções de vias aéreas superiores (tosse e/ou espirros e/ou coriza e/ou obstrução nasal), ampliou-se a indicação de coleta da PRE e/ou cultura de orofaringe, a fim de se avaliar o real impacto da utilização do método diagnóstico.

Dentre os métodos diagnósticos disponíveis para definição do agente etiológico das tonsilites, a cultura de secreção de orofaringe é o padrão-ouro (American Academy of Pediatrics, 2000; Bisno et al., 2002; Gerber et al., 2009; Tanz et al., 2009; Shulman et al., 2012). Entretanto, com o surgimento da PRE e, em função de ser um exame com resultado precoce, pode-se utilizar tal método diagnóstico como triagem para a definição da conduta, usar antibiótico ou não, num primeiro momento. Vários autores recomendam que frente a um resultado negativo da PRE seja realizada a cultura como exame comprobatório (Webb, 1998; Woods, 1999; American Academy of Pediatrics, 2000; Atlas et al., 2005; Linder et al., 2005; Fontes et al., 2007; Cardoso et al., 2009; Gerber et al., 
2009; Morais et al., 2009; Mateo et al., 2010; Giraldez-Garcia et al., 2011; Regoli et al., 2011). Porém, estudos, em diversos países, vêm sendo realizados com o intuito de comparar, em especial, a sensibilidade e a especificidade da PRE, assim como o VPP e o VPN, em relação ao padrão-ouro, a cultura de orofaringe. Os resultados têm demonstrando que, quando realizada com técnica adequada, por pessoa treinada, e em indivíduos com suspeita clínico epidemiológica de tonsilite por EBHGA, a PRE apresenta valores bastante elevados de sensibilidade e especificidade, o mesmo ocorrendo com o VPP e o VPN (Needham et al., 1998; Webb, 1998; Mclsaac et al., 2000; Giesseker et al., 2002; Edmonson; Farwell, 2005; Santos et al., 2005; Buchbinder et al., 2007; Fontes et al., 2007; Al-Najar, 2008; Cardoso et al., 2009; Lasseter et al., 2009; Tanz et al., 2009; Gurol et al., 2010; Rogo et al., 2010; Ruiz-Aragón et al., 2010; Sarikaya et al., 2010; Regueras De Lorenzo et al., 2012; Cohen et al., 2012; Lean et al., 2014).

Apesar de a grande maioria dos autores recomendarem a coleta da cultura de orofaringe concomitante naqueles casos em que a PRE é negativa (Webb, 1998; Woods, 1999; Linder et al., 2005; Fontes et al., 2007; Wald, 2007; Morais et al., 2009; Giraldez-Garcia et al., 2011; Regoli et al., 2011; Shulman et al., 2012), os resultados desses estudos vêm apontando para uma possível mudança nessas recomendações. A Academia Americana de Pediatria considera plausível a não realização de cultura de orofaringe naquelas situações em que a PRE é negativa e, sabidamente, o teste tem sensibilidade superior a 95\%. Além disso, o executor do teste deve ter a certeza de que a técnica de coleta foi adequada (American Academy of Pediatrics, 2000). 
Não foi possível, pelo desenho do presente estudo, avaliar sensibilidade, especificidade ou VPP da PRE, pois não se colheu cultura de orofaringe naqueles em que a PRE foi positiva, porém, ao se calcular o VPN, verificou-se, como em outros estudos, que o resultado foi bastante satisfatório.

Se a definição da conduta fosse através da avaliação clínica, antibióticos teriam sido prescritos em $25,1 \%$ dos casos desnecessariamente, pois o diagnóstico clinico mostrou-se um fraco preditor de infecção pelo EBHGA com baixos índices de sensibilidade, especificidade, VPP e VPN.

Estudos semelhantes realizados em diferentes países, com crianças e adultos, também demostraram diminuição no uso dos antibióticos quando usada a PRE como ferramenta diagnóstica. Essa redução, na prescrição de antibióticos, variou de 10 a 44\% (Needham et al., 1998; Gerber; Shulman, 2004; Linder et al., 2005; Samore et al., 2005; Buchbinder et al., 2007; Al-Najar, 2008; Ayanruoh et al., 2009; Sabuncu et al., 2009; Tanz et al., 2009; Deuster et al., 2010; Giraldez-Garcia et al., 2011; Llor et al., 2011; Regueras De Lorenzo et al., 2012; Pulcini et al., 2012; Litvin et al., 2012; Cardoso et al., 2013). Rosemberg et al. (2002) demonstrou que houve redução significativa na prescrição de antibióticos, quando se realizou a PRE em todas as crianças que apresentassem risco clínico e/ou epidemiológico para infecção pelo EBHGA.

Linder et al. (2005) num estudo realizado por um período de 9 anos, observou que houve diferença estatística quando comparou a prescrição de antibióticos nas crianças que foram submetidas à coleta da PRE (57\%) e naquelas em que não foi colhido o exame (73\%). 
Ayanrouh et al. (2009) demonstrou que a disponibilidade da PRE pode alterar a prática clínica substancialmente. Em seu estudo, houve redução de $50 \%$ na taxa de prescrição de antibióticos para o tratamento das tonsilites.

Al-Najar e Uduman (2008) ao realizar um estudo em que utilizou a PRE como método diagnóstico para definição da conduta, teve como resultado a prescrição de antibióticos em apenas 15\% dos pacientes, número bastante inferior ao que se observa em estudos semelhantes.

Needhan et al. (1998) demonstrou que ao utilizar a PRE houve prescrição adequada de antibiótico naqueles com cultura negativa em $72 \%$ dos casos e nos com cultura positiva em $81 \%$ dos pacientes. Se a avaliação clínica fosse a única ferramenta diagnóstica a prescrição adequada nos pacientes com cultura positiva teria ocorrido em $42 \%$ e nos com cultura negativa em $61 \%$ dos casos.

Buchbinder et al. (2007) comprovou que a utilização da PRE na prática clínica tem um forte impacto na redução do uso de antibióticos. Em seu estudo, o uso do exame evitou a prescrição de antibiótico desnecessariamente em 130 pacientes dentre 216 estudados.

Regueras De Lorenzo et al. (2012) demonstrou que o uso da PRE reduziu a prescrição inadequada de antibióticos de 29,5 a $51,9 \%$ dos pacientes com faringotonsilite.

Madurell et al. (2010) comprovou que a utilização da PRE também tem impacto na redução da prescrição de antibióticos para tratamento de tonsilites em adultos. Seus resultados demonstraram redução em $10 \%$ do uso de antibióticos no grupo submetido à PRE em comparação àquele que teve a conduta definida pela avaliação clínica. 
Maltezou et al. (2008) demonstrou que com o uso da PRE e cultura de orofaringe houve redução de $44 \%$ na prescrição de antibióticos para 0 tratamento da tonsilite aguda.

Portanto, os resultados descritos neste estudo, assim como nos descritos anteriormente, demonstram a relevância em se fazer o diagnóstico etiológico preciso a fim de se evitar o uso abusivo e inadequado de antibióticos. O uso inadvertido de antibióticos é o principal fator desencadeante do aumento da resistência bacteriana aos antimicrobianos, além do risco de eventos adversos que podem ocorrer em decorrência do uso dessa medicação (Werner; Deasy, 2009; Deuster et al., 2010; Le Marechal et al., 2013).

Em contrapartida, em 15,1\% dos casos, se a avaliação clínica fosse utilizada como único método diagnóstico, os pacientes deixariam de receber antibioticoterapia apesar de infecção pelo EBHGA. Com isso, apresentariam um risco aumentado das complicações supurativas e não supurativas, dentre elas, a febre reumática $(\mathrm{FR})$.

A febre reumática (FR) aguda é uma doença inflamatória, imunomediada, não supurativa que pode ocorrer após infecção causada pelo EBHGA (Henningham, 2012; Pandey et al., 2012; Walker et al., 2014). Pode manifestarse como artrite, cardite, Coréia de Sydehan, eritema marginado ou nódulos subcutâneos (Carapetis et al., 2005; Costa et al., 2009). Alguns pacientes não apresentam quaisquer sintomas clínicos que precedam o aparecimento da FR, tornando o diagnóstico e tratamento difíceis e por vezes, tardios. Estes eventos patológicos, habitualmente, iniciam-se após uma a três semanas da doença estreptocócica aguda (Henningham, 2012; Pandey et al., 2012). Quando não tratada ou tratada inadequadamente, cerca de 0,3 a $3 \%$ dos pacientes 
infectados com idade entre 5 e 15 anos podem desenvolver a FR (World Health Organization, 2004; Matthys et al., 2007; Costa et al., 2009; Gerber et al., 2009; Litvin et al., 2012; Pandey et al., 2012) e aproximadamente um a dois terços deles poderão desenvolver a cardite reumática (Costa et al., 2009). A exposição repetida a infecções pelo EBHGA, frequentemente, precede 0 desenvolvimento da FR (Henningham, 2012).

A patogênese da Febre Reumática Aguda envolve uma interação entre os fatores de virulência do EBHGA e a susceptibilidade do hospedeiro (Henningham, 2012).

Acreditava-se que ocorria a deposição de imunoglobulinas e complemento no tecido miocárdico dos pacientes com FR. Atualmente, há evidências de que os anticorpos antiproteína $\mathrm{M}$ e anti $\mathrm{N}$-acetil glucosamina (carboidrato A), produzidos após a infecção pelo EBHGA apresentem reação cruzada com o tecido miocárdico, miosina, o endotélio e glicoproteínas das válvulas cardíacas. A susceptibilidade de hospedeiro também tem sido relatada como um possível fator no desenvolvimento da FR. Um estudo relatou maior freqüência de haplótipos de HLA DRB1 * 0701 e DQB1 * 0201 em pacientes com doença reumática em comparação com indivíduos saudáveis (Henningham, 2012).

Outrora, acreditava-se que a FR ocorria, apenas, em indivíduos previamente acometidos pelo EBHGA em infecções faríngeas. Entretanto, estudos recentes demonstraram a presença de cepa de EBHGA, comumente encontradas na pele, associadas à presença de FR (Walker et al., 2014). Comunidades aborígenes do centro e norte da Austrália estão entre as populações com maior taxa mundial de frequência de FR e DRC. Nessas comunidades, a colonização faríngea por EBHGA é incomum. Em contrapartida, o impetigo é a principal 
manisfestação da infecção estreptocócica. Situação semelhante ocorre em outras regiões de clima tropical, como no Sul do Pacífico, incluindo Nova Caledônia e Fiji. Já, em regiões de clima temperado da América do Norte e Europa, as infecções faríngeas estreptocócicas são as principais causas da FR e DRC (Wessels, 2011; Pandey et al., 2012). Isto sugere, então, que a epidemiologia da FR pode variar de acordo com a localização geográfica.

A cada ano, no mundo, são diagnosticados 616 milhões casos de faringite e 111 milhões casos de impetigo causados pelo EBHGA (Carapetis et al., 2005; Walker et al., 2014). Estima-se que a mortalidade mundial secundária às doenças causadas pelo EBHGA e suas seqüelas (febre reumática, doença reumática do coração, glomerulonefrite pós-estreptocócicas e doenças invasivas) seja de cerca de 500.000 casos ao ano. No mundo, a doença reumática do coração (DRC) tem uma prevalência de 15,6 milhões casos, com incidência de 282.000 e mortalidade de 233.000 a cada ano (World Health Organization, 2004; Carapetis et al., 2005; Costa et al., 2009; Regoli et al., 2011; Pandey et al., 2012; Brasil, 2013; Walker et al., 2014). Na América Latina, 21.000 casos de febre reumática (FR) ocorrem anualmente (Costa et al., 2009). No Brasil, no período compreendido entre 2009 e 2010, cerca de 3000 pacientes necessitaram de internação hospitalar para tratamento de febre reumática, o que contabilizou um custo de $\mathrm{R} \$ 5$ milhões. Dentre as cirurgias cardíacas realizadas no Brasil (2013), 26\% são para a correção de valvopatia reumática.

Apesar do declínio na prevalência da FR, que vem ocorrendo, nas últimas três décadas, nos países desenvolvidos, a doença reumática do coração (DRC), secundária a febre reumática, continua a ser a doença cardíaca adquirida mais 
comum em crianças e adultos jovens, nos países em desenvolvimento e em populações desfavorecidas de países desenvolvidos (Pandey et al., 2012). No Brasil, a doença reumática do coração permanece como a maior causa de doença cardíaca adquirida entre crianças e adultos jovens (Costa et al., 2009). Neste estudo, se não houvesse a utilização da PRE e/ou cultura de orofaringe para determinação da conduta, até 4 pacientes poderiam desenvolver a febre reumática, partindo-se da premissa de que o risco de desenvolver a FR em indivíduos não tratados ou tratados inadequadamente é de 0,3 a 3\% (World Health Organization, 2004; Matthys et al., 2007; Costa et al., 2009; Gerber et al., 2009; Litvin et al., 2012; Pandey et al., 2012; Walker et al., 2014).

E desses pacientes hipoteticamente acometidos pela $\mathrm{FR}$, de 1 a 3 poderiam vir a desenvolver a Doença Reumática do Coração, pois cerca de 1/3 a 2/3 dos indivíduos acometidos pela FR podem vir a desenvolver a cardiopatia associada (Costa et al., 2009).

Entretanto, a hipotética prevenção da febre reumática deve ser ponderada levando-se em consideração o risco do desenvolvimento da resistência bacteriana aos antimicrobianos e suas consequências (Samore et al., 2005; Smeesters et al., 2006; Ayanruoh et al., 2009; Deuster et al., 2010; Werner; Deasy, 2009).

Alguns estudos também demonstram o impacto da utilização da PRE no intuito de se identificar e tratar precocemente infecções causadas pelo EBHGA, a fim de se evitar, especialmente, complicações tardias, como a Febre Reumática. Needhan demonstrou que a prescrição de antibióticos para pacientes com cultura de orofaringe positiva teria ocorrido em $35 \%$ dos pacientes, se a análise clínica fosse o determinante para a definição da conduta. Entretanto, com o uso 
da PRE a prescrição adequada de antibióticos para pacientes com cultura de orofaringe ocorreu em 90\% dos casos (Needhan et al., 1998). Regueras De Lorenzo et al. (2012) demonstrou que a utilização da PRE impediu que $28,4 \%$ das crianças com infecção pelo EBHGA deixassem de receber antibiótico. Cardoso et al. (2013) demonstrou que $17,1 \%$ dos pacientes deixariam de receber antibiótico, apesar de a infecção ter sido causada pelo EBHGA.

Esses estudos, portanto, vêm corroborar os dados de literatura e normatizações de condutas que propõem, então, a utilização da PRE e/ou cultura de orofaringe não só para evitar o uso abusivo de antibióticos, como também, para proporcionar a introdução de antibióticos naqueles casos que podem apresentar risco de complicações como a Febre Reumática (Needham et al., 1998; Carapetis et al., 2005; Nascimento-Carvalho; Marques, 2006; Matthys et al., 2007; Costa et al., 2009; Gerber et al., 2009; Chiappini et al., 2011; Giraldez-Garcia et al., 2011; Regoli et al., 2011; Piñeiro-Pérez et al., 2011; Pandey et al., 2012; Regueras De Lorenzo et al., 2012; Shulman et al., 2012; Cardoso et al., 2013).

Portanto, o que se verifica é que, assim como neste estudo, o uso de métodos microbiológicos, como a PRE, determina a mudança na conduta final.

A mudança na conduta e o acerto no diagnóstico já foi demonstrado que independe da experiência do médico que assiste ao doente. Estudos mostraram que clínicos experientes podem falhar ao diagnosticar a faringotonsilite estreptocócica do grupo A em 25 a $40 \%$ dos casos quando o diagnóstico é baseado apenas nos dados clínico-epidemiológicos (Gerber; Shulman, 2004). Ibia et al. (2005) demonstrou em seu estudo, baseado na avaliação das respostas a um questionário para determinar os conhecimentos 
dos alunos de graduação em Medicina sobre o uso adequado de antibióticos para o tratamento de infecções de vias aéreas superiores, que $65,6 \%$ dos alunos aguardariam o resultado da cultura de orofaringe antes de prescrever 0 antibiótico, demonstrando conhecimento da normatização internacional, apesar da pouca experiência profissional.

Nesse estudo foi observado que não houve diferença estatisticamente significante com relação ao diagnóstico clínico correto ao se comparar médicos experientes com médicos recém-formados, tampouco ao se comparar com os alunos da Graduação.

A sazonalidade da tonsilite causada pelo EBHGA é bastante marcante em alguns países, especialmente aqueles com clima temperado (Choby, 2009; Gerber et al., 2009; Sabuncu et al., 2009; Chiappini et al., 2011; Regoli et al., 2011; Wessels, 2011; Shulman et al., 2012; Weber, 2014). A infecção estreptocócica é considerada como mais comum no final do inverno e início da primavera. Esse pico de incidência sazonal é de tal forma valorizado que o protocolo de condutas da Sociedade Americana de Infectologia para 0 diagnóstico e tratamento de tonsilites na infância, publicado em 2002, propõe a estação do ano como um fator a ser valorizado na definição da suspeita da etiologia viral versus bacteriana.

Neste estudo, apesar de aparentemente existir uma maior prevalência de PRE positiva no período compreendido entre julho e novembro (inverno e primavera), ao se avaliar estatisticamente, não se pôde observar que haja correlação entre as temperaturas e amplitudes de temperatura com a frequência de PRE positiva. Isso se explica, provavelmente, pelo fato de na 
cidade de São Paulo, as estações do ano não apresentarem uma caracterização bem definida.

Ainda que esse não fosse um objetivo deste estudo, fez-se uma breve pesquisa no que diz respeito ao custo benefício da aplicação do protocolo proposto para o atendimento de crianças e adolescentes com faringotonsilite aguda. O que se observou foi que a conduta proposta, ou seja, realização de PRE em todos os pacientes com suspeita clínica epidemiológica de faringotonsilite aguda seguida da coleta de cultura de orofaringe naqueles em que a PRE foi negativa foi até 6,76 vezes mais caro do que a simples prescrição do antibiótico para todos os pacientes. Resultados semelhantes foram encontrados em outros estudos (Lieu et al., 1990; Lean et al., 2014). Entretanto, a relação custo benefício não pode e não deve ser avaliada, apenas com o custo final do tratamento. A decisão de tratar todos aumenta o risco de reações alérgicas ao antibiótico, além, de ser causa importante de indução ao aumento de resistência bacteriana aos antimicrobianos (Lieu et al., 1990; Pichichero, 1995). 
8 CONCLUSÕES 
A prova rápida para a detecção do Estreptococo beta-hemolítico do grupo A é um método simples para ser implantado em Pronto-Socorro de Hospital Geral.

A sua utilização leva a redução no uso de antimicrobianos o que tem como consequências, evitar o uso desnecessário de antibióticos nos casos com PRE e/ou cultura de orofaringe negativas e indicar o seu uso naqueles em que a PRE é positiva, contribuindo,possivelmente, para a redução das complicações secundárias às faringotonsilites estreptocócicas, especialmente a Febre Reumática.

A frequência de faringotonsilites no PSI do HU-USP, durante o período do estudo, foi bastante elevada. E a frequência dessa infecção causada pelo EBHGA foi de $41,6 \%$.

O diagnóstico clínico demonstrou ser um instrumento diagnóstico impreciso para a definição da conduta em crianças com faringotonsilites agudas, pois apresentou valores de sensibilidade, especificidade, VPN e VPP baixos para a identificação de infecção pelo EBHGA.

E essa imprecisão foi independente da qualificação dos médicos responsáveis pelo atendimento, pois, médicos experientes ( Médicos Assistentes) tiveram a mesma taxa de acerto diagnóstico, quando se comparou com médicos recémformados (Residentes de 1ำ ano) e médicos em formação (Alunos do 5ํano da Graduação em Medicina).

A despeito do que ocorre em outros países, não foi possível demonstrar sazonalidade da infecção pelo EBHGA, na cidade de São Paulo, durante o período do estudo. 
9 CONSIDERAÇÕES FINAIS 
O assunto abordado nessa Tese deve ser avaliado com muito critério e atenção. A faringotonsilite trata-se de infecção extremamente frequente na faixa etária pediátrica fazendo parte, portanto, da rotina de atendimento de pediatras, tanto em serviços de emergência, bem como, em serviços ambulatoriais.

Entretanto, a descrição dos resultados dessa Tese, assim como, da literatura médica mundial moderna, apontam para a necessidade de se proceder um diagnóstico etiológico adequado dessa patologia tão comum aos pediatras.

Deparar-se com a limitação da avaliação clínica para realização do diagnóstico de uma infecção tão frequente na nossa prática clínica, pode gerar desconforto e até mesmo, indagações da sua veracidade. Esses resultados, vão na contramão de uma tendência mundial que se prega nos cursos de Graduação e Pós-Graduação em Medicina, que prezam tanto, a prática da Medicina mais tradicional, em que os diagnósticos devem basear-se, primariamente, em uma avaliação clínica adequada. Mas, em algumas situações, infelizmente, ainda que sejamos muito cuidadosos e criteriosos, haverá uma limitação da nossa possibilidade de firmar um diagnóstico preciso, sendo necessário, então, que recorramos a técnicas laboratoriais.

A relevância desse trabalho está, exatamente, na simplicidade, e na prevalêcia dessa infecção. E nos aponta para uma direção que demonstra a importância que esse diagnóstico preciso possui. Do ponto de vista individual, o uso criterioso de antibióticos diminui o risco de eventos adversos, bem como, diminui o custo do tratamento. Já ao se avaliar epidemiologicamente, no âmbito global, a prática da prescrição de antibióticos de forma consensiosa permite que haja uma diminuição do risco da resistência das bactérias aos 
antimicrobianos, o que favorece uma diminuição do risco do surgimento de infecções resistentes.

No outro extremo, ao se identificar o agente etiológico de forma precisa e precoce, diminui-se o risco das complicações, especialmente, da Febre Reumática, tanto no âmbito individual como global. Com isso, diminui-se não só a morbidade da doença, bem como, o custo final do tratamento.

Dessa forma, o resultado final dessa Tese nos permite, então, sugerir que ocorra uma normatização sistemática para a condução do diagnóstico e tratamento das faringotonsilites agudas na faixa etária pediátrica, especialmente, nos serviços de atenção primária às crianças. Pois, dessa maneira, talvez seja possível que, de curto a médio prazo, possamos reduzir não só as complicações dessa infecção, bem como, utilizarmos antibióticos de forma adequada, a fim de se diminuir o risco de infecções resistentes. E o impacto final dessa adequação de conduta será em última instância a redução do custo do tratamento. 
10 ANEXOS 


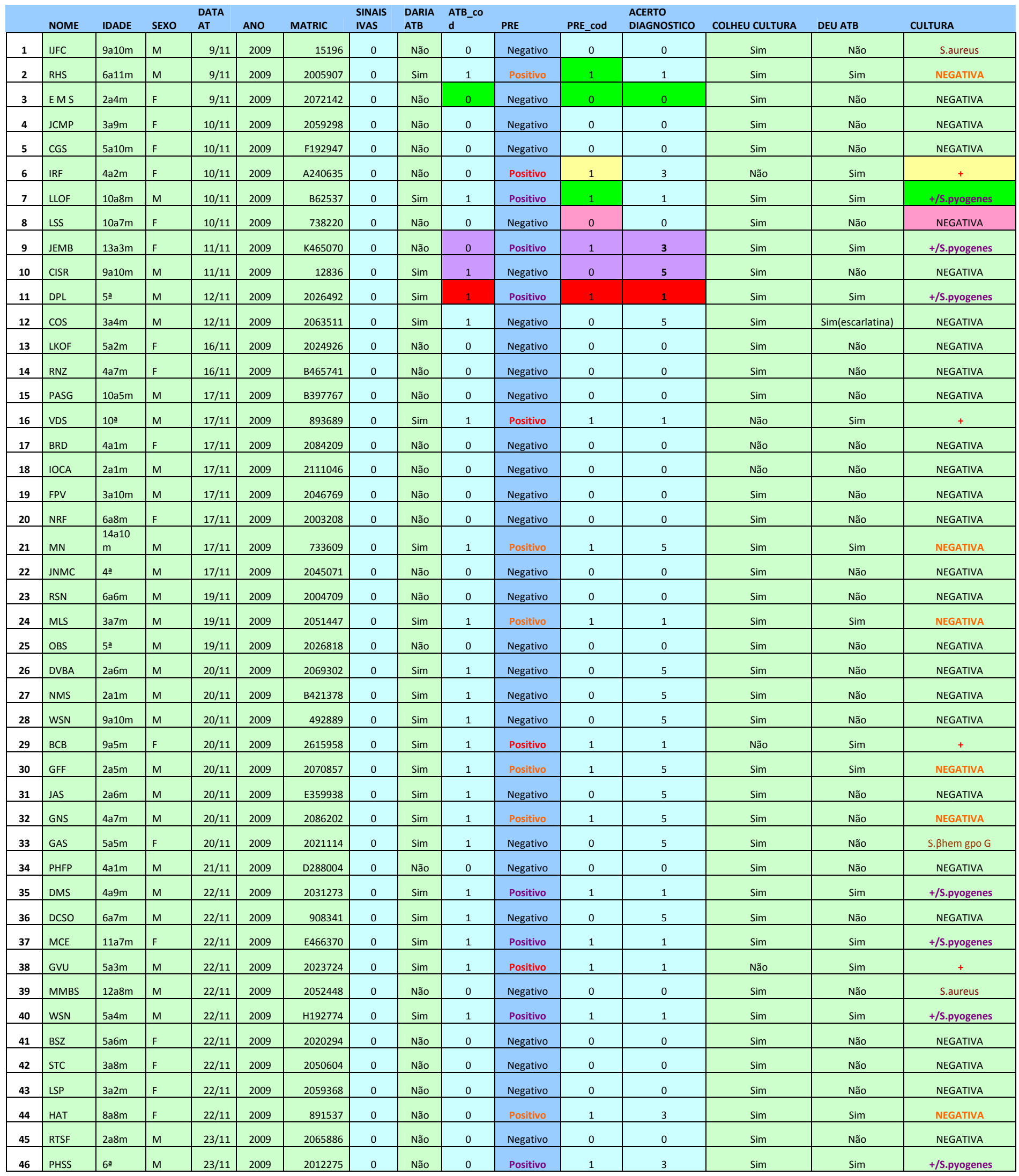




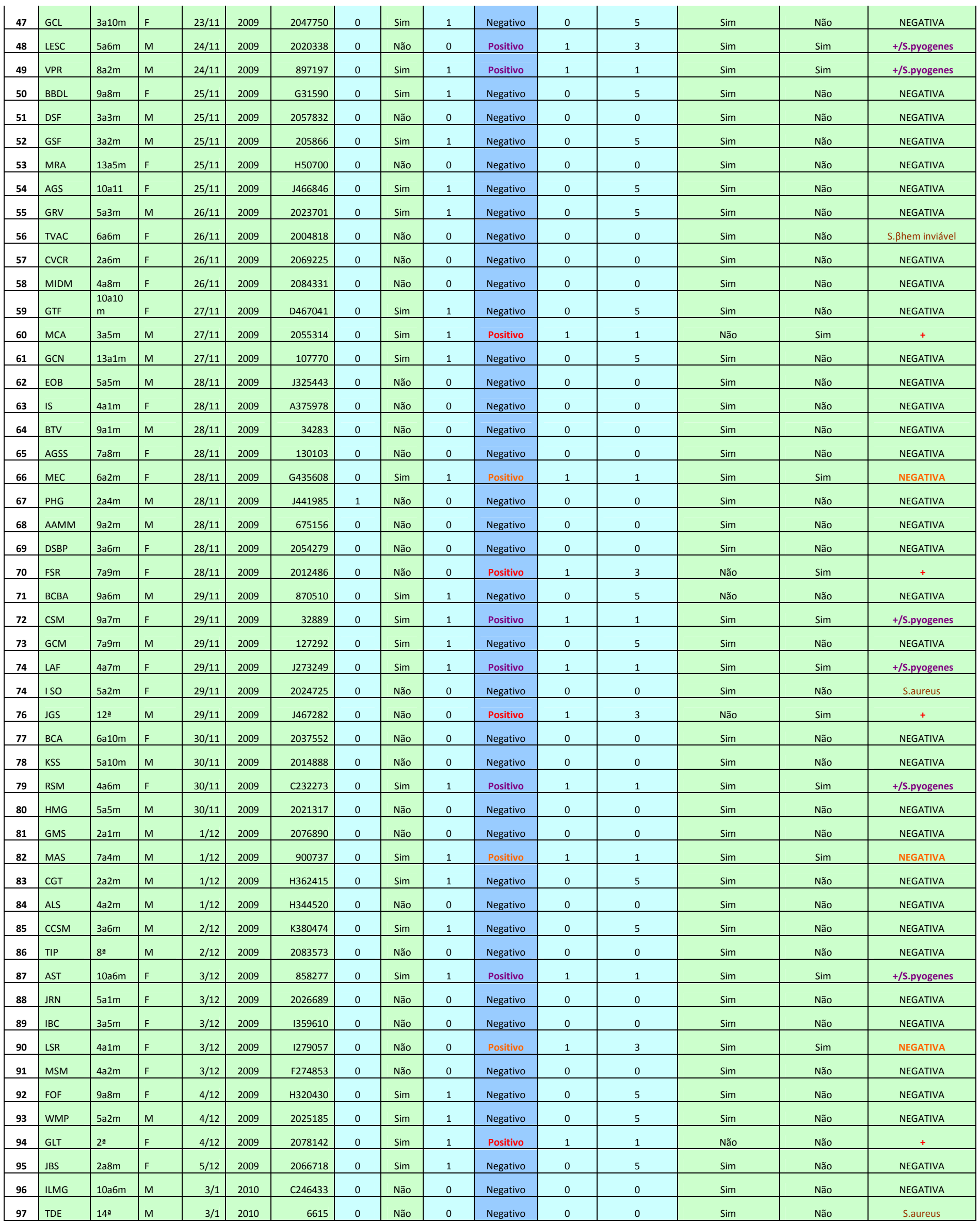




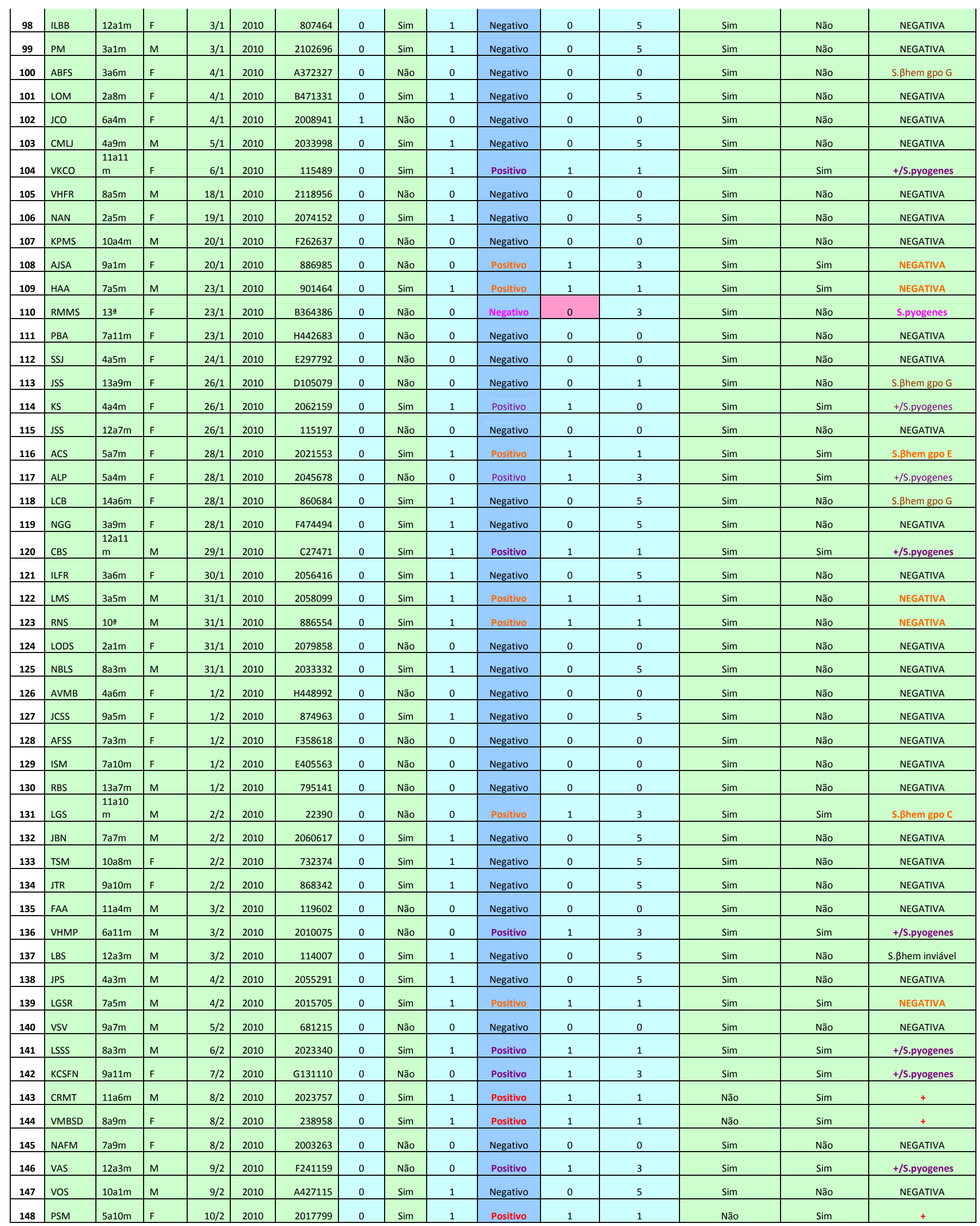




\begin{tabular}{|c|c|c|c|c|c|c|c|c|c|c|c|c|c|c|c|}
\hline 149 & KCV & $3 \mathrm{a} 5 \mathrm{~m}$ & M & $10 / 2$ & 2010 & K441308 & 0 & Não & 0 & Negativo & 0 & 0 & sim & Não & NEGATIVA \\
\hline 150 & KAF & $11 \mathrm{a} 7 \mathrm{~m}$ & M & $10 / 2$ & 2010 & 2042775 & 0 & Não & 0 & Positivo & 1 & 3 & Não & Sim & + \\
\hline 151 & STM & $10 \mathrm{a} 7 \mathrm{~m}$ & $\mathrm{~F}$ & $10 / 2$ & 2010 & 897252 & 0 & Sim & 1 & Positivo & 1 & 1 & Não & Sim & + \\
\hline 153 & SCFS & $3 a 11 \mathrm{~m}$ & $\mathrm{~F}$ & $11 / 2$ & 2010 & 2109750 & 0 & Não & 0 & Negativo & 0 & 0 & $\operatorname{sim}$ & Não & NEGATIVA \\
\hline 154 & AJS & \begin{tabular}{|l|}
$\begin{array}{l}\text { 14a11 } \\
\mathrm{m}\end{array}$ \\
\end{tabular} & $\mathrm{F}$ & $11 / 2$ & 2010 & 782297 & 0 & Não & 0 & Positivo & 1 & 3 & Não & Sim & NEGATIVA \\
\hline 157 & AVS & $8 \mathrm{a} 1 \mathrm{~m}$ & M & $13 / 2$ & 2010 & K290614 & 0 & Não & 0 & Positivo & 1 & 3 & Sim & Não & NEGATIVA \\
\hline 158 & EOS & $2 \mathrm{a} 6 \mathrm{~m}$ & $\mathrm{~F}$ & $13 / 2$ & 2010 & 2073145 & 0 & Não & 0 & Negativo & 0 & 0 & Sim & Não & NEGATIVA \\
\hline 159 & DCSO & $6 a 10 \mathrm{~m}$ & M & $13 / 2$ & 2010 & 908341 & 0 & Não & 0 & Positivo & 1 & 3 & Sim & Não & NEGATIVA \\
\hline 160 & MCGBM & $3 \mathrm{a} 2 \mathrm{~m}$ & $\mathrm{~F}$ & $13 / 2$ & 2010 & F476634 & 0 & Sim & 1 & Negativo & 0 & 5 & Sim & Não & NEGATIVA \\
\hline 161 & MRS & 3азm & M & $13 / 2$ & 2010 & 2061761 & 0 & Não & 0 & Negativo & 0 & 0 & $\operatorname{sim}$ & Não & NEGATIVA \\
\hline 165 & DRSB & $2 \mathrm{a} 11 \mathrm{~m}$ & $\mathrm{~F}$ & $14 / 2$ & 2010 & 1476720 & 0 & sim & 1 & Negativo & 0 & 5 & Sim & Não & NEGATIVA \\
\hline 166 & JBG & $7 \mathrm{a} 5 \mathrm{~m}$ & $\mathrm{~F}$ & $15 / 2$ & 2010 & $\mathrm{~J} 115911$ & 0 & Não & 0 & Negativo & 0 & 0 & Sim & Não & NEGATIVA \\
\hline 167 & RO & $6 a 6 m$ & $\mathrm{~F}$ & $15 / 2$ & 2010 & 2008912 & 0 & Não & 0 & Positivo & 1 & 3 & Não & Sim & + \\
\hline 168 & ISC & $6 a 9 m$ & M & $15 / 2$ & 2010 & 2005470 & 0 & sim & 1 & Negativo & 0 & 5 & Sim & Não & S.ßhem gpo C \\
\hline 169 & JEBC & $2 \mathrm{a} 7 \mathrm{~m}$ & $\mathrm{~F}$ & $15 / 2$ & 2010 & С389068 & 0 & Não & 0 & Negativo & 0 & 0 & Sim & Não & NEGATIVA \\
\hline 170 & LFS & $2 \mathrm{a} 2 \mathrm{~m}$ & M & $15 / 2$ & 2010 & H392643 & 0 & Sim & 1 & Negativo & 0 & 5 & Sim & Não & NEGATIVA \\
\hline 171 & IP & $13 \mathrm{a} 2 \mathrm{~m}$ & $\mathrm{~F}$ & $16 / 2$ & 2010 & 897019 & 0 & sim & 1 & Positivo & 1 & 1 & Sim & Sim & + \\
\hline 172 & MPP & 3 a & $\mathrm{F}$ & $18 / 2$ & 2010 & 2090051 & 0 & Sim & 1 & Negativo & 0 & 5 & Sim & Não & NEGATIVA \\
\hline 173 & IGS & $3 \mathrm{a} 4 \mathrm{~m}$ & M & $18 / 2$ & 2010 & 2065431 & 0 & Não & 0 & Negativo & 0 & 0 & Sim & Não & NEGATIVA \\
\hline 174 & GKN & $4 \mathrm{a} 11 \mathrm{~m}$ & M & $18 / 2$ & 2010 & F477202 & 0 & sim & 1 & Positivo & 1 & 1 & Sim & Sim & + \\
\hline 182 & css & $13 a 5 m$ & M & $20 / 2$ & 2010 & 806421 & 0 & Não & 0 & Negativo & 0 & 0 & $\mathrm{Sim}$ & Não & S. Bhem gpo C \\
\hline 183 & WSG & $14 \mathrm{a} 3 \mathrm{~m}$ & M & $21 / 2$ & 2010 & 101374 & 0 & sim & 1 & Positivo & 1 & 1 & Sim & Sim & + \\
\hline 184 & vJS & $9 a 3 m$ & $\mathrm{~F}$ & $21 / 2$ & 2010 & $\mathrm{~J} 344632$ & 0 & Não & 0 & Negativo & 0 & 0 & Sim & Não & NEGATIVA \\
\hline 185 & JDS & 12a9m & M & $21 / 2$ & 2010 & F203354 & 0 & sim & 1 & Negativo & 0 & 5 & Sim & Não & NEGATIVA \\
\hline 186 & FS & $5 \mathrm{a} 5 \mathrm{~m}$ & $\mathrm{~F}$ & $22 / 2$ & 2010 & 2025212 & 0 & sim & 1 & Positivo & 1 & 1 & Não & $\mathrm{Sim}$ & + \\
\hline 187 & GRMS & $5 a 7 m$ & M & $22 / 2$ & 2010 & $F 211543$ & 0 & Não & 0 & Negativo & 0 & 0 & Sim & Não & NEGATIVA \\
\hline 188 & LLRB & $2 \mathrm{a} 6 \mathrm{~m}$ & M & $22 / 2$ & 2010 & 2023303 & 0 & Não & 0 & Negativo & 0 & 0 & Sim & Não & NEGATIVA \\
\hline 189 & GAI & $9 a 11 \mathrm{~m}$ & $\mathrm{~F}$ & $23 / 2$ & 2010 & E169636 & 0 & Não & 0 & Negativo & 0 & 0 & Sim & Não & NEGATIVA \\
\hline 190 & DSB & $11 \mathrm{a} 5 \mathrm{~m}$ & $\mathrm{~F}$ & $23 / 2$ & 2010 & 907868 & 0 & sim & 1 & Negativo & 0 & 5 & Sim & Não & NEGATIVA \\
\hline 191 & GAS & $3 a 9 m$ & $\mathrm{~F}$ & $23 / 2$ & 2010 & K454800 & 0 & Não & 0 & Positivo & 1 & 3 & Sim & Sim & $+/$ S. pyogenes \\
\hline 192 & FSG & $7 \mathrm{a} 2 \mathrm{~m}$ & M & $23 / 2$ & 2010 & 905023 & 0 & sim & 1 & Negativo & 0 & 5 & Sim & Não & NEGATIVA \\
\hline 193 & WNL & $5 \mathrm{a} 2 \mathrm{~m}$ & $\mathrm{~F}$ & $23 / 2$ & 2010 & 2029111 & 0 & Sim & 1 & Negativo & 0 & 5 & Sim & Não & NEGATIVA \\
\hline 194 & NCS & $8 \mathrm{a} 7 \mathrm{~m}$ & $\mathrm{~F}$ & $23 / 2$ & 2010 & 2106545 & 0 & Não & 0 & Positivo & 1 & 3 & Sim & Sim & NEGATIVA \\
\hline 195 & FRSR & $5 \mathrm{a} 11 \mathrm{~m}$ & M & $23 / 2$ & 2010 & 1477929 & 0 & Não & 0 & Negativo & 0 & 0 & Sim & Não & NEGATIVA \\
\hline 196 & KNSS & $3 \mathrm{a} 4 \mathrm{~m}$ & $\mathrm{~F}$ & $24 / 2$ & 2010 & 2060636 & 0 & Sim & 1 & Positivo & 1 & 1 & Não & Sim & + \\
\hline 197 & IGS & $5 \mathrm{a} 1 \mathrm{~m}$ & $\mathrm{~F}$ & $24 / 2$ & 2010 & K232148 & 0 & Não & 0 & Negativo & 0 & 0 & Sim & Não & NEGATIVA \\
\hline 198 & LFAO & $2 \mathrm{a} 5 \mathrm{~m}$ & M & $25 / 2$ & 2010 & 1360865 & 0 & Sim & 1 & Negativo & 0 & 5 & Sim & Não & NEGATIVA \\
\hline 199 & FAC & $\begin{array}{l}\text { 10a10 } \\
m\end{array}$ & M & $25 / 2$ & 2010 & 2024798 & 0 & Sim & 1 & Positivo & 1 & 1 & Não & Sim & + \\
\hline
\end{tabular}




\begin{tabular}{|c|c|c|c|c|c|c|c|c|c|c|c|c|c|c|c|}
\hline 200 & WAD & $5 \mathrm{a} 8 \mathrm{~m}$ & M & $25 / 2$ & 2010 & 2020728 & 0 & sim & 1 & Positivo & 1 & 1 & Sim & Sim & +/S.pyogenes \\
\hline 201 & IA & $6 a 7 m$ & $\mathrm{~F}$ & $25 / 2$ & 2010 & 2023844 & 0 & Sim & 1 & Negativo & 0 & 5 & Sim & Não & NEGATIVA \\
\hline 202 & JPSN & $3 \mathrm{a} 11 \mathrm{~m}$ & M & $26 / 2$ & 2010 & 2051193 & 0 & Não & 0 & Negativo & 0 & 0 & Sim & Não & NEGATIVA \\
\hline 204 & TTS & $4 \mathrm{a} 4 \mathrm{~m}$ & $\mathrm{~F}$ & $26 / 2$ & 2010 & 2045136 & 0 & Não & 0 & Negativo & 0 & 0 & Sim & Não & NEGATIVA \\
\hline 205 & GD & $9 \mathrm{a} 2 \mathrm{~m}$ & $\mathrm{~F}$ & $26 / 2$ & 2010 & 883261 & 0 & sim & 1 & Positivo & 1 & 1 & Sim & Sim & +/S.pyogenes \\
\hline 206 & NM & $4 \mathrm{a} 1 \mathrm{~m}$ & $\mathrm{~F}$ & $27 / 2$ & 2010 & $F 265007$ & 0 & sim & 1 & Negativo & 0 & 5 & Sim & Não & NEGATIVA \\
\hline 208 & VGSC & $6 a 8 m$ & $\mathrm{~F}$ & $28 / 2$ & 2010 & B437578 & 0 & Sim & 1 & Positivo & 1 & 1 & Sim & Sim & +/S.pyogenes \\
\hline 209 & Jso & $7 \mathrm{a} 2 \mathrm{~m}$ & M & $28 / 2$ & 2010 & F463284 & 0 & Sim & 1 & Negativo & 0 & 5 & Sim & Não & S.pyogenes \\
\hline 210 & JLAS & $3 a 7 m$ & M & $28 / 2$ & 2010 & 2057298 & 1 & Não & 0 & Negativo & 0 & 0 & Sim & Não & NEGATIVA \\
\hline 211 & BFS & $9 a 3 m$ & M & $1 / 3$ & 2010 & D478701 & 0 & Sim & 1 & Negativo & 0 & 5 & Sim & Não & NEGATIVA \\
\hline 212 & BSA & $9 \mathrm{a} 11 \mathrm{~m}$ & $\mathrm{~F}$ & $2 / 3$ & 2010 & C127557 & 0 & Não & 0 & Negativo & 0 & 0 & Sim & Não & NEGATIVA \\
\hline 216 & YAS & $11 \mathrm{agm}$ & M & $4 / 3$ & 2010 & 849912 & 0 & Não & 0 & Negativo & 0 & 0 & Sim & Não & NEGATIVA \\
\hline 217 & PSR & $5 \mathrm{a} 2 \mathrm{~m}$ & $\mathrm{~F}$ & $4 / 3$ & 2010 & 2029286 & 0 & Não & 0 & Negativo & 0 & 0 & Sim & Não & NEGATIVA \\
\hline 218 & TMS & $2 \mathrm{a} 4 \mathrm{~m}$ & M & $5 / 3$ & 2010 & 2087921 & 0 & Sim & 1 & Negativo & 0 & 5 & Sim & Não & NEGATIVA \\
\hline 219 & BLDM & $11 \mathrm{a} 6 \mathrm{~m}$ & $\mathrm{~F}$ & $5 / 3$ & 2010 & 122989 & 1 & Não & 0 & Negativo & 0 & 0 & Sim & Não & NEGATIVA \\
\hline 220 & CMS & $3 \mathrm{a} 10 \mathrm{~m}$ & $\mathrm{~F}$ & $5 / 3$ & 2010 & 2075714 & 0 & $\operatorname{sim}$ & 1 & Negativo & 0 & 5 & $\mathrm{sim}$ & Não & NEGATIVA \\
\hline 221 & ACMC & $2 \mathrm{a} 3 \mathrm{~m}$ & $\mathrm{~F}$ & $6 / 3$ & 2010 & B398641 & 0 & $\operatorname{sim}$ & 1 & Negativo & 0 & 5 & Sim & Não & NEGATIVA \\
\hline 222 & GCJ & $6 \mathrm{a} 2 \mathrm{~m}$ & $\mathrm{~F}$ & $6 / 3$ & 2010 & 2014334 & 0 & Sim & 1 & Negativo & 0 & 5 & Sim & Sim & S.pyogenes \\
\hline 223 & NSS & $3 \mathrm{a} 9 \mathrm{~m}$ & $\mathrm{~F}$ & $6 / 3$ & 2010 & 2058228 & 0 & Não & 0 & Negativo & 0 & 0 & Sim & Não & NEGATIVA \\
\hline 224 & JLM & $2 \mathrm{a} 7 \mathrm{~m}$ & $\mathrm{~F}$ & $6 / 3$ & 2010 & 2073471 & 0 & Não & 0 & Negativo & 0 & 0 & $\mathrm{Sim}$ & Não & NEGATIVA \\
\hline 225 & EGOC & $3 \mathrm{a} 10 \mathrm{~m}$ & M & $7 / 3$ & 2010 & 2104136 & 0 & Não & 0 & Positivo & 1 & 3 & Sim & Sim & +/S.pyogenes \\
\hline 233 & SОВ & $5 a 9 m$ & M & $11 / 3$ & 2010 & G236702 & 0 & sim & 1 & Positivo & 1 & 1 & Sim & Sim & $+/$ S. pyogenes \\
\hline 234 & FIN & $8 \mathrm{a} 9 \mathrm{~m}$ & $\mathrm{~F}$ & $11 / 3$ & 2010 & 885937 & 0 & Sim & 1 & Negativo & 0 & 5 & Sim & Não & NEGATIVA \\
\hline 235 & DACC & $9 \mathrm{a} 2 \mathrm{~m}$ & M & $12 / 3$ & 2010 & 2090559 & 1 & Não & 0 & Negativo & 0 & 0 & Sim & Não & NEGATIVA \\
\hline 236 & GAC & $8 \mathrm{a} 1 \mathrm{~m}$ & M & $12 / 3$ & 2010 & 899983 & 0 & Sim & 1 & Negativo & 0 & 5 & Sim & Não & S.pyogenes \\
\hline 237 & PJS & $4 \mathrm{a} 1 \mathrm{~m}$ & $\mathrm{~F}$ & $12 / 3$ & 2010 & 2038107 & 1 & Sim & 1 & Positivo & 1 & 1 & Sim & Não & +/S.pyogenes \\
\hline 238 & ACOR & $7 \mathrm{a} 4 \mathrm{~m}$ & $\mathrm{~F}$ & $12 / 3$ & 2010 & 34803 & 0 & Não & 0 & Negativo & 0 & 0 & Sim & Não & NEGATIVA \\
\hline 239 & MKP & $6 \mathrm{a} 9 \mathrm{~m}$ & $\mathrm{~F}$ & $13 / 3$ & 2010 & D178255 & 0 & Não & 0 & Positivo & 1 & 3 & Sim & $\operatorname{sim}$ & +/S.pyogenes \\
\hline 240 & LDS & $5 \mathrm{a} 10 \mathrm{~m}$ & $\mathrm{~F}$ & $13 / 3$ & 2010 & 2019019 & 0 & Não & 0 & Negativo & 0 & 0 & Sim & Não & NEGATIVA \\
\hline 241 & LAS & $8 a 6 m$ & $\mathrm{~F}$ & $13 / 3$ & 2010 & 891038 & 0 & Não & 0 & Negativo & 0 & 0 & Sim & Não & NEGATIVA \\
\hline 242 & MLM & ga & M & $13 / 3$ & 2010 & B99589 & 0 & sim & 1 & Positivo & 1 & 1 & Sim & Sim & $+/$ S. pyogenes \\
\hline 243 & BSSS & $2 \mathrm{a} 5 \mathrm{~m}$ & $\mathrm{~F}$ & $13 / 3$ & 2010 & 2076082 & 0 & Não & 0 & Negativo & 0 & 0 & Sim & Não & NEGATIVA \\
\hline 244 & AKPS & $2 \mathrm{a} 11 \mathrm{~m}$ & $\mathrm{~F}$ & $13 / 3$ & 2010 & 2083308 & 0 & sim & 1 & Negativo & 0 & 5 & Sim & Não & NEGATIVA \\
\hline 245 & VJAS & $\begin{array}{l}\text { 10a11 } \\
\mathrm{m}\end{array}$ & M & $15 / 3$ & 2010 & 121943 & 0 & Sim & 1 & Positivo & 1 & 1 & Sim & Sim & +/S.pyogenes \\
\hline 246 & MAL & $7 \mathrm{a} 1 \mathrm{~m}$ & $\mathrm{~F}$ & $15 / 3$ & 2010 & 2040666 & 0 & Não & 0 & Negativo & 0 & 0 & Sim & Não & S.pyogenes \\
\hline 247 & GAPS & $\begin{array}{l}\text { 11a11 } \\
\text { m }\end{array}$ & $\mathrm{F}$ & $15 / 3$ & 2010 & 1175222 & 0 & Não & 0 & Positivo & 1 & 3 & Sim & Não & +/S.pyogenes \\
\hline 248 & IFMV & $4 a 6 m$ & $\mathrm{~F}$ & $15 / 3$ & 2010 & B271124 & 1 & Não & 0 & Negativo & 0 & 0 & Sim & Não & NEGATIVA \\
\hline 249 & GCSS & $6 \mathrm{a} 1 \mathrm{~m}$ & $\mathrm{~F}$ & $15 / 3$ & 2010 & 2026234 & 0 & Não & 0 & Positivo & 1 & 3 & Não & Sim & + \\
\hline 250 & RAF & $3 \mathrm{a} 10 \mathrm{~m}$ & M & $15 / 3$ & 2010 & 2053046 & 1 & Não & 0 & Positivo & 1 & 3 & Não & Sim & + \\
\hline
\end{tabular}




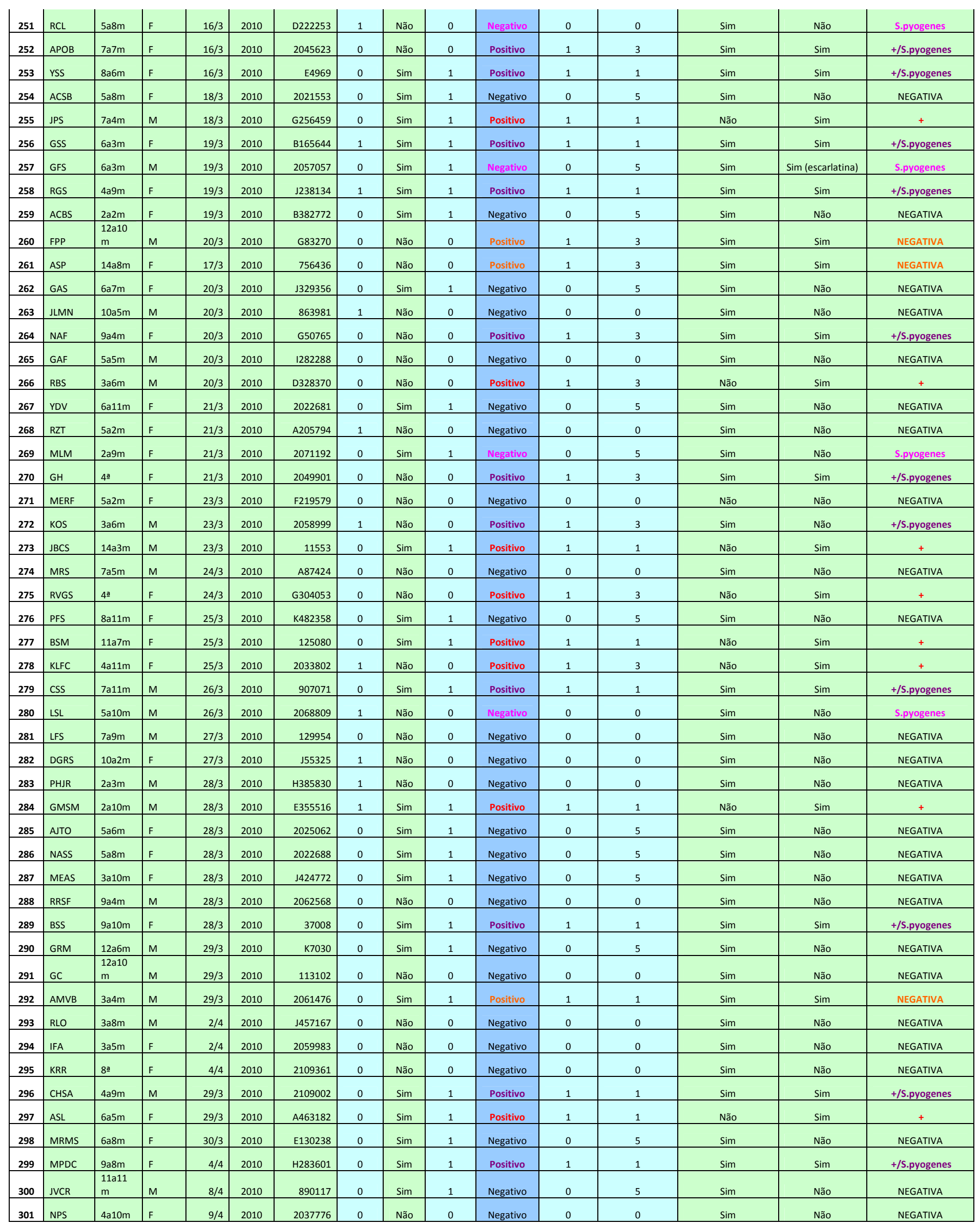




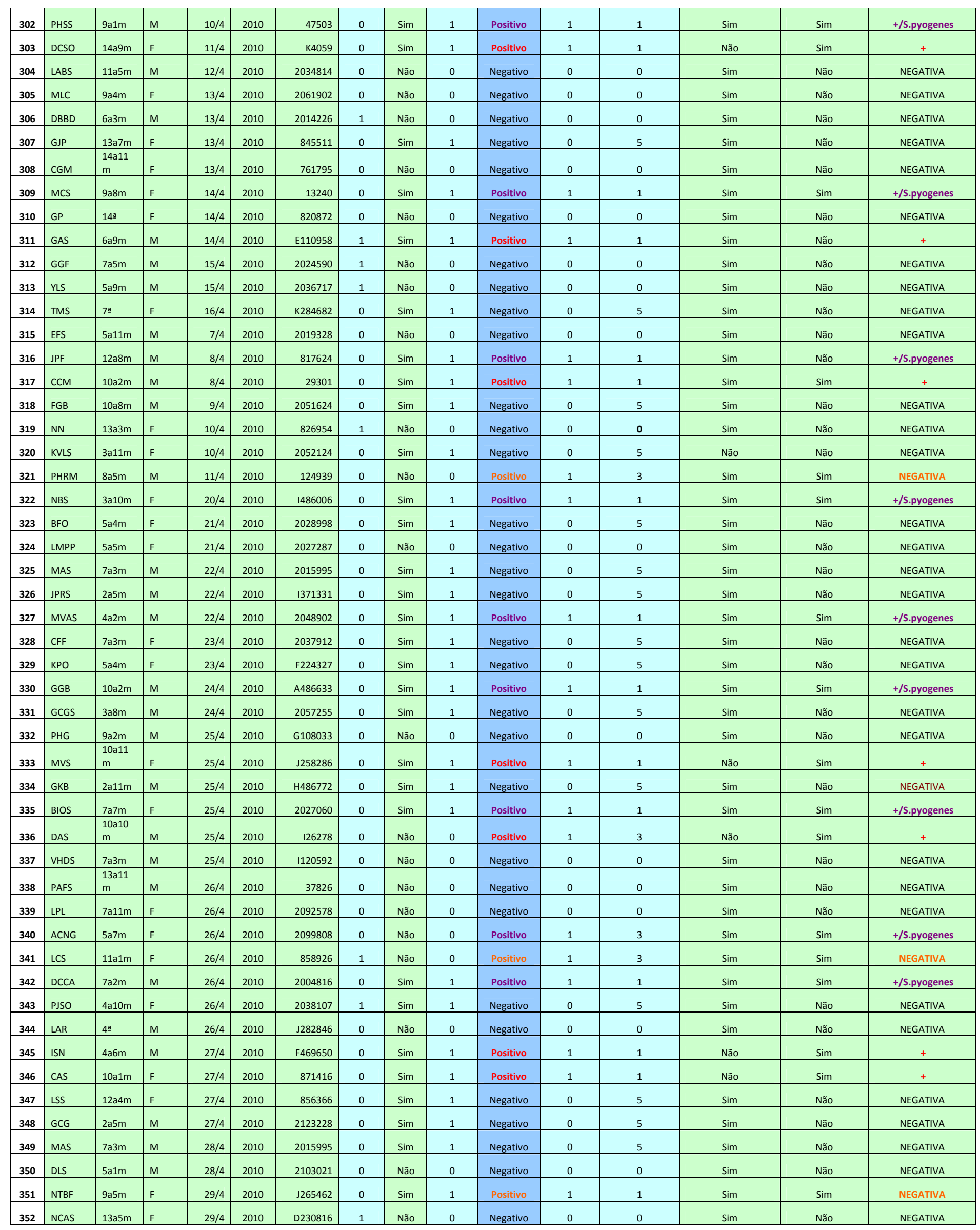




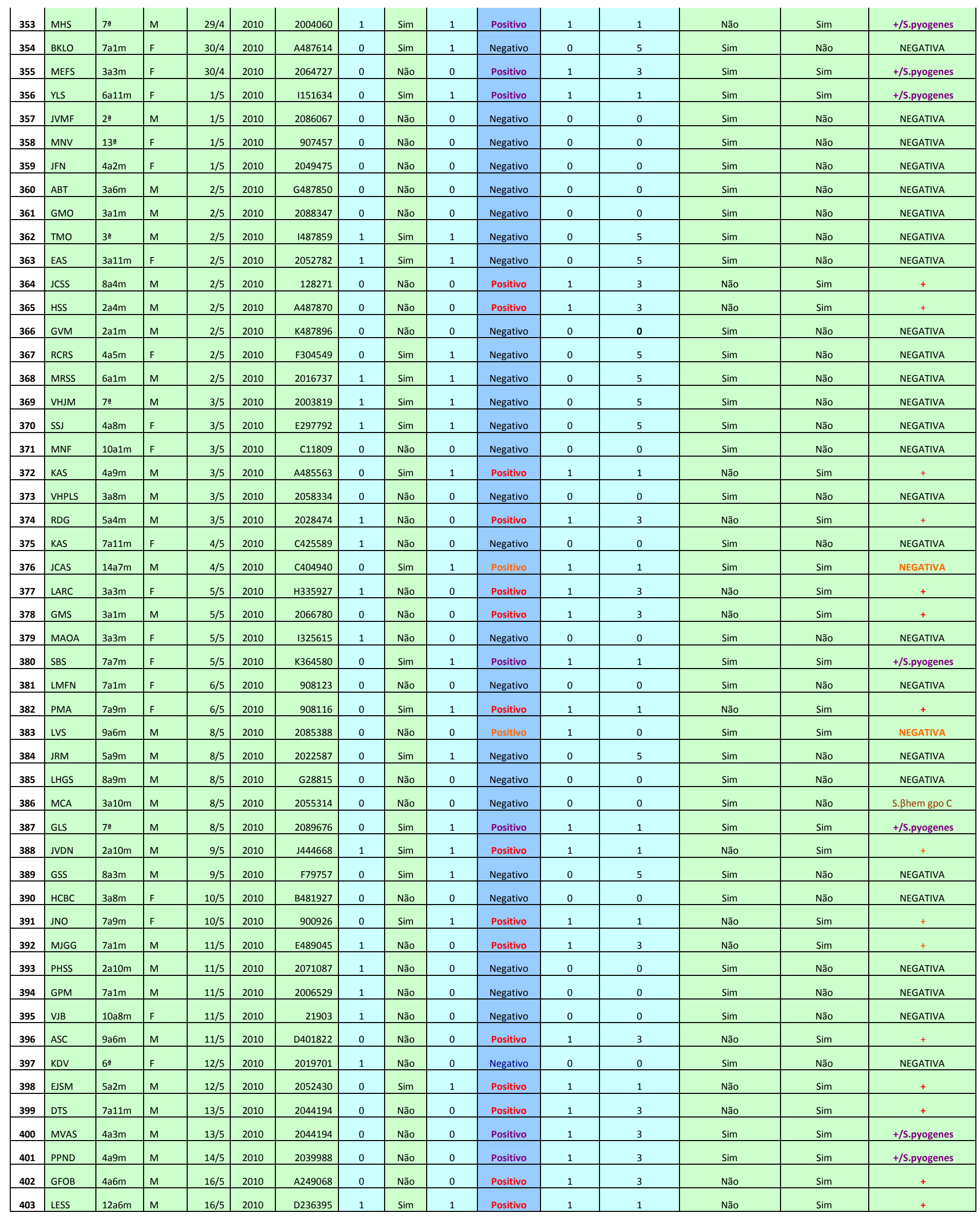




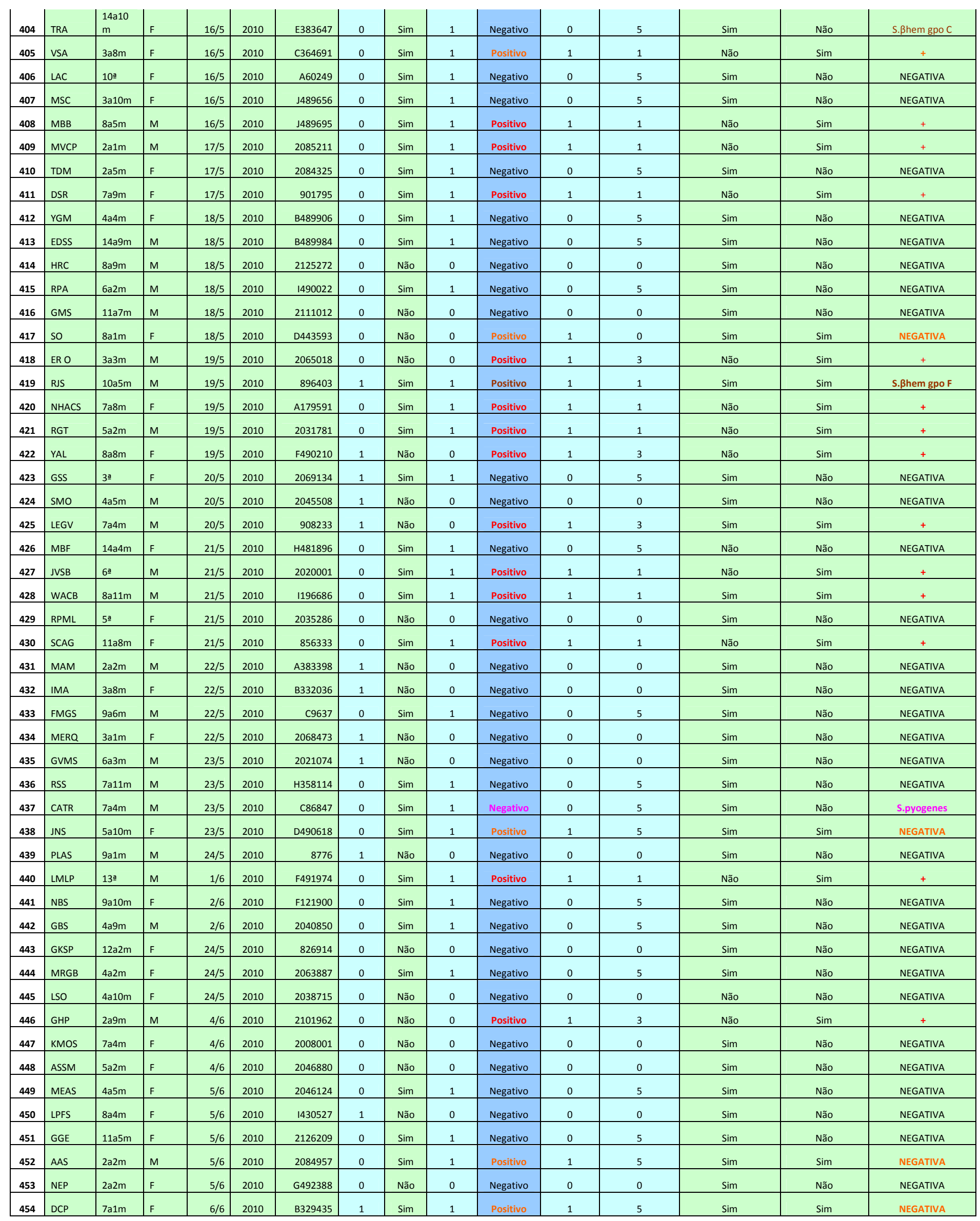




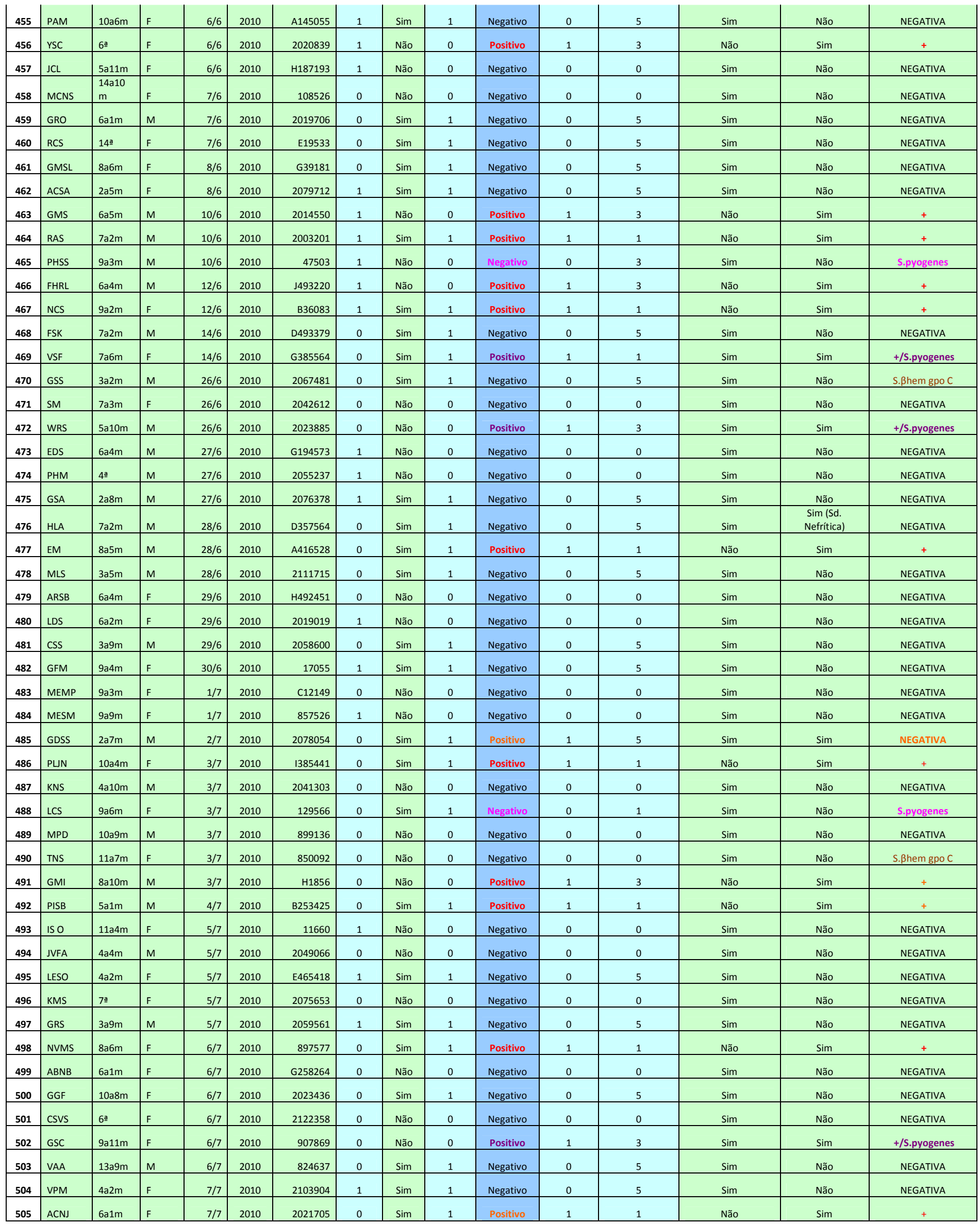




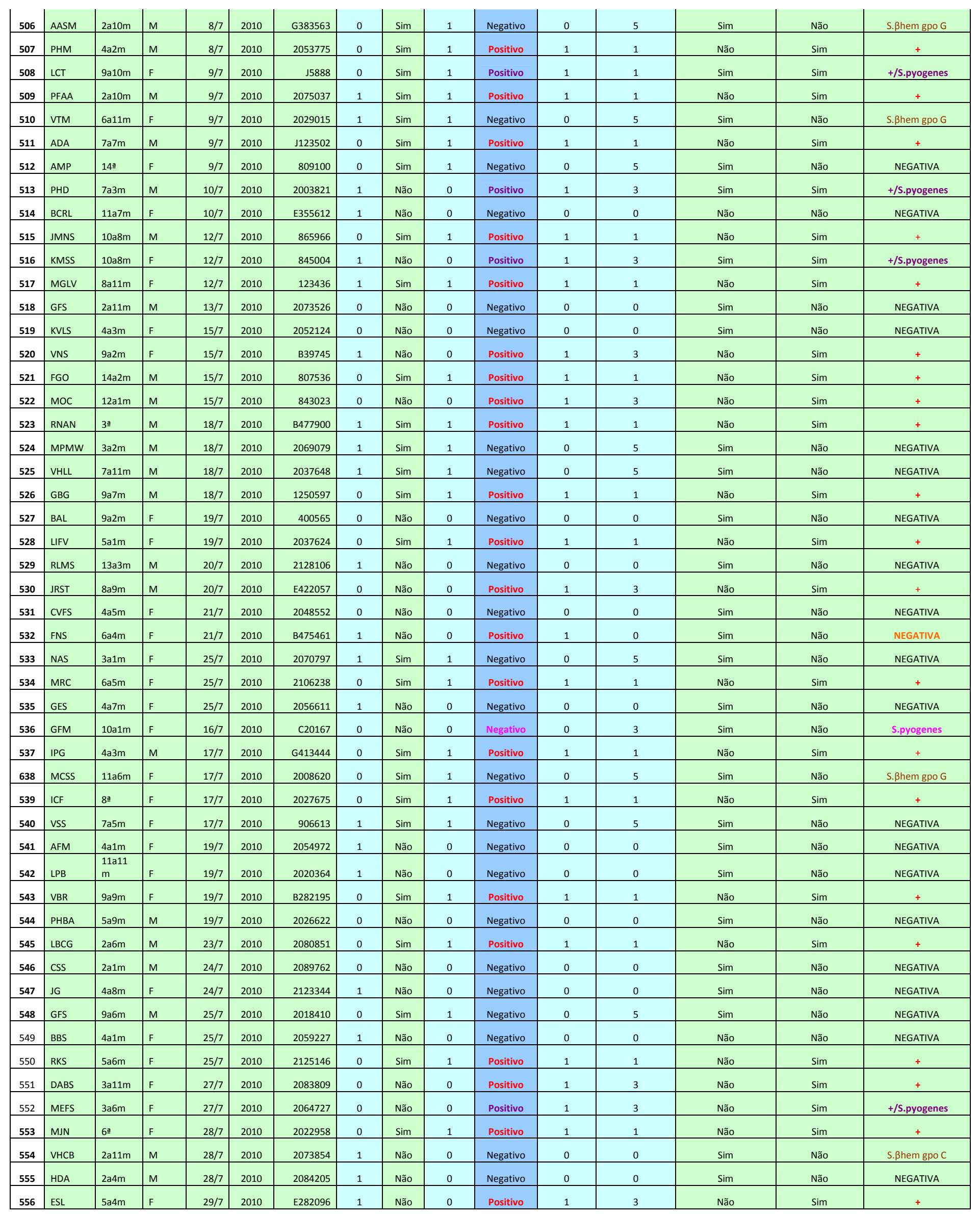




\begin{tabular}{|c|c|c|c|c|c|c|c|c|c|c|c|c|c|c|c|}
\hline 557 & $\mathrm{BPL}$ & $11 \mathrm{a} 9 \mathrm{~m}$ & $\mathrm{~F}$ & $30 / 7$ & 2010 & 855513 & 1 & Sim & 1 & Negativo & 0 & 5 & Sim & Não & S.ßhem gpo C \\
\hline 558 & ROM & 13 a & M & $30 / 7$ & 2010 & 2038677 & 0 & Sim & 1 & Positivo & 1 & 1 & Não & Sim & + \\
\hline 559 & MJC & $9 \mathrm{a} 6 \mathrm{~m}$ & $\mathrm{~F}$ & $30 / 7$ & 2010 & 2038617 & 0 & Sim & 1 & Negativo & 0 & 5 & Sim & Não & NEGATIVA \\
\hline 560 & ASM & $4 \mathrm{a} 4 \mathrm{~m}$ & $\mathrm{M}$ & $30 / 7$ & 2010 & 2127968 & 0 & Sim & 1 & Positivo & 1 & 1 & Não & Sim & + \\
\hline 561 & GDSS & $2 \mathrm{a} 8 \mathrm{~m}$ & M & $30 / 7$ & 2010 & 2078054 & 1 & Não & 0 & Positivo & 1 & 3 & Não & Sim & + \\
\hline 562 & SSR & $8 \mathrm{a} 1 \mathrm{~m}$ & $M$ & $30 / 7$ & 2010 & 2086273 & 0 & Sim & 1 & Negativo & 0 & 5 & Sim & Não & NEGATIVA \\
\hline 563 & ABLS & $5 \mathrm{a} 10 \mathrm{~m}$ & $\mathrm{~F}$ & $30 / 7$ & 2010 & 2025491 & 0 & Não & 0 & Negativo & 0 & 0 & Sim & Não & NEGATIVA \\
\hline 564 & LMFN & $7 \mathrm{a} 4 \mathrm{~m}$ & $\mathrm{~F}$ & $31 / 7$ & 2010 & 908123 & 0 & Sim & 1 & Negativo & 0 & 5 & Sim & Não & NEGATIVA \\
\hline 565 & RNP & $5 \mathrm{a} 2 \mathrm{~m}$ & $\mathrm{~F}$ & $1 / 8$ & 2010 & C236994 & 0 & Sim & 1 & Negativo & 0 & 5 & Sim & Não & NEGATIVA \\
\hline 566 & BSAS & $6{ }^{a}$ & $\mathrm{~F}$ & $1 / 8$ & 2010 & E204603 & 0 & Não & 0 & Positivo & 1 & 3 & Não & $\mathrm{Sim}$ & + \\
\hline 567 & ATSJ & $5 \mathrm{a} 5 \mathrm{~m}$ & M & $1 / 8$ & 2010 & 2107283 & 0 & Não & 0 & Positivo & 1 & 3 & Sim & Sim & +/S.pyogenes \\
\hline 568 & JPMG & $2 \mathrm{a} 5 \mathrm{~m}$ & M & $2 / 8$ & 2010 & K444635 & 0 & Não & 0 & Positivo & 1 & 3 & Não & Sim & + \\
\hline 569 & KA & $7 \mathrm{a} 1 \mathrm{~m}$ & $\mathrm{~F}$ & $4 / 8$ & 2010 & G264107 & 1 & Sim & 1 & Negativo & 0 & 5 & Sim & Não & NEGATIVA \\
\hline 570 & JDR & $7 \underline{a}$ & $M$ & $5 / 8$ & 2010 & 2007763 & 0 & Sim & 1 & Positivo & 1 & 1 & Não & Sim & + \\
\hline 571 & KSP & $3 \mathrm{a} 11 \mathrm{~m}$ & M & $5 / 8$ & 2010 & 2087190 & 1 & Sim & 1 & Negativo & 0 & 5 & Sim & Não & NEGATIVA \\
\hline 572 & NDD & $14 \mathrm{a}$ & M & $6 / 8$ & 2010 & 20666546 & 0 & Sim & 1 & Positivo & 1 & 1 & Sim & Sim & $+/$ S.pyogenes \\
\hline 573 & GFMS & $8 \mathrm{a} 7 \mathrm{~m}$ & $\mathrm{~F}$ & $6 / 8$ & 2010 & 2032292 & 0 & Sim & 1 & Positivo & 1 & 1 & Não & Sim & + \\
\hline 574 & IJP & $3 \mathrm{a}$ & $\mathrm{F}$ & $7 / 8$ & 2010 & 2127824 & 1 & Não & 0 & Negativo & 0 & 0 & Sim & Não & NEGATIVA \\
\hline 575 & AYCM & $3 \mathrm{a} 6 \mathrm{~m}$ & $\mathrm{~F}$ & $7 / 8$ & 2010 & H343710 & 1 & Não & 0 & Negativo & 0 & 0 & Sim & Não & NEGATIVA \\
\hline 576 & $\mathrm{BCB}$ & $10 \mathrm{a} 2 \mathrm{~m}$ & $\mathrm{~F}$ & $8 / 8$ & 2010 & 2015958 & 0 & Não & 0 & Negativo & 0 & 0 & Sim & Não & NEGATIVA \\
\hline 577 & LFO & $2 \mathrm{a} 10 \mathrm{~m}$ & M & $8 / 8$ & 2010 & 1360865 & 1 & Sim & 1 & Negativo & 0 & 5 & Sim & Não & NEGATIVA \\
\hline 578 & NGR & $6 a 3 m$ & $\mathrm{~F}$ & $8 / 8$ & 2010 & 2019733 & 1 & Não & 0 & Positivo & 1 & 3 & Não & $\mathrm{Sim}$ & + \\
\hline 579 & $\mathrm{JK}$ & $6 \mathrm{a}$ & $\mathrm{F}$ & $8 / 8$ & 2010 & 2023555 & 0 & Sim & 1 & Positivo & 1 & 1 & Não & Sim & + \\
\hline 580 & CASM & $5 \mathrm{a} 10 \mathrm{~m}$ & $\mathrm{M}$ & $8 / 8$ & 2010 & 2025830 & 0 & Sim & 1 & Negativo & 0 & 5 & Sim & Não & NEGATIVA \\
\hline 581 & AM & $7 \mathrm{a} 4 \mathrm{~m}$ & M & $9 / 8$ & 2010 & A342661 & 0 & Não & 0 & Negativo & 0 & 0 & Sim & Não & S. Bhem gpo C \\
\hline 582 & PCR & $12 \mathrm{a} 9 \mathrm{~m}$ & $\mathrm{~F}$ & $9 / 8$ & 2010 & 864594 & 0 & Não & 0 & Positivo & 1 & 3 & Não & Sim & + \\
\hline 583 & SSS & $5 \mathrm{a} 5 \mathrm{~m}$ & $\mathrm{~F}$ & $10 / 8$ & 2010 & 2032050 & 0 & Sim & 1 & Positivo & 1 & 1 & Não & Sim & + \\
\hline 584 & VL & $12^{\mathrm{a}}$ & $\mathrm{M}$ & $10 / 8$ & 2010 & 2014974 & 1 & Sim & 1 & Positivo & 1 & 1 & Não & Sim & + \\
\hline 585 & FPM & $3 \mathrm{a} 2 \mathrm{~m}$ & M & $10 / 8$ & 2010 & 2069804 & 1 & Sim & 1 & Positivo & 1 & 1 & Não & Sim & + \\
\hline 586 & PP & $8 \mathrm{a}$ & $\mathrm{F}$ & $10 / 8$ & 2010 & 2010627 & 1 & Não & 0 & Negativo & 0 & 0 & Sim & Não & NEGATIVA \\
\hline 587 & KEADA & $8 \mathrm{a} 6 \mathrm{~m}$ & M & $11 / 8$ & 2010 & E90904 & 1 & Não & 0 & Negativo & 0 & 0 & Sim & Não & NEGATIVA \\
\hline 588 & RAO & $12 \mathrm{a} 9 \mathrm{~m}$ & $M$ & $11 / 8$ & 2010 & 842405 & 0 & Não & 0 & Positivo & 1 & 3 & Não & Sim & + \\
\hline 589 & MS & $10 \mathrm{a} 7 \mathrm{~m}$ & $\mathrm{M}$ & $11 / 8$ & 2010 & 192075 & 0 & Sim & 1 & Negativo & 0 & 5 & Sim & $\mathrm{Sim}$ & NEGATIVA \\
\hline 590 & JVS & $11 \mathrm{a} 2 \mathrm{~m}$ & $\mathrm{M}$ & $11 / 8$ & 2010 & 781587 & 0 & Não & 0 & Positivo & 1 & 3 & Não & Sim & + \\
\hline 591 & JHBM & $4 a 9 m$ & $M$ & $12 / 8$ & 2010 & 2043767 & 1 & Não & 0 & Negativo & 0 & 0 & Sim & Não & NEGATIVA \\
\hline 592 & $\begin{array}{l}\text { LMMM } \\
0 \\
\end{array}$ & $3 \mathrm{a} 3 \mathrm{~m}$ & $\mathrm{~F}$ & $12 / 8$ & 2010 & 2103995 & 0 & Sim & 1 & Negativo & 0 & 5 & Sim & Não & NEGATIVA \\
\hline 593 & AFS & $7 \mathrm{a} 10 \mathrm{~m}$ & $\mathrm{~F}$ & $12 / 8$ & 2010 & $\mathrm{~J} 500768$ & 0 & Sim & 1 & Positivo & 1 & 1 & Não & Sim & + \\
\hline 594 & $\mathrm{PP}$ & $8 \mathrm{a}$ & $\mathrm{F}$ & $12 / 8$ & 2010 & 2010627 & 1 & Não & 0 & Negativo & 0 & 0 & Sim & Não & NEGATIVA \\
\hline 595 & RFS & $9 \mathrm{a} 6 \mathrm{~m}$ & $M$ & $13 / 8$ & 2010 & H462892 & 1 & Não & 0 & Negativo & 0 & 3 & Sim & Não & S.pyogenes \\
\hline 596 & GKO & $10 \mathrm{a} 3 \mathrm{~m}$ & $\mathrm{~F}$ & $13 / 8$ & 2010 & 872202 & 0 & Não & 0 & Negativo & 0 & 0 & Sim & Não & NEGATIVA \\
\hline 597 & ABSN & $2 \mathrm{a} 2 \mathrm{~m}$ & $\mathrm{~F}$ & $13 / 8$ & 2010 & 2111304 & 0 & Não & 0 & Negativo & 0 & 0 & Sim & Não & NEGATIVA \\
\hline 598 & KSF & $4 \mathrm{a} 1 \mathrm{~m}$ & $M$ & $13 / 8$ & 2010 & 2055491 & 0 & Sim & 1 & Positivo & 1 & 1 & Não & Sim & + \\
\hline 599 & HASB & $3 a 3 m$ & $\mathrm{~F}$ & $13 / 8$ & 2010 & D414168 & 0 & Não & 0 & Negativo & 0 & 0 & Sim & Não & NEGATIVA \\
\hline 600 & JMBS & $12 \mathrm{a} 1 \mathrm{~m}$ & $\mathrm{~F}$ & $13 / 8$ & 2010 & H500987 & 1 & Não & 0 & Negativo & 0 & 0 & Sim & Não & NEGATIVA \\
\hline 601 & CFS & $11 \mathrm{a} 5 \mathrm{~m}$ & $M$ & $14 / 8$ & 2010 & 861575 & 0 & Sim & 1 & Negativo & 0 & 5 & Sim & Não & NEGATIVA \\
\hline 602 & IAF & $9 a 3 m$ & M & $14 / 8$ & 2010 & 120782 & 0 & Sim & 1 & Positivo & 1 & 5 & Sim & Sim & NEGATIVA \\
\hline 603 & RSS & $3 a 3 m$ & $\mathrm{M}$ & $15 / 8$ & 2010 & 2069068 & 1 & Sim & 1 & Positivo & 1 & 1 & Não & Sim & + \\
\hline 604 & DNV & $3 \mathrm{a} 5 \mathrm{~m}$ & $\mathrm{M}$ & $15 / 8$ & 2010 & 2066128 & 1 & Sim & 1 & Positivo & 1 & 1 & Não & Sim & + \\
\hline 605 & EHFA & $3 \mathrm{a} 1 \mathrm{~m}$ & $M$ & $15 / 8$ & 2010 & 2071263 & 1 & Sim & 1 & Negativo & 0 & 5 & Sim & Não & NEGATIVA \\
\hline 606 & LEIS & $6 \mathrm{a} 1 \mathrm{~m}$ & $\mathrm{M}$ & $16 / 8$ & 2010 & 2120001 & 1 & Não & 0 & Negativo & 0 & 0 & Sim & Não & NEGATIVA \\
\hline 607 & ELS & $4 a 10 m$ & M & $16 / 8$ & 2010 & 2042966 & 0 & Sim & 1 & Positivo & 1 & 1 & Não & Sim & + \\
\hline
\end{tabular}




\begin{tabular}{|c|c|c|c|c|c|c|c|c|c|c|c|c|c|c|c|}
\hline 608 & SLL & $11 \mathrm{a} 3 \mathrm{~m}$ & $\mathrm{~F}$ & $16 / 8$ & 2010 & A501245 & 0 & sim & 1 & Positivo & 1 & 1 & Não & Sim & + \\
\hline 609 & SOP & $4 a$ & $\mathrm{~F}$ & $17 / 8$ & 2010 & B416744 & 0 & Não & 0 & Negativo & 0 & 0 & Sim & Não & NEGATIVA \\
\hline 610 & ACM & $5 a 4 m$ & $F$ & $17 / 8$ & 2010 & 2036847 & 0 & Sim & 1 & Negativo & 0 & 5 & Sim & Não & NEGATIVA \\
\hline 612 & VMP & 49 & M & $18 / 8$ & 2010 & 2056869 & 1 & sim & 1 & Negativo & 0 & 5 & Sim & Não & NEGATIVA \\
\hline 613 & ADSP & 3a9m & $M$ & $18 / 8$ & 2010 & 2061737 & 1 & sim & 1 & Negativo & 0 & 5 & Sim & Não & NEGATIVA \\
\hline 614 & LAA & $9 a 8 m$ & M & $18 / 8$ & 2010 & 2001798 & 1 & Não & 0 & Negativo & 0 & 0 & sim & Não & NEGATIVA \\
\hline 616 & KMO & $7 \mathrm{a} 1 \mathrm{~m}$ & M & $19 / 8$ & 2010 & 2007762 & 0 & Não & 0 & Negativo & 0 & 0 & Sim & Não & NEGATIVA \\
\hline 617 & JSSN & $3 a 10 \mathrm{~m}$ & M & $19 / 8$ & 2010 & 2127874 & 0 & sim & 1 & Negativo & 0 & 5 & Sim & Não & NEGATIVA \\
\hline 618 & GAS & $3 a 10 \mathrm{~m}$ & M & $19 / 8$ & 2010 & 2100907 & 0 & Não & 0 & Negativo & 0 & 0 & sim & Não & NEGATIVA \\
\hline 619 & JVFB & $3 a 6 m$ & M & $19 / 8$ & 2010 & 2064863 & 0 & sim & 1 & Positivo & 1 & 1 & Sim & Sim & +/S.pyogenes \\
\hline 620 & BAL & $3 a 9 m$ & $F$ & $20 / 8$ & 2010 & 1359724 & 0 & Não & 0 & Negativo & 0 & 0 & Sim & Não & NEGATIVA \\
\hline 624 & KAS & $9 \mathrm{a} 2 \mathrm{~m}$ & $\mathrm{~F}$ & $21 / 8$ & 2010 & C49667 & 0 & sim & 1 & Positivo & 1 & 1 & Sim & Sim & $+/$ S. pyogenes \\
\hline 625 & MFAM & $2 a 9 m$ & $F$ & $21 / 8$ & 2010 & 2077734 & 0 & Não & 0 & Negativo & 0 & 0 & Sim & Não & NEGATIVA \\
\hline 626 & GVS & $10 \mathrm{a} 1 \mathrm{~m}$ & M & $21 / 8$ & 2010 & K60588 & 0 & sim & 1 & Negativo & 0 & 5 & Sim & Não & NEGATIVA \\
\hline 627 & BMG & $5 a 7 m$ & $F$ & $21 / 8$ & 2010 & H257371 & 1 & Não & 0 & Negativo & 0 & 0 & sim & Não & NEGATIVA \\
\hline 628 & LFFS & $4 a 11 m$ & M & $21 / 8$ & 2010 & E355982 & 0 & sim & 1 & Positivo & 1 & 1 & Não & sim & + \\
\hline 629 & LPO & $5 a 4 m$ & M & $21 / 8$ & 2010 & 2045480 & 0 & Sim & 1 & Negativo & 0 & 5 & Sim & Não & NEGATIVA \\
\hline 630 & GVS & $10 \mathrm{a} 1 \mathrm{~m}$ & M & $21 / 8$ & 2010 & K60588 & 0 & Sim & 1 & Negativo & 0 & 5 & Sim & Não & NEGATIVA \\
\hline 631 & EFR & $5 a 8 m$ & F & $22 / 8$ & 2010 & 2086064 & 0 & Sim & 1 & Positivo & 1 & 1 & Não & Sim & + \\
\hline 632 & LIAL & $7 a 7 m$ & M & $22 / 8$ & 2010 & 2122662 & 1 & Não & 0 & Negativo & 0 & 0 & Sim & Não & NEGATIVA \\
\hline 633 & LHMZ & $2 \mathrm{a} 10 \mathrm{~m}$ & $M$ & $22 / 8$ & 2010 & E476293 & 0 & $\mathrm{sim}$ & 1 & Negativo & 0 & 5 & $\mathrm{Sim}$ & Sim & NEGATIVA \\
\hline 641 & GRM & $2 a 6 m$ & M & $22 / 8$ & 2010 & 2082355 & 0 & Não & 0 & Positivo & 1 & 3 & Não & Sim & + \\
\hline 642 & YSG & $2 \mathrm{a} 6 \mathrm{~m}$ & M & $22 / 8$ & 2010 & 2096315 & 0 & sim & 1 & Positivo & 1 & 1 & Sim & Sim & +/S.pyogenes \\
\hline 643 & ACS & $6 a 1 \mathrm{~m}$ & $\mathrm{~F}$ & $23 / 8$ & 2010 & 2022197 & 1 & Não & 0 & Negativo & 0 & 0 & $\mathrm{sim}$ & Não & NEGATIVA \\
\hline 644 & LPB & $10 \underline{a}$ & M & $23 / 8$ & 2010 & 1501967 & 1 & Não & 0 & Negativo & 0 & 0 & sim & Não & S.ßhem gpo C \\
\hline 645 & MSR & $13 \mathrm{a} 2 \mathrm{~m}$ & M & $23 / 8$ & 2010 & H438343 & 1 & Não & 0 & Negativo & 0 & 0 & sim & Não & NEGATIVA \\
\hline 646 & PAL & $3 \mathrm{a} 2 \mathrm{~m}$ & $F$ & $23 / 8$ & 2010 & 2089588 & 0 & Não & 0 & Positivo & 1 & 3 & Não & Sim & + \\
\hline 647 & IAF & $3 a 6 m$ & $F$ & $23 / 8$ & 2010 & 1341256 & 0 & Não & 0 & Negativo & 0 & 0 & Sim & Não & NEGATIVA \\
\hline 648 & TEFC & $2 \mathrm{a} 6 \mathrm{~m}$ & M & $23 / 8$ & 2010 & 1445600 & 1 & Sim & 1 & Negativo & 0 & 5 & Sim & Não & NEGATIVA \\
\hline 649 & GEAS & $14{ }^{a}$ & M & $23 / 8$ & 2010 & 804728 & 0 & Não & 0 & Positivo & 1 & 3 & Não & Sim & + \\
\hline 650 & OGP & $5 \mathrm{a} 2 \mathrm{~m}$ & M & $23 / 8$ & 2010 & F245524 & 0 & sim & 1 & Negativo & 0 & 5 & Sim & Não & NEGATIVA \\
\hline 651 & ITO & $13 \mathrm{a} 1 \mathrm{~m}$ & $\mathrm{~F}$ & $23 / 8$ & 2010 & 333060 & 0 & $\mathrm{sim}$ & 1 & Positivo & 1 & 1 & Não & Sim & + \\
\hline 652 & CCR & $11 \mathrm{a} 7 \mathrm{~m}$ & $\mathrm{~F}$ & $23 / 8$ & 2010 & 9044 & 0 & Não & 0 & Negativo & 0 & 0 & Sim & Não & NEGATIVA \\
\hline 653 & MSSV & $11^{\mathrm{a}}$ & $\mathrm{F}$ & $23 / 8$ & 2010 & 897953 & 0 & sim & 1 & Negativo & 0 & 5 & Sim & Não & NEGATIVA \\
\hline 654 & ICASS & $4 a 3 m$ & $F$ & $23 / 8$ & 2010 & 2084107 & 0 & Não & 0 & Positivo & 1 & 0 & Sim & Sim & NEGATIVA \\
\hline 655 & LRTR & 3a & $\mathrm{F}$ & $24 / 8$ & 2010 & 2075010 & 1 & Não & 0 & Negativo & 0 & 0 & Sim & Não & S. Bhem gpo C \\
\hline 656 & SCA & $13 \mathrm{a} 1 \mathrm{~m}$ & M & $24 / 8$ & 2010 & 2054713 & 1 & Não & 0 & Negativo & 0 & 0 & sim & Não & NEGATIVA \\
\hline 657 & ACS & $4 a 10 m$ & M & $24 / 8$ & 2010 & 2043395 & 1 & Não & 0 & Negativo & 0 & 0 & $\mathrm{sim}$ & Não & NEGATIVA \\
\hline 658 & GMRGS & $10 \mathrm{a} 5 \mathrm{~m}$ & $F$ & $24 / 8$ & 2010 & 2072854 & 1 & Não & 0 & Negativo & 0 & 0 & Sim & Não & NEGATIVA \\
\hline
\end{tabular}




\begin{tabular}{|c|c|c|c|c|c|c|c|c|c|c|c|c|c|c|c|}
\hline 659 & GSS & $605 \mathrm{~m}$ & M & $25 / 8$ & 2010 & 2016742 & 1 & Não & 0 & Negativo & 0 & 0 & Sim & Não & NEGATIVA \\
\hline 660 & SSR & $3 a 9 m$ & $\mathrm{~F}$ & $25 / 8$ & 2010 & 2061759 & 1 & Sim & 1 & Negativo & 0 & 5 & $\operatorname{sim}$ & Não & NEGATIVA \\
\hline 661 & NLLS & $7 \mathrm{a} 3 \mathrm{~m}$ & M & $25 / 8$ & 2010 & 2005761 & 0 & sim & 1 & Negativo & 0 & 5 & Sim & Não & S. Bhem gpo C \\
\hline 663 & $A B A B$ & $8 \mathrm{a} 2 \mathrm{~m}$ & $\mathrm{~F}$ & $25 / 8$ & 2010 & 899163 & 0 & Não & 0 & Negativo & 0 & 0 & $\operatorname{sim}$ & Não & NEGATIVA \\
\hline 664 & CLGG & $7 \mathrm{a} 4 \mathrm{~m}$ & M & $25 / 8$ & 2010 & 2125026 & 0 & Sim & 1 & Negativo & 0 & 5 & $\operatorname{sim}$ & Não & NEGATIVA \\
\hline 665 & KDSS & $3 \mathrm{a} 10 \mathrm{~m}$ & M & $27 / 8$ & 2010 & 2063566 & 0 & Sim & 1 & Positivo & 1 & 1 & Não & sim & + \\
\hline 667 & LYOS & $6 \mathrm{a} 3 \mathrm{~m}$ & $\mathrm{~F}$ & $27 / 8$ & 2010 & 2019691 & 0 & Não & 0 & Positivo & 1 & 3 & Não & Sim & + \\
\hline 668 & KRO & $7 \mathrm{a} 1 \mathrm{~m}$ & M & $28 / 8$ & 2010 & 2016059 & 1 & Não & 0 & Negativo & 0 & 0 & Sim & Não & NEGATIVA \\
\hline 669 & MS & $12 \mathrm{a} 7 \mathrm{~m}$ & $\mathrm{~F}$ & $28 / 8$ & 2010 & C426075 & 0 & sim & 1 & Positivo & 1 & 1 & Não & Sim & + \\
\hline 670 & $\mathrm{CIR}$ & $4 \mathrm{a} 9 \mathrm{~m}$ & M & $28 / 8$ & 2010 & 2090026 & 0 & Sim & 1 & Positivo & 1 & 1 & Não & Sim & + \\
\hline 671 & EGM & $6 a 8 m$ & M & $28 / 8$ & 2010 & H416980 & 0 & Não & 0 & Negativo & 0 & 0 & sim & Não & NEGATIVA \\
\hline 675 & JSL & $8 \mathrm{a} 3 \mathrm{~m}$ & M & $29 / 8$ & 2010 & H9792 & 1 & Não & 0 & Negativo & 0 & 0 & Sim & Não & NEGATIVA \\
\hline 676 & SSB & $7 \mathrm{a} 5 \mathrm{~m}$ & $\mathrm{~F}$ & $29 / 8$ & 2010 & K503090 & 0 & sim & 1 & Positivo & 1 & 1 & Não & Sim & + \\
\hline 677 & KFS & $8 \mathrm{a} 10 \mathrm{~m}$ & M & $29 / 8$ & 2010 & $J 10344$ & 1 & Não & 0 & Positivo & 1 & 3 & Não & Sim & + \\
\hline 678 & AGS & $4 \mathrm{a} 4 \mathrm{~m}$ & $\mathrm{~F}$ & $29 / 8$ & 2010 & 2051723 & 1 & Não & 0 & Negativo & 0 & 0 & $\mathrm{sim}$ & Não & NEGATIVA \\
\hline 679 & LHMR & $3 a 3 m$ & $\mathrm{~F}$ & $29 / 8$ & 2010 & 2070509 & 1 & Sim & 1 & Negativo & 0 & 5 & Sim & Não & NEGATIVA \\
\hline 680 & BMS & $3 a 7 m$ & $\mathrm{~F}$ & $29 / 8$ & 2010 & 1331326 & 1 & Sim & 1 & Negativo & 0 & 5 & Sim & Não & NEGATIVA \\
\hline 681 & $A C Z$ & $606 \mathrm{~m}$ & $\mathrm{~F}$ & $30 / 8$ & 2010 & 2129258 & 0 & Sim & 1 & Positivo & 1 & 1 & Não & Sim & + \\
\hline 682 & BSM & $4 a 7 m$ & $\mathrm{~F}$ & $30 / 8$ & 2010 & 2124598 & 0 & Não & 0 & Positivo & 1 & 3 & Não & Sim & + \\
\hline 683 & VGOB & $4 a 7 m$ & $\mathrm{~F}$ & $30 / 8$ & 2010 & 2047672 & 1 & Não & 0 & Positivo & 1 & 3 & Não & sim & + \\
\hline 684 & NMAS & $8 \mathrm{a} 8 \mathrm{~m}$ & $\mathrm{~F}$ & $30 / 8$ & 2010 & 126682 & 0 & sim & 1 & Positivo & 1 & 1 & Não & Sim & + \\
\hline 692 & PAS & $11 \mathrm{a} 5 \mathrm{~m}$ & $M$ & $31 / 8$ & 2010 & G80121 & 0 & sim & 1 & Positivo & 1 & 1 & Não & sim & + \\
\hline 693 & ISS & $2 \mathrm{a} 7 \mathrm{~m}$ & $\mathrm{~F}$ & $31 / 8$ & 2010 & 2082445 & 0 & Não & 0 & Negativo & 0 & 0 & Sim & Não & NEGATIVA \\
\hline 694 & LFB & $\begin{array}{l}11 \mathrm{a} 10 \\
\mathrm{~m}\end{array}$ & M & $1 / 9$ & 2010 & 2039354 & 0 & Sim & 1 & Positivo & 1 & 1 & Não & Sim & + \\
\hline 695 & EOA & $2 \mathrm{a} 7 \mathrm{~m}$ & $\mathrm{~F}$ & $2 / 9$ & 2010 & 2080913 & 1 & Não & 0 & Negativo & 0 & 0 & $\mathrm{Sim}$ & Não & NEGATIVA \\
\hline 696 & TCSD & $13 \mathrm{a} 7 \mathrm{~m}$ & $\mathrm{~F}$ & $2 / 9$ & 2010 & 111061 & 1 & Não & 0 & Positivo & 1 & 3 & Não & sim & + \\
\hline 697 & $\operatorname{CSN}$ & $\begin{array}{l}\text { 14a11 } \\
\text { m }\end{array}$ & $\mathrm{F}$ & $2 / 9$ & 2010 & 774802 & 0 & Não & 0 & Negativo & 0 & 0 & $\mathrm{Sim}$ & Não & NEGATIVA \\
\hline 698 & LRG & $14 a 6 m$ & $\mathrm{~F}$ & $2 / 9$ & 2010 & 104791 & 0 & Sim & 1 & Negativo & 0 & 5 & Sim & Não & S.ßhhem gpo C \\
\hline 699 & JDR & $7 \mathrm{a} 1 \mathrm{~m}$ & M & $2 / 9$ & 2010 & 2007763 & 0 & Sim & 1 & Positivo & 1 & 1 & $\operatorname{sim}$ & Sim & +/S.pyogenes \\
\hline 700 & TGF & $13 \mathrm{a} 6 \mathrm{~m}$ & $\mathrm{~F}$ & $2 / 9$ & 2010 & E275447 & 0 & sim & 1 & Positivo & 1 & 1 & Não & sim & + \\
\hline 701 & LLGN & $6 a 8 m$ & M & $2 / 9$ & 2010 & 2014100 & 0 & Sim & 1 & Positivo & 1 & 1 & Não & Sim & + \\
\hline 702 & GCL & $7 \mathrm{a} 8 \mathrm{~m}$ & M & $2 / 9$ & 2010 & C153274 & 1 & Não & 0 & Negativo & 0 & 0 & Sim & Não & NEGATIVA \\
\hline 703 & LGT & $3 a 5 m$ & M & $3 / 9$ & 2010 & 2113265 & 1 & Não & 0 & Negativo & 0 & 0 & Sim & Não & NEGATIVA \\
\hline 704 & TLS & $3 a 9 m$ & M & $3 / 9$ & 2010 & J341426 & 1 & Não & 0 & Negativo & 0 & 0 & $\operatorname{sim}$ & Não & NEGATIVA \\
\hline 705 & MEAS & $6 \mathrm{a} 2 \mathrm{~m}$ & $\mathrm{~F}$ & $3 / 9$ & 2010 & 2080139 & 1 & Não & 0 & Negativo & 0 & 0 & Sim & Não & NEGATIVA \\
\hline 706 & CEEV & $6 \mathrm{a} 2 \mathrm{~m}$ & M & $4 / 9$ & 2010 & 2049295 & 0 & Não & 0 & Negativo & 0 & 0 & $\operatorname{sim}$ & Não & NEGATIVA \\
\hline 707 & LSE & $8 \mathrm{a} 4 \mathrm{~m}$ & $\mathrm{~F}$ & $4 / 9$ & 2010 & 111689 & 0 & Sim & 1 & Negativo & 0 & 1 & Sim & Não & S.pyogenes \\
\hline 708 & BM & 6a & $\mathrm{F}$ & $4 / 9$ & 2010 & 2032468 & 0 & Não & 0 & Positivo & 1 & 0 & sim & sim & NEGATIVA \\
\hline 709 & KACS & $10 \mathrm{a} 9 \mathrm{~m}$ & $\mathrm{~F}$ & $4 / 9$ & 2010 & 877148 & 1 & Não & 0 & Negativo & 0 & 0 & Sim & Não & NEGATIVA \\
\hline
\end{tabular}




\begin{tabular}{|c|c|c|c|c|c|c|c|c|c|c|c|c|c|c|c|}
\hline 710 & VJCG & $12^{\mathrm{a}}$ & M & $4 / 9$ & 2010 & 13338 & 0 & sim & 1 & Negativo & 0 & 5 & sim & Não & NEGATIVA \\
\hline 711 & LBG & $3 \mathrm{a} 8 \mathrm{~m}$ & M & $4 / 9$ & 2010 & 2063782 & 1 & Não & 0 & Negativo & 0 & 0 & $\operatorname{sim}$ & Não & NEGATIVA \\
\hline 712 & ASR & $8 \mathrm{a} 7 \mathrm{~m}$ & $\mathrm{~F}$ & $4 / 9$ & 2010 & 126535 & 0 & Não & 0 & Negativo & 0 & 0 & Sim & Não & NEGATIVA \\
\hline 714 & MAS & $4 a 7 m$ & $M$ & $5 / 9$ & 2010 & F265377 & 0 & Não & 0 & Positivo & 1 & 3 & $\mathrm{Sim}$ & sim & $+/$ S.pyogenes \\
\hline 715 & GAST & $7 \mathrm{a} 2 \mathrm{~m}$ & $M$ & $5 / 9$ & 2010 & 2006454 & 0 & sim & 1 & Positivo & 1 & 1 & Não & sim & + \\
\hline 716 & JVC & $8 \mathrm{a}$ & $M$ & $5 / 9$ & 2010 & H56347 & 0 & Não & 0 & Positivo & 1 & 3 & Não & $\mathrm{sim}$ & + \\
\hline 718 & MRS & $11 \mathrm{a} 6 \mathrm{~m}$ & $M$ & $5 / 9$ & 2010 & 10870 & 0 & sim & 1 & Negativo & 0 & 5 & Sim & Não & NEGATIVA \\
\hline 719 & LPS & $3 \mathrm{a} 10 \mathrm{~m}$ & $\mathrm{~F}$ & $6 / 9$ & 2010 & 2089035 & 1 & Não & 0 & Negativo & 0 & 0 & Sim & Não & NEGATIVA \\
\hline 720 & MBFA & $2 \mathrm{a} 11 \mathrm{~m}$ & $M$ & $6 / 9$ & 2010 & H504067 & 1 & Não & 0 & Negativo & 0 & 0 & Sim & Não & NEGATIVA \\
\hline 721 & JVGB & $8 \mathrm{a} 7 \mathrm{~m}$ & $\mathrm{~F}$ & $6 / 9$ & 2010 & E504091 & 0 & sim & 1 & Positivo & 1 & 1 & Não & sim & + \\
\hline 722 & AVM & $8 \mathrm{a} 4 \mathrm{~m}$ & $\mathrm{~F}$ & $6 / 9$ & 2010 & 2018869 & 0 & Sim & 1 & Positivo & 1 & 1 & Não & sim & + \\
\hline 726 & NJO & $11 \mathrm{a} 4 \mathrm{~m}$ & $\mathrm{~F}$ & $7 / 9$ & 2010 & K550003 & 1 & Não & 0 & Positivo & 1 & 3 & Não & Sim & + \\
\hline 727 & VHOF & $5 \mathrm{a} 8 \mathrm{~m}$ & $M$ & $7 / 9$ & 2010 & E220970 & 0 & sim & 1 & Positivo & 1 & 1 & Não & $\mathrm{sim}$ & + \\
\hline 728 & TAD & $7 \mathrm{a} 8 \mathrm{~m}$ & $\mathrm{~F}$ & $7 / 9$ & 2010 & $\mathrm{~J} 144788$ & 0 & Não & 0 & Negativo & 0 & 0 & $\mathrm{Sim}$ & Não & NEGATIVA \\
\hline 729 & SMA & $7 \mathrm{a} 4 \mathrm{~m}$ & $\mathrm{~F}$ & $7 / 9$ & 2010 & 2004394 & 0 & Sim & 1 & Positivo & 1 & 1 & Não & $\mathrm{sim}$ & + \\
\hline 730 & FPC & $2 \mathrm{a} 4 \mathrm{~m}$ & M & $7 / 9$ & 2010 & K439022 & 0 & Não & 0 & Positivo & 1 & 3 & Não & sim & + \\
\hline 731 & BCSG & $\begin{array}{l}\text { 13a10 } \\
\mathrm{m}\end{array}$ & $\mathrm{F}$ & $8 / 9$ & 2010 & 2033549 & 0 & sim & 1 & Positivo & 1 & 1 & Não & sim & + \\
\hline 732 & KFC & $2 \mathrm{a} 3 \mathrm{~m}$ & $M$ & 9/9 & 2010 & K504406 & 0 & sim & 1 & Negativo & 0 & 5 & $\mathrm{Sim}$ & Não & NEGATIVA \\
\hline 733 & AHLS & $12 \mathrm{a} 6 \mathrm{~m}$ & $M$ & 9/9 & 2010 & 22123 & 0 & sim & 1 & Negativo & 0 & 5 & $\mathrm{Sim}$ & Não & NEGATIVA \\
\hline 734 & SSN & $3 \mathrm{a} 3 \mathrm{~m}$ & $\mathrm{~F}$ & $9 / 9$ & 2010 & 2112808 & 0 & Não & 0 & Negativo & 0 & 0 & $\mathrm{Sim}$ & Não & NEGATIVA \\
\hline 735 & ARS & $6 \mathrm{a} 5 \mathrm{~m}$ & $M$ & 9/9 & 2010 & 1504422 & 0 & sim & 1 & Positivo & 1 & 1 & Não & $\mathrm{sim}$ & + \\
\hline 743 & JTSIC & $3 \mathrm{a} 10 \mathrm{~m}$ & $\mathrm{~F}$ & $26 / 8$ & 2010 & 1306860 & 0 & Não & 0 & Negativo & 0 & 0 & $\mathrm{Sim}$ & Não & NEGATIVA \\
\hline 744 & LVG & $4 \mathrm{a} 11 \mathrm{~m}$ & $\mathrm{~F}$ & $26 / 8$ & 2010 & K432871 & 0 & Não & 0 & Negativo & 0 & 0 & $\mathrm{Sim}$ & Não & NEGATIVA \\
\hline 745 & GFS & $6 \mathrm{a} 6 \mathrm{~m}$ & $\mathrm{~F}$ & $27 / 8$ & 2010 & 2016574 & 0 & Não & 0 & Negativo & 0 & 0 & Sim & Não & NEGATIVA \\
\hline 746 & ESD & 5 a & $M$ & $27 / 8$ & 2010 & 2041205 & 0 & sim & 1 & Positivo & 1 & 1 & Não & $\mathrm{sim}$ & + \\
\hline 747 & HAM & $3 \mathrm{a} 4 \mathrm{~m}$ & $M$ & $27 / 8$ & 2010 & 2069716 & 0 & sim & 1 & Negativo & 0 & 5 & $\mathrm{Sim}$ & Não & NEGATIVA \\
\hline 748 & FBO & $2 \mathrm{a} 1 \mathrm{~m}$ & $M$ & $14 / 9$ & 2010 & B421638 & 0 & Não & 0 & Negativo & 0 & 0 & $\mathrm{Sim}$ & Não & NEGATIVA \\
\hline 749 & PVMA & $3 \mathrm{a} 9 \mathrm{~m}$ & $M$ & $14 / 9$ & 2010 & 2130928 & 0 & Sim & 1 & Positivo & 1 & 1 & $\mathrm{Sim}$ & Não & $+/$ S.pyogenes \\
\hline 750 & MEB & $4 a 3 m$ & $\mathrm{~F}$ & $14 / 9$ & 2010 & 2053738 & 0 & sim & 1 & Negativo & 0 & 5 & $\mathrm{Sim}$ & Não & NEGATIVA \\
\hline 751 & SCS & $3 \mathrm{a} 9 \mathrm{~m}$ & $\mathrm{~F}$ & $15 / 9$ & 2010 & G315467 & 0 & sim & 1 & Negativo & 0 & 1 & Sim & Não & S.pyogenes \\
\hline 752 & ACSP & $4 \mathrm{a} 8 \mathrm{~m}$ & $\mathrm{~F}$ & $16 / 9$ & 2010 & 2047247 & 0 & sim & 1 & Negativo & 0 & 5 & $\mathrm{Sim}$ & Não & NEGATIVA \\
\hline 753 & ESS & $7 \mathrm{a} 10 \mathrm{~m}$ & $M$ & $16 / 9$ & 2010 & 2079657 & 0 & Sim & 1 & Positivo & 1 & 1 & Não & Sim & + \\
\hline 754 & LHSF & $5 \mathrm{a} 10 \mathrm{~m}$ & $M$ & $17 / 9$ & 2010 & B293590 & 0 & Não & 0 & Negativo & 0 & 0 & Sim & Não & S.pyogenes \\
\hline 755 & EIR & $10 \mathrm{a} 8 \mathrm{~m}$ & M & $17 / 9$ & 2010 & G98913 & 1 & Não & 0 & Negativo & 0 & 0 & Sim & Não & NEGATIVA \\
\hline 756 & MRAO & $6 \mathrm{a} 3 \mathrm{~m}$ & $M$ & $17 / 9$ & 2010 & 2020940 & 0 & sim & 1 & Positivo & 1 & 1 & Sim & sim & $+/$ S. pyogenes \\
\hline 757 & TA & $7 \mathrm{a} 5 \mathrm{~m}$ & $M$ & $7 / 10$ & 2010 & E99974 & 0 & sim & 1 & Positivo & 1 & 1 & $\mathrm{Sim}$ & Sim & $+/$ S.pyogenes \\
\hline 758 & VAO & $5 \mathrm{a} 7 \mathrm{~m}$ & $M$ & $8 / 10$ & 2010 & 2031767 & 0 & Sim & 1 & Positivo & 1 & 1 & Não & Sim & + \\
\hline 759 & RPA & $12 \mathrm{a} 9 \mathrm{~m}$ & $\mathrm{~F}$ & $8 / 10$ & 2010 & 2042319 & 0 & Não & 0 & Negativo & 0 & 0 & $\mathrm{Sim}$ & Não & NEGATIVA \\
\hline 760 & AFCS & $4 \mathrm{a} 11 \mathrm{~m}$ & M & $8 / 10$ & 2010 & 2105723 & 0 & sim & 1 & Positivo & 1 & 1 & Sim & sim & +/S.pyogenes \\
\hline
\end{tabular}




\begin{tabular}{|c|c|c|c|c|c|c|c|c|c|c|c|c|c|c|c|}
\hline 761 & CR & $10 \mathrm{a} 9 \mathrm{~m}$ & M & $10 / 10$ & 2010 & 27162 & 0 & Não & 0 & Negativo & 0 & 0 & $\operatorname{sim}$ & Não & NEGATIVA \\
\hline 762 & TBO & $13 \mathrm{a} 1 \mathrm{~m}$ & $\mathrm{~F}$ & $10 / 10$ & 2010 & 35620 & 0 & Sim & 1 & Positivo & 1 & 1 & Sim & Sim & +/S.pyogenes \\
\hline 763 & JVS & 10a3m & M & $10 / 10$ & 2010 & K234455 & 1 & Sim & 1 & Negativo & 0 & 5 & Sim & Não & S. Bhem gpo C \\
\hline 765 & RSC & $4 a 6 m$ & M & $11 / 10$ & 2010 & G508547 & 1 & Não & 0 & Negativo & 0 & 0 & Sim & Não & NEGATIVA \\
\hline 766 & AST & $11 \mathrm{a} 4 \mathrm{~m}$ & $\mathrm{~F}$ & $11 / 10$ & 2010 & 858277 & 0 & Não & 0 & Negativo & 0 & 3 & Sim & Não & S.pyogenes \\
\hline 767 & VSP & $9 \mathrm{a} 2 \mathrm{~m}$ & M & $11 / 10$ & 2010 & C11563 & 1 & Não & 0 & Negativo & 0 & 0 & Sim & Não & NEGATIVA \\
\hline 769 & GBA & $12 \mathrm{a} 2 \mathrm{~m}$ & $\mathrm{~F}$ & $13 / 10$ & 2010 & 119422 & 0 & Sim & 1 & Positivo & 1 & 5 & $\mathrm{sim}$ & Sim & NEGATIVA \\
\hline 770 & GBSL & $5 \mathrm{a} 8 \mathrm{~m}$ & M & $13 / 10$ & 2010 & E508773 & 0 & Sim & 1 & Positivo & 1 & 1 & Sim & Sim & +/S.pyogenes \\
\hline 771 & TOS & $6 \mathrm{a} 4 \mathrm{~m}$ & $\mathrm{~F}$ & $13 / 10$ & 2010 & 2020134 & 0 & Sim & 1 & Negativo & 0 & 5 & Sim & Não & NEGATIVA \\
\hline 772 & MGE & 10a9m & $\mathrm{F}$ & $14 / 10$ & 2010 & A326002 & 0 & Sim & 1 & Negativo & 0 & 5 & $\operatorname{sim}$ & Não & NEGATIVA \\
\hline 773 & GAM & $11 \mathrm{a} 9 \mathrm{~m}$ & $\mathrm{~F}$ & $14 / 10$ & 2010 & C64391 & 0 & Não & 0 & Negativo & 0 & 0 & Sim & Não & NEGATIVA \\
\hline 777 & RT & $14 \mathrm{a} 2 \mathrm{~m}$ & M & $15 / 10$ & 2010 & 796006 & 0 & Não & 0 & Negativo & 0 & 0 & $\operatorname{sim}$ & Não & NEGATIVA \\
\hline 778 & NCSC & $5 \mathrm{a} 4 \mathrm{~m}$ & M & $15 / 10$ & 2010 & 2036548 & 0 & Sim & 1 & Negativo & 0 & 5 & Sim & Não & NEGATIVA \\
\hline 779 & GAM & $11 \mathrm{agm}$ & $\mathrm{F}$ & $16 / 10$ & 2010 & C64391 & 0 & Não & 0 & Negativo & 0 & 0 & Sim & Não & NEGATIVA \\
\hline 780 & RFSA & $7 \underline{a}$ & $\mathrm{~F}$ & $16 / 10$ & 2010 & 2011133 & 0 & Sim & 1 & Positivo & 1 & 1 & Não & Sim & + \\
\hline 781 & KLSL & $2 \mathrm{a} 7 \mathrm{~m}$ & M & $16 / 10$ & 2010 & G395569 & 0 & $\operatorname{sim}$ & 1 & Positivo & 1 & 1 & Não & $\operatorname{sim}$ & + \\
\hline 782 & RMM & $6 \mathrm{a} 10 \mathrm{~m}$ & M & $17 / 10$ & 2010 & 2056809 & 1 & Não & 0 & Positivo & 1 & 3 & Não & Sim & + \\
\hline 783 & TIP & $8 \mathrm{a} 11 \mathrm{~m}$ & M & $17 / 10$ & 2010 & 2083573 & 0 & Sim & 1 & Negativo & 0 & 5 & Sim & Não & NEGATIVA \\
\hline 784 & LRAB & gạ & $\mathrm{F}$ & $17 / 10$ & 2010 & D314207 & 0 & Não & 0 & Negativo & 0 & 0 & Sim & Não & NEGATIVA \\
\hline 785 & ESC & $8 \mathrm{a}$ & M & $17 / 10$ & 2010 & G175217 & 0 & Sim & 1 & Positivo & 1 & 1 & Não & Sim & + \\
\hline 786 & ERC & $3 \mathrm{a} 11 \mathrm{~m}$ & $\mathrm{~F}$ & $17 / 10$ & 2010 & 2064071 & 1 & Não & 0 & Positivo & 1 & 3 & Não & Sim & + \\
\hline 794 & ITOM & $14 \mathrm{a} 2 \mathrm{~m}$ & $\mathrm{~F}$ & $20 / 10$ & 2010 & 107692 & 1 & Sim & 1 & Negativo & 0 & 5 & $\operatorname{sim}$ & Não & NEGATIVA \\
\hline 795 & GQS & $10 \mathrm{a} 3 \mathrm{~m}$ & $\mathrm{~F}$ & $20 / 10$ & 2010 & 2021594 & 0 & Não & 0 & Negativo & 0 & 0 & Sim & Não & NEGATIVA \\
\hline 796 & JKN & $2 \mathrm{a} 11 \mathrm{~m}$ & $\mathrm{~F}$ & $20 / 10$ & 2010 & 2126032 & 1 & Não & 0 & Negativo & 0 & 0 & sim & Não & NEGATIVA \\
\hline 797 & MGFS & $3 \mathrm{a} 2 \mathrm{~m}$ & $\mathrm{~F}$ & $20 / 10$ & 2010 & 2073315 & 0 & Sim & 1 & Negativo & 0 & 5 & Sim & Não & NEGATIVA \\
\hline 798 & GFR & $6 a 8 m$ & $\mathrm{~F}$ & $20 / 10$ & 2010 & 2016574 & 0 & Não & 0 & Negativo & 0 & 0 & Não & Não & NEGATIVA \\
\hline 799 & MMP & $4 a 8 m$ & M & $21 / 10$ & 2010 & K269157 & 0 & Sim & 1 & Positivo & 1 & 1 & Sim & Sim & + \\
\hline 800 & YLC & $8 \mathrm{a} 6 \mathrm{~m}$ & M & $21 / 10$ & 2010 & 2060561 & 0 & Não & 0 & Negativo & 0 & 0 & sim & Não & NEGATIVA \\
\hline 801 & MN & $8 \mathrm{a} 5 \mathrm{~m}$ & M & $23 / 10$ & 2010 & 2035372 & 1 & Não & 0 & Negativo & 0 & 0 & $\operatorname{sim}$ & Não & NEGATIVA \\
\hline 802 & FAC & $14 \mathrm{a} 7 \mathrm{~m}$ & M & $23 / 10$ & 2010 & 827877 & 0 & Não & 0 & Positivo & 1 & 3 & Não & Sim & + \\
\hline 803 & MOC & $8 \mathrm{a} 4 \mathrm{~m}$ & M & $24 / 10$ & 2010 & J510132 & 0 & sim & 1 & Positivo & 1 & 1 & Não & Sim & + \\
\hline 804 & JCVM & $5 \mathrm{a} 2 \mathrm{~m}$ & M & $25 / 10$ & 2010 & C242449 & 0 & Não & 0 & Positivo & 1 & 0 & Sim & Sim & NEGATIVA \\
\hline 805 & MERV & $6 \mathrm{a} 7 \mathrm{~m}$ & $\mathrm{~F}$ & $25 / 10$ & 2010 & 2017649 & 1 & Sim & 1 & Positivo & 1 & 1 & $\operatorname{sim}$ & Sim & +/S.pyogenes \\
\hline 806 & RMT & $12 \mathrm{a} 2 \mathrm{~m}$ & M & $26 / 10$ & 2010 & 2093439 & 1 & Não & 0 & Negativo & 0 & 0 & Sim & Não & NEGATIVA \\
\hline 807 & GGB & $5 \mathrm{a} 1 \mathrm{~m}$ & M & $26 / 10$ & 2010 & $\mathrm{H} 242063$ & 1 & sim & 1 & Positivo & 1 & 1 & Não & Sim & + \\
\hline 808 & $J G B$ & $8 \mathrm{a} 10 \mathrm{~m}$ & $\mathrm{~F}$ & $26 / 10$ & 2010 & 2042754 & 1 & Sim & 1 & Positivo & 1 & 1 & Não & Sim & + \\
\hline 809 & BTA & $12 \mathrm{a} 3 \mathrm{~m}$ & $\mathrm{~F}$ & $23 / 10$ & 2010 & J330593 & 0 & Sim & 1 & Negativo & 0 & 5 & Sim & Não & NEGATIVA \\
\hline 810 & TVL & $12 \mathrm{agm}$ & $\mathrm{F}$ & $23 / 10$ & 2010 & 1295047 & 0 & Sim & 1 & Negativo & 0 & 5 & Sim & Não & NEGATIVA \\
\hline 811 & LOP & $13 \mathrm{a} 8 \mathrm{~m}$ & $\mathrm{~F}$ & $22 / 10$ & 2010 & 864271 & 0 & Não & 0 & Negativo & 0 & 0 & Sim & Não & NEGATIVA \\
\hline
\end{tabular}




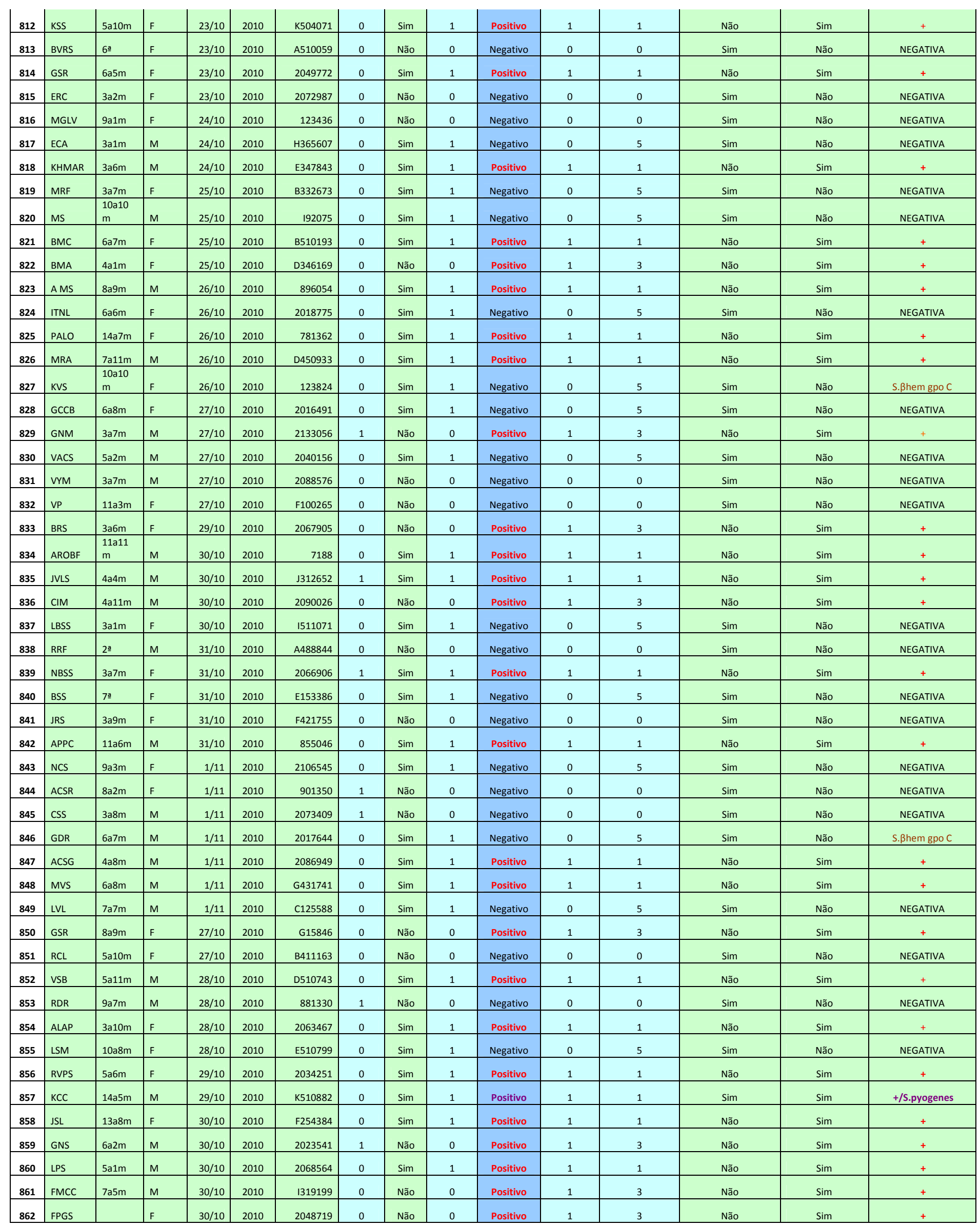




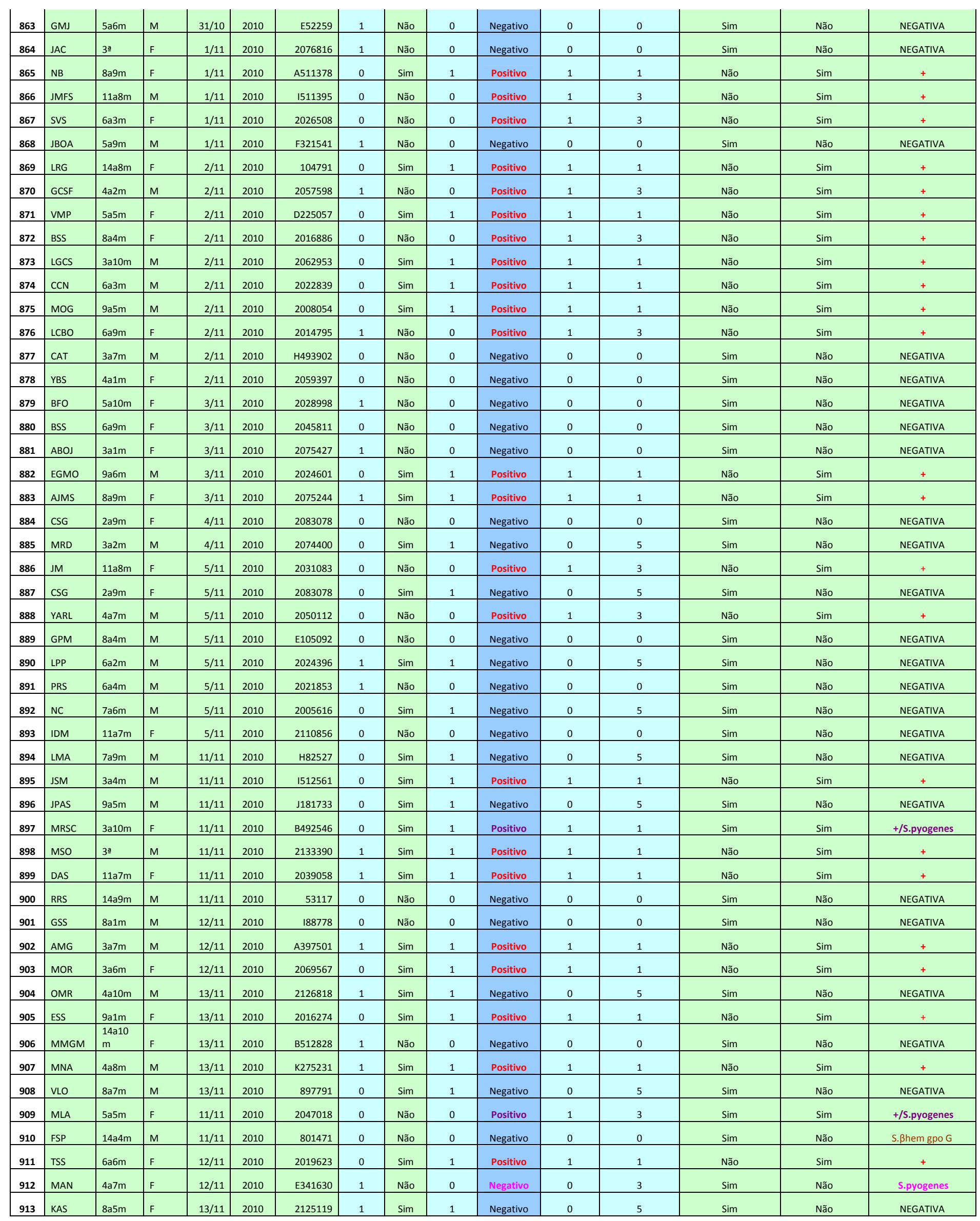




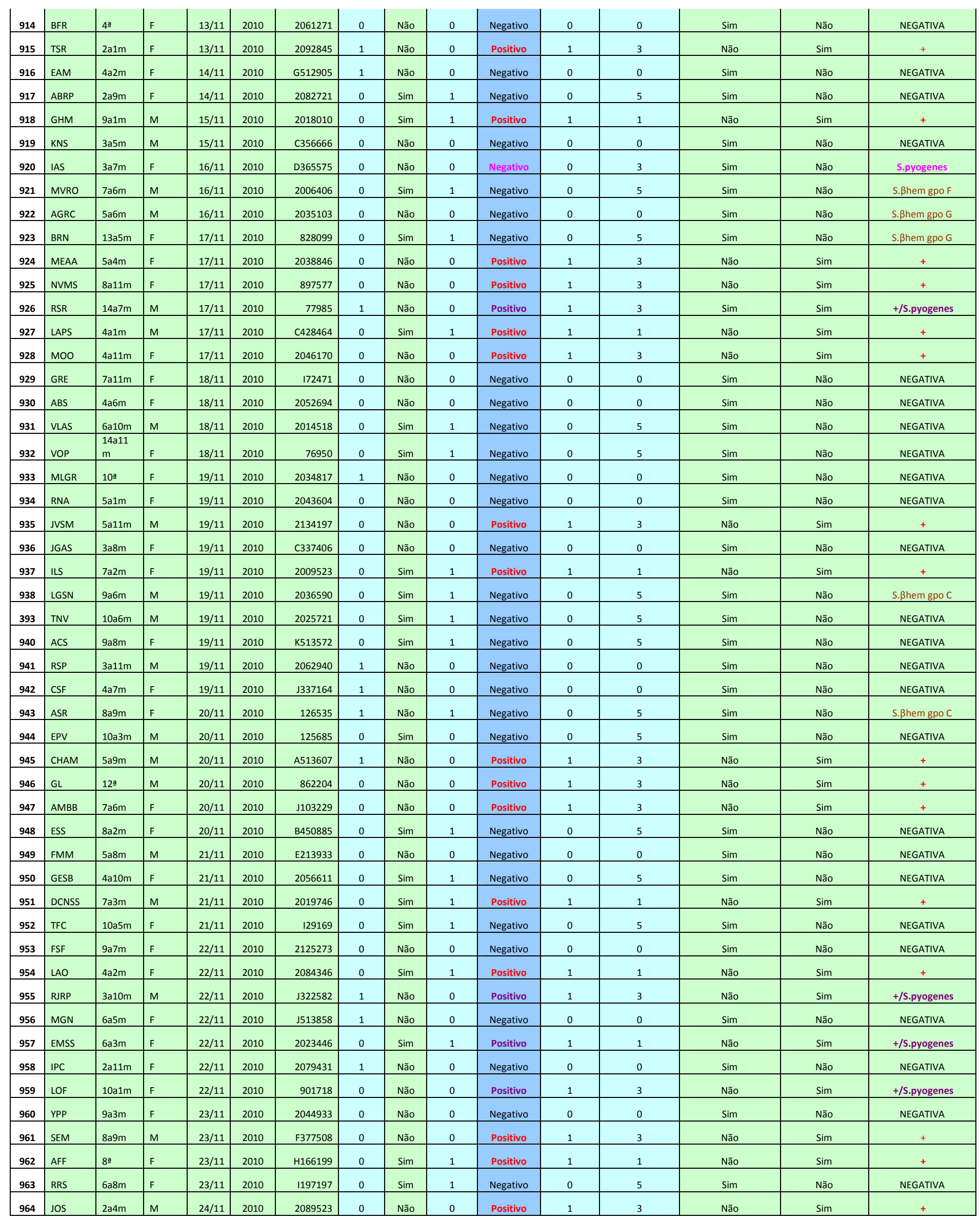




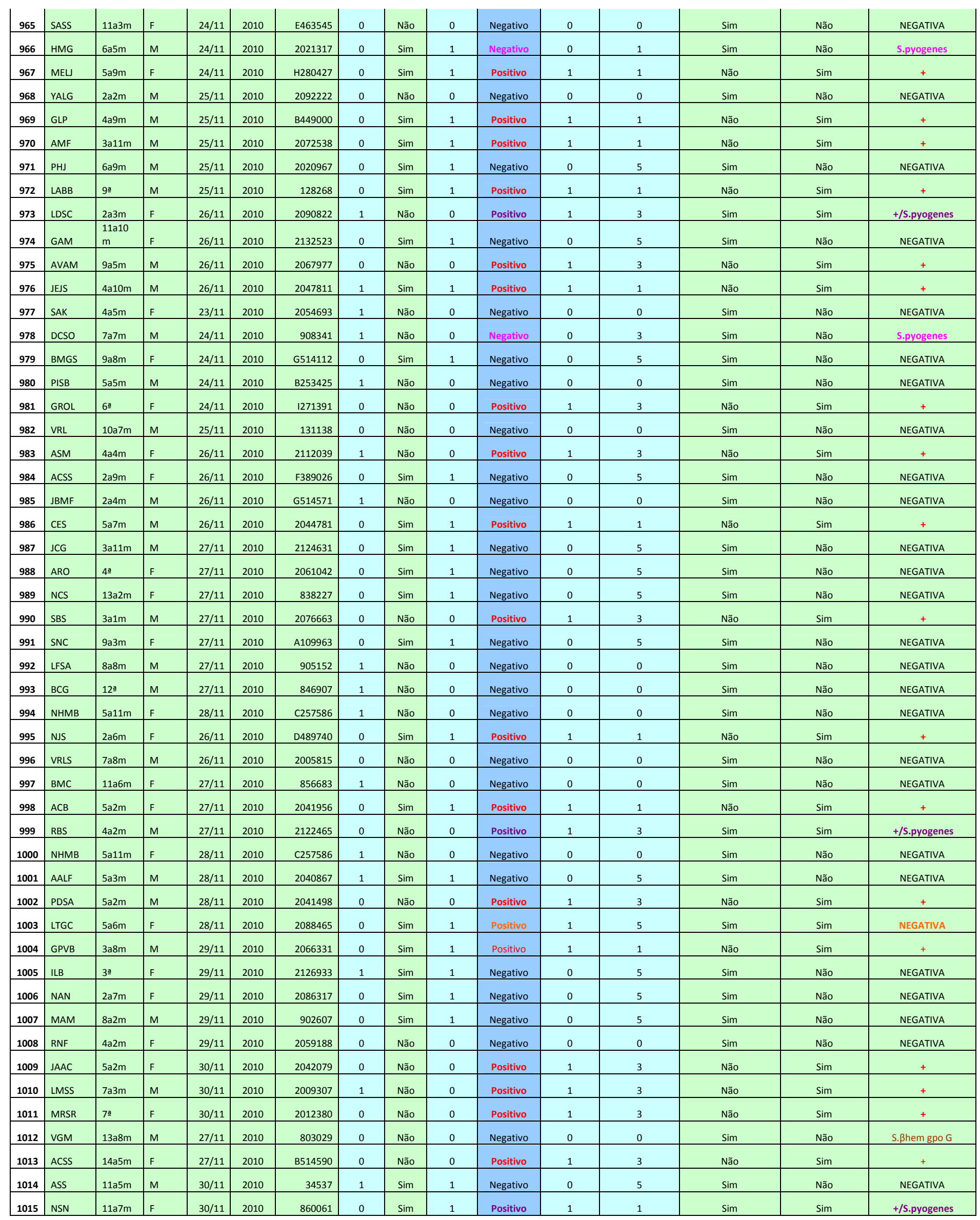




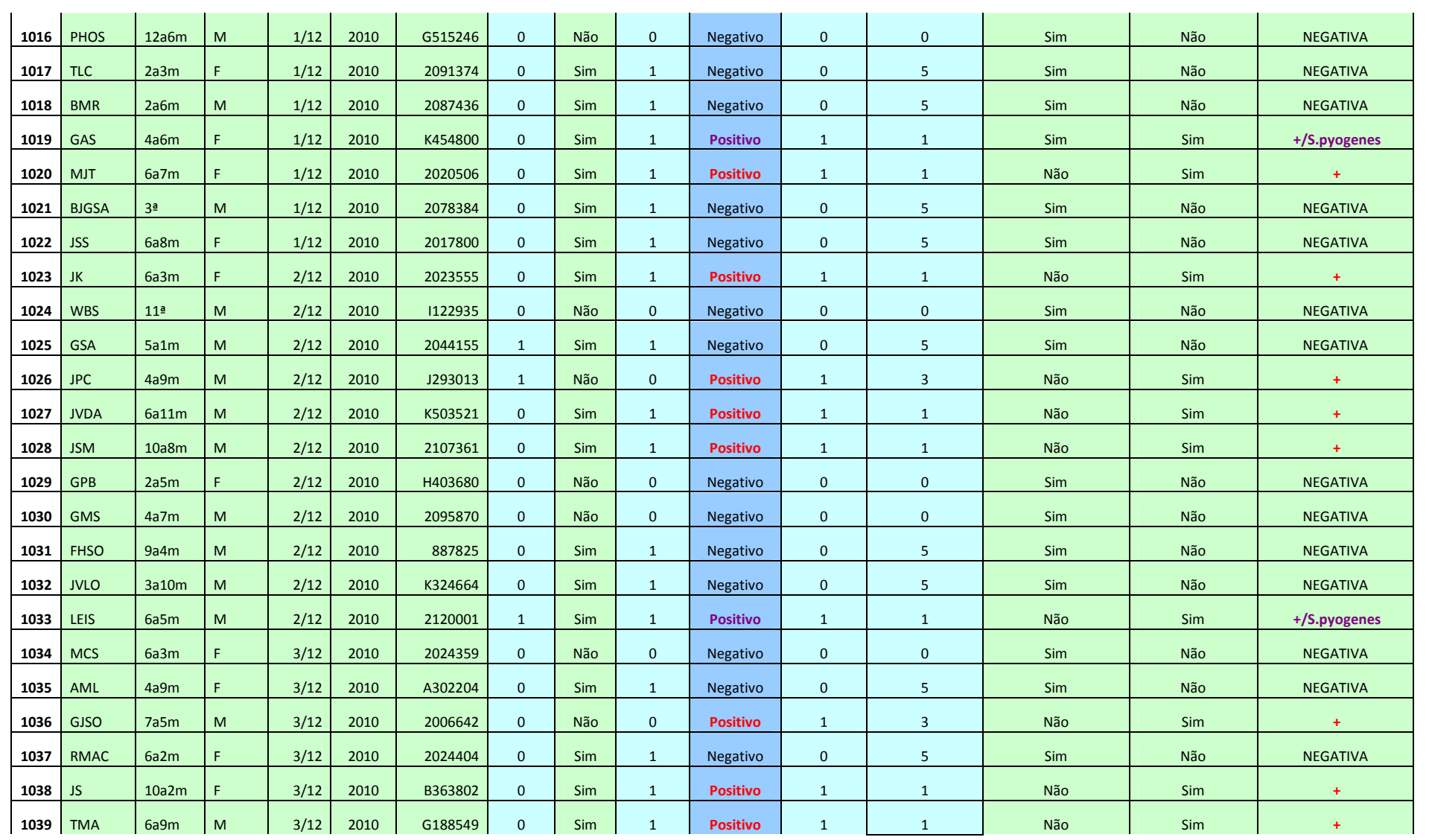


Artigo Original

\title{
Impacto do uso da prova rápida para estreptococo beta-hemolítico do grupo A no diagnóstico e tratamento da faringotonsilite aguda em pronto-socorro de Pediatria
}

\author{
Impact of the rapid antigen detection test in diagnosis and treatment of acute pharyngotonsillitis in a \\ Pediatric emergency room
}

Débora Morais Cardoso', Alfredo Elias Gilio', Shieh Huei Hsin ${ }^{3}$, Beatriz Marcondes Machadơ, Milena De Paulis ${ }^{5}$, João Paulo B. Lotufo , Marina Baquerizo Martinez", Sandra Josefina E. Grisp

\section{RESUMO}

Objetivo: Avaliar o impacto da realização rotineira da prova rápida para pesquisa de estreptococo do grupo $\mathrm{A}$ no diagnóstico e tratamento da faringotonsilite aguda em crianças.

Métodos: Estudo prospectivo e observacional que contou com a utilização de protocolo de pesquisa estabelecido na Unidade de Emergência do Hospital Universitário da Universidade de São Paulo para o atendimento de crianças e adolescentes com faringotonsilite aguda.

Resultados: Com base na avaliação clínica, dos 650 pacientes estudados, antimicrobianos seriam prescritos para 389 indivíduos $(59,8 \%)$ e, com o uso da pesquisa de estreptococo do grupo $\mathrm{A}$, foram prescritos em 286 pacientes $(44,0 \%)$. Das 261 crianças que não receberiam antibiótico pelo quadro clínico, 111 (42,5\%) tiveram pesquisa de estreptococo do grupo $\mathrm{A}$ positiva. $\mathrm{O}$ diagnóstico baseado no quadro clínico apresentou sensibilidade de $61,1 \%$, especificidade de $47,7 \%$, valor preditivo positivo de $44,9 \%$ e valor preditivo negativo de $57,5 \%$
Conclusões: $\mathrm{O}$ diagnóstico clínico da faringotonsilite estreptocócica mostrou baixa sensibilidade e especificidade. $\mathrm{O}$ uso rotineiro da prova rápida para pesquisa de estreptococo permitiu a redução do uso de antibióticos e a identificação de um grupo de risco para as complicações da infecção estreptocócica, pois $42,5 \%$ dos pacientes com prova rápida positiva não receberiam antibióticos, se levado em consideração apenas o diagnóstico clínico.

Palavras-chave: tonsilite/diagnóstico; Streptococcus grupo A; criança; adolescente.

\section{ABSTRACT}

Objective: To evaluate the impact of the routine use of rapid antigen detection test in the diagnosis and treatment of acute pharyngotonsillitis in children.

Methods: This is a prospective and observational study, with a protocol compliance design established at the Emergency Unit of the University Hospital of Universidade de
Instituicao: Hospital Universitário da Universidade de Sao Paulo (USP), Sao Paulo, SP, Brasil

'Doutoranda do Programa de Pós-Graduaçao da Faculdade de Medicina da USP; Médica Assistente do Pronto-Socorro de Pediatria e da Enfermaria de Pediatria do Hospital Universitário da USP, Sao Paulo, SP, Brasil Professor Doutor do Departarnento de Pediatria da Faculdade de Medicina da USP: Diretor da Divisaao de Clínica Pediátrica do Hospital Universitário da USP, Sao Paulo, SP, Brasil

Médico Assistente da Unidade de Terapia Intensiva Pediatrica do Hospital Universitário da USP, Sao Paulo, SP, Brasil

"Doutora em Ciências Médicas pela Faculdade de Medicina da USP; Médica Assistente do Pronto-Socorro de Pediatria do Hospital Universitário da USP. Sao Paulo, SP, Brasil

Mestre ern Ciencias Médicas pela Faculdade de Medicina da USP; Médica Assistente do Pronto-Socorro de Pediatria do Hospital Universitário da USP, Sao Paulo, SP, Brasil

Mestre ern Ciências Médicas pela Faculdade de Medicina da USP; Chefe do Pronto-Socorro de Pediatria do Hospital Universitário da USP, Sao Paulo, $\mathrm{SP}$, Brasil
TProfessora Titular da Faculdade de Ciências Farmacêuticas da USP: Diretora do Laboratório Clínico do Hospital Universitário da USP, Sao Paulo, SP, Brasil

EProfessora Titular do Departamento de Pediatria da Faculdade de Medicina da USP, Sao Paulo, SP, Brasil

Endereço para correspondencia: Débora Morais Cardoso

Avenida Doutor Lineu Prestes, 2.555

CEP 05508-000 - Sao Paulo/SP

E-mail: débora@u.usp.br

Conflito de interesse: nada a declarar

Pecebido em: 6/6/2012

Aprovado ern: 8/10/2012 
São Paulo for the care of children and adolescents diagnosed with acute pharyngitis.

Results: 650 children and adolescents were enrolled. Based on clinical findings, antibiotics would be prescribed for 389 patients (59.8\%); using the rapid antigen detection test, they were prescribed for 286 patients (44.0\%). Among the 261 children who would not have received antibiotics based on the clinical evaluation, $111(42.5 \%)$ had positive rapid antigen detection test. The diagnosis based only on clinical evaluation showed $61.1 \%$ sensitivity, $47.7 \%$ specificity, $44.9 \%$ positive predictive value, and $57.5 \%$ negative predictive value.

Conclusions: The clinical diagnosis of streptococcal pharyngotonsillitis had low sensitivity and specificity. The routine use of rapid antigen detection test led to the reduction of antibiotic use and the identification of a risk group for complications of streptococcal infection, since $42.5 \%$ positive rapid antigen detection test patients would not have received antibiotics based only on clinical diagnosis.

Key-words: tonsillitis/diagnosis; Streptocaccus group A; child; adolescent.

\section{Introdução}

A faringotonsilite aguda é uma doença comum na faixa etária pediátrica. É causada por vários agentes etiológicos, sendo que a frequência de cada um deles varia de acordo com a idade da criança, a estação do ano e a área geográfica ${ }^{(1)}$. Os vírus são os agentes etiológicos mais comuns ${ }^{(2-4)}$. Dentre os agentes bacterianos das faringotonsilites, o estreptococo beta-hemolítico do grupo A de Lancefield (EBGA) é responsável por 15 a $30 \%$ dos $\operatorname{casos}^{(2-11)}$. O curso natural da faringotonsilite causada pelo EBGA é autolimitado, na maioria dos casos, com resolução dos sinais e sintomas entre dois e cinco dias ${ }^{(6)}$. A antibioticoterapia está indicada para reduzir o tempo da doença, a morbidade e para prevenir complicações supurativas, transmissão do EBGA (após 24 horas de antibioticoterapia não há transmissão do agente bacteriano) e complicações não supurativas (febre reumática) $)^{(2,6,7)}$.

Apenas pelos sinais e sintomas clínicos, é difícil diferenciar os quadros virais dos bacterianos ${ }^{(1-4,4)}$. Em 1981, Centor et $a l^{(11)}$ propuseram um modelo clínico para determinar a probabilidade de a infecção estreptocócica ocorrer em pacientes adultos que procuravam um serviço de emergência com história de dor de garganta e febre. O modelo consistia na avaliação de quatro variáveis clínicas: exsudato tonsilar, linfonodomegalia cervical dolorosa, febre e ausência de tosse. Pacientes com as quatro variáveis apresentaram probabilidade de $56 \%$ de cultura de orofaringe positiva para EBGA; três variáveis, $32 \%$; duas, $15 \%$; uma, $6,5 \%$; e nenhuma, $2,5 \%^{(11)}$. Ao longo dos anos, diversos autores adotaram o sistema de pontuação como critério de escolha para diagnóstico e tratamento da faringotonsilite aguda. Os critérios de Centor et al passaram a ser modificados e utilizados como base para definir de novos escores clínicos para o diagnóstico da faringotonsilite, especialmente na faixa etária pediátrica. Entretanto, os escores descritos apresentam variação de sensibilidade de 12 a $93 \%$ e especificidade de 30 a $93 \%$ (4,6,10,12-17). Em função disso, o Comitê de Febre Reumática, Endocardite e Doença de Kawasaki da Associação Americana de Cardiologia, a Academia Americana de Pediatria, a Sociedade Americana de Pediatria e, mais recentemente, a Sociedade Brasileira de Pediatria recomendam que o diagnóstico de faringotonsilite em pacientes com suspeita clínico-epidemiológica de infecção pelo EBGA seja confirmado por meio do uso de técnicas microbiológicas ${ }^{(3,4,6,15,17-20)}$.

Dentre os métodos microbiológicos disponíveis, a cultura de secreção da orofaringe é o padrão-ouro para o diagnóstico da faringotonsilite estreptocócica do grupo $A^{(8,17-19,21)}$. Apresenta sensibilidade de 90 a $95 \%$ para a detecção do $\mathrm{EBGA}^{(17)}$, porém, o tempo de semeadura da secreção deve ser superior a 24 horas, com leitura do resultado em 24 a 48 ho$\operatorname{ras}^{(2,17)}$. A prova rápida para EBGA (PRE) é um imunoensaio para a detecção de antígenos do agente etiológico na orofaringe. Apresenta especificidade em torno de $95 \% \%^{(2-4,8,21-24)}$, no entanto, sua sensibilidade é variável, de 87,0 a 96,7\%(2-4,8,24).

Em 2006, Cardoso et al realizaram um trabalho prospectivo no pronto-socorro do Hospital Universitário da Universidade de São Paulo (USP) para comparar os diagnósticos clínico e microbiológico em crianças com faringotonsilite aguda. A conclusão dos autores foi de que o exame clínico, sem o uso de técnicas microbiológicas, é insuficiente para detectar a faringotonsilite causada pelo $\mathrm{EBGA}^{(3)}$. A partir de abril de 2008 , instituiu-se, como rotina neste serviço, um protocolo de atendimento aos pacientes com suspeita de faringotonsilite aguda baseado nas recomendações da Sociedade Brasileira de Pediatria ${ }^{(25)}$. As crianças com mais de dois anos de idade, queixando-se de dor de garganta, febre e ausência de sinais de infecções virais, passaram a ser submetidas à coleta da prova rápida para EBGA. Nas crianças em que a PRE é negativa, colhe-se novo swab para a realização da cultura de orofaringe e aguarda-se o resultado 
sem a introdução de antibióticos. Nos casos em que a PRE é positiva, inicia-se o tratamento com antibiótico.

Apesar de o uso de técnicas microbiológicas para o diagnóstico e tratamento da faringotonsilite na infância ser recomendado pela Sociedade Brasileira de Pediatria ${ }^{(25)}$, não há em nosso meio estudos que avaliem a utilidade desta conduta no pronto-socorro. Portanto, o objetivo deste estudo foi avaliar o impacto da utilização rotineira da prova rápida para pesquisa de estreptococo no diagnóstico e tratamento de crianças e adolescentes com faringotonsilite aguda.

\section{Método}

Foi realizado um estudo prospectivo e observacional do protocolo de atendimento instituído no pronto-socorro infantil do Hospital Universitário da USP, no período de abril a novembro de 2008. O estudo foi aprovado pela Comissão de Ética em Pesquisa do Hospital Universitário da USP.

O Hospital Universitário da USP atende ao público em geral. No pronto-socorro infantil, a equipe de atendimento é formada por médicos assistentes ligados ao Departamento de Pediatria da Faculdade de Medicina da USP, responsáveis pela atenção médica e pela supervisão de residentes de Pediatria e alunos do $5^{\circ}$ ano da faculdade, em regime de internato.

Foram considerados critérios de inclusão para análise do estudo: idade entre 2 e 15 anos; história de dor de garganta e febre; ausência de sinais de infecção viral (tosse, obstrução nasal, lacrimejamento ocular e diarreia), excetuando-se coriza, quando sintoma único. Foram considerados critérios de exclusão: uso de antibiótico nas últimas 24 horas ou PRE com resultado negativo sem coleta de cultura de orofaringe.

Foram avaliados os resultados da PRE para EBGA. O teste utilizado foi o Clearview Strep $A^{\star}$ (Oxoid), que consiste em um imunoensaio rápido para detectar qualitativamente antígenos de estreptococos do grupo A. O material examinado foi a secreção de orofaringe. Utilizou-se um swab introduzido na orofaringe com cuidado para não tocar em mucosa jugal, língua ou úvula. Com movimento vigoroso, procedeu-se à coleta da secreção em tonsilas. A prova rápida foi realizada imediatamente, com método de acordo com as recomendações do fabricante. Os exames foram colhidos pelos médicos responsáveis pelo atendimento da criança ou por enfermeira, todos previamente treinados. Quando a PRE mostrou resultado negativo, procedeu-se à coleta da cultura de secreção de orofaringe, seguindo as recomendações da literatura, a fim de minimizar o erro de interpretação causado por uma coleta com técnica inadequada. Após a coleta dos exames foram preenchidos os seguintes dados do paciente: nome (iniciais) da criança; idade; data do atendimento; e resultado da PRE para estreptococo do grupo A. Três perguntas foram direcionadas ao médico que atendeu a criança:

- Há sinais de infecções de vias aéreas superiores?

- Você indicaria antibiótico pelos dados clínicos?

- Você prescreveu antibiótico após o exame?

Foram avaliadas as características demográficas da população estudada (idade e sexo) e os agentes etiológicos com crescimento na cultura de orofaringe. Para determinar o desempenho da PRE nas diversas faixas etárias, os pacientes foram divididos em menores e maiores de 60 meses. A cultura de orofaringe foi considerada negativa quando não houve identificação de qualquer agente etiológico ou se foram identificados agentes da flora bacteriana habitual da orofaringe (S. viridans) ou agentes etiológicos não causadores de tonsilite (Haemopbilus spp., Neisseria spp. Streptococcus pneumoniae). A cultura de orofaringe foi considerada positiva quando identificados os seguintes agentes etiológicos: Streptococcus pyogenes, Estreptococo beta hemolítico dos grupos G, F e C, Estreptococos beta hemolíticos inviáveis para identificação de sorogrupos e Estreptococo beta hemolítico não tipável.

Utilizou-se uma amostra de conveniência no período de estudo. As comparações entre as variáveis categóricas foram feitas pelos testes do qui-quadrado ou exato de Fisher, quando aplicável. As comparações entre as variáveis contínuas, com distribuição paramétrica, foram realizadas com teste $t$ de Student ou ANOVA e as comparações não paramétricas, pelo teste de Mann-Whitney. O nível de significância considerado foi 0,05 . Os pacotes estatísticos utilizados foram o PASW Statistics 17.0 da SPSS e o WINKS SDA 6.0.9 da Windowns Kwistat, versão demo.

\section{Resultados}

Foram estudados 673 pacientes, sendo 20 excluídos por serem menores de dois anos. Foram incluídas 653 crianças, porém, em três delas não houve registro adequado de dados. Portanto, foram analisadas 650 crianças.

A distribuição por sexo mostrou: 327 crianças do masculino $(50,3 \%)$ e $323(49,7 \%)$ do feminino. Quanto à idade, 242 $(37,2 \%)$ tinham de 24 a 60 meses e $408(62,8 \%)$ eram maiores do que 60 meses, sendo $259(39,9 \%)$ com 60 a 120 meses de idade, e $149(22,9 \%)$ com idade superior a 120 meses. A prova rápida foi positiva em 286 casos (44\%). A comparação 
dos resultados da PRE com a intenção de administração de antibióticos pelo médico com base apenas nos dados clínicos é mostrada na Tabela 1. Não houve relação significativa entre o resultado da PRE e o diagnóstico clínico. Ao considerar o resultado da PRE como padrão-ouro para o diagnóstico da faringotonsilite por EBGA, a indicação médica pela clínica teria sensibilidadade de $61,1 \%$ (175/286), especificidade de $47,7 \%$ (150/314), valor preditivo positivo de $44,9 \%$ $(175 / 389)$ e valor preditivo negativo de $57,55 \%$ (150/261).

A Tabela 2 mostra o acerto do diagnóstico de acordo com a faixa etária. Verificou-se que não houve diferença significativa no acerto entre as faixas etárias estudadas.

\section{Discussão}

O EBGA é o principal agente bacteriano causador de faringotonsilite aguda, com prevalência de 15 a 30\% $\%^{(2-5,25,26)}$. Apesar de a etiologia viral ser a mais comum, faringotonsilites são frequentemente tratadas com antibióticos ${ }^{(2,4,7)}$. Neste estudo, observou-se prevalência de infecção pelo EBGA de $44 \%$, superior à descrita em outros estudos ${ }^{(4,22)}$. Entretanto, resultado semelhante foi descrito por Morais et al, que descreveram prevalência de $43 \%$ de tonsilite por EBGA em crianças $^{(26)}$.

A faringotonsilite causada pelo EBGA é mais frequente em crianças acima de cinco anos e que mostram achados clínicos de doença bacteriana (febre, odinofagia, cefaleia,

Tabela 1 - Comparação dos resultados da prova rápida estreptocócica e da intenção de administração de antibiótico pelo médico de acordo com a clínica da criança

\begin{tabular}{|c|c|c|c|}
\hline \multirow{2}{*}{$\begin{array}{l}\text { Daria } \\
\text { antibiótico } \\
\text { pela clínica? }\end{array}$} & \multicolumn{2}{|c|}{$\begin{array}{c}\text { Resultado da prova } \\
\text { rápida estreptocócica }\end{array}$} & \multirow{2}{*}{ Valor $p$} \\
\hline & Positiva & Negativa & \\
\hline Sim (389 casos) & $175(44,9 \%)$ & $214(55,1 \%)$ & \multirow{2}{*}{0,57} \\
\hline Não (261 casos) & $111(42,5 \%)$ & $150(57,5 \%)$ & \\
\hline
\end{tabular}

vômitos e dor abdominal; hiperemia, hipertrofia e exsudato purulento em tonsilas; adenopatia cervical anterior dolorosa; e petéquias em palato) e ausência de sinais e sintomas das infecções de vias aéreas superiores (tosse, coriza, lacrimejamento ocular, obstrução de vias aéreas superiores e diarreia) (9). Neste estudo, houve significância estatística quando avaliada a positividade da PRE de acordo com a idade maior de 60 meses. Entretanto, a PRE foi positiva em $31,8 \%$ das crianças menores de 60 meses, sugerindo a necessidade de realizar o exame também nestes pacientes. Acredita-se que a tonsilite causada pelo EBGA seja menos prevalente na faixa etária inferior a cinco anos devido à alta incidência de infecções virais, além da menor aderência da bactéria ao epitélio tonsilar. Outros autores também identificaram o EBGA em $30 \%$ das tonsilites em crianças com idade inferior a 60 meses, especialmente nas idades de 24 a 36 meses $^{(26,27) \text {. }}$

Os dados clínico-epidemiológicos não apresentaram especificidade e sensibilidade suficientes para o diagnóstico de faringotonsilite causada pelo EBGA. Desde a década de 1970, inúmeros autores em diversos países têm tentado estabelecer um escore clínico com alta sensibilidade e especificidade para detectar faringotonsilite estreptocócica, porém, sem sucesso ${ }^{(1,4,4,7,7,10,12-17)}$. A avaliação clínica inicial, baseada em achados clínico-epidemiológicos e realizada por médicos que atenderam as crianças, gerou diagnóstico clínico inadequado em 50\% dos casos, o que corrobora os dados da literatura. Tais dados demonstram que a avaliação clínica, sem o uso de técnicas microbiológicas, é um instrumento diagnóstico impreciso para identificar a faringotonsilite estreptocócica do grupo $\mathrm{A}^{(3)}$.

No presente estudo, antibióticos teriam sido prescritos em $32,9 \%$ dos casos desnecessariamente. Estudos semelhantes também mostram a queda do uso de antibióticos quando a PRE é usada como ferramenta diagnóstica ${ }^{(*)}$. A prescrição desnecessária de antibióticos gera aumento da resistência bacteriana, além do risco de eventos adversos que podem ocorrer devido à exposição a estas medicações. Intervenções para diminuir a prescrição inadvertida de antibióticos devem ser providenciadas, sendo

Tabela 2 - Comparação do resultado da prova rápida estreptocócica positiva, indicação de antibiótico pelo médico e diagnóstico clínico correto nas faixas etárias de 24 a 60 meses e maior que 60 meses

\begin{tabular}{|c|c|c|c|c|}
\hline \multicolumn{2}{|l|}{ Variáveis } & $\begin{array}{c}24 \text { a } 60 \text { meses } \\
n=242\end{array}$ & $\begin{array}{c}>60 \text { meses } \\
n=408\end{array}$ & Valor $p$ \\
\hline Prova rápida estreptocócica & & $91(37,6 \%)$ & $195(47,7 \%)$ & 0,011 \\
\hline $\begin{array}{l}\text { Indicação de antibiótico } \\
\text { pelo médico }\end{array}$ & $\begin{array}{l}\text { Sim } \\
\text { Não }\end{array}$ & $\begin{array}{r}143(59,0 \%) \\
99(41,0 \%)\end{array}$ & $\begin{array}{l}246(60,0 \%) \\
162(40,0 \%)\end{array}$ & 0,762 \\
\hline Diagnóstico clínico correto & $\begin{array}{l}\text { Sim } \\
\text { Não }\end{array}$ & $\begin{array}{l}118(48,8 \%) \\
124(51,2 \%)\end{array}$ & $\begin{array}{l}207(50,7 \%) \\
201(49,3 \%)\end{array}$ & 0,627 \\
\hline
\end{tabular}


Impacto do uso da prova rápida para estreptococo beta-hemolítico do grupo $\mathrm{A}$

no diagnóstico e tratamento da faringotonsilite aguda em pronto-socorro de Pediatria

o uso de técnicas diagnósticas microbiológicas, como a PRE, uma das intervenções recomendadas ${ }^{(28)}$.

Por outro lado, em $17,1 \%$ dos casos, se a avaliação clínica fosse utilizada como único método diagnóstico, pacientes com faringotonsilite por EBGA deixariam de receber antibióticos. Com isso, estariam sob risco de complicações supurativas e não supurativas. A febre reumática é muito prevalente nos países em desenvolvimento ${ }^{(29)}$. No Brasil, entre 2005 e 2007 cerca de 30.000 pacientes necessitaram de internação hospitalar para tratamento de febre reumática, o que contabilizou um custo para o Sistema Único de Saúde de R $\$ 162.000,00$. Dentre as cirurgias cardíacas realizadas no Brasil, $26 \%$ são direcionadas à correção de valvopatia reumática ${ }^{(30)}$.

Estudos semelhantes ao presente foram realizados em outros países e também demonstraram dificuldades para a decisão terapêutica empírica nos casos de faringotonsilite. Em tais análises, a disponibilidade do uso da PRE para EBGA no diagnóstico da tonsilite aguda permitiu que houvesse redução na prescrição de antibióticos e garantiu que as crianças com infecção pelo EBGA fossem tratadas precocemente, reduzindo, portanto, o risco de complicações tardias ${ }^{(8,26,31,32)}$. Esses resultados corroboram, portanto, dados de literatura de que, para diagnóstico e tratamento adequados da tonsilite por EBGA, somente a avaliação clínica baseada nos sinais e sintomas é um instrumento diagnóstico ruim.

O diagnóstico deve ser baseado em suspeita clínica e epidemiológica, confirmada por método microbiológico que permita identificar precocemente o agente etiológico. A PRE para EBGA é um imunoensaio rápido para a detecção de antígenos do carboidrato do grupo $\mathrm{A}$ do agente etiológico na orofaringe. Em vista de sua alta especificidade, preconiza-se que nos casos em que a PRE é positiva não se realize cultura de orofaringe concomitante ${ }^{(22)}$. Por outro lado, devido à sensibilidade variável de acordo com a intensidade da doença, técnica de coleta inadequada, baixa quantidade de antígenos e tipo de kit utilizado ${ }^{(18,20,22,24)}$, recomenda-se que, frente a uma prova rápida negativa, proceda-se à coleta

\section{Referências bibliográficas}

1. Wald ER, Green MD, Schwartz B, Barbadora K. A streptococcal score card revisited. Pediatr Emerg Care 1998;14:109-11.

2. Webb KH. Does culture confirmation of high-sensitivity rapid streptococcal tests make sense? A medical decision analysis. Pediatrics 1998;101:E2.

3. Cardoso DM, Sabino HM, Gilio AE, Machado BM, Lotufo JP, Passadore LF et al. Streptococcal pharyngitis: comparison between the clinical and microbiological diagnosis. Pediatria (Säo Paulo) 2009:31:94-8.

4. Santos AG, Berezin EN. Comparative analysis of clinical and laboratory methods for diagnosing streptococcal sore throat. J Pediatr (Rio J) 2005;81:23-8. da cultura de orofaringe $\mathrm{e}^{(2,24,26,27,32)}$. Vários estudos foram realizados para comparar a PRE e a cultura de orofaringe, observando-se que a sensibilidade da PRE varia de 87,0 a $96,7 \%$; a especificidade, de 95,1 a $100,0 \%$; o valor preditivo positivo, de 84,9 a $95,0 \%$; e o valor preditivo negativo, de 93,8 a $98,9 \%^{(2-4,8,24)}$.

Este estudo apresenta algumas limitações. Em primeiro lugar, não foi utilizado um escore clínico padronizado para o diagnóstico da tonsilite. Tal opção foi feita porque o objetivo principal era reproduzir as práticas mais frequentes na clínica diária e, não, comparar os métodos diagnósticos por escore versus método microbiológico. Entretanto, foram adotados como critérios de inclusão para o estudo dados de história clínica e do exame físico, que invariavelmente são citados na maior parte dos escores existentes. Em segundo lugar, a avaliação clínica e a coleta de exames foram realizadas por diferentes profissionais a cada atendimento. Isso, sem dúvida, impossibilita a uniformidade dos dados encontrados e analisados. Porém, o atendimento realizado por alunos foi supervisionado por um médico assistente ou residente. Além disso, em todas as PRE negativas procedeu-se à coleta da cultura de orofaringe, reduzindo a possibilidade de resultados falso-negativos. Outra limitação é não ter efetuado a análise de custo-efetividade da adoção de protocolo com o PRE, mas, sem dúvida, a redução do uso de antibióticos agrega um benefício importante para a criança e para o serviço de saúde, além do impacto eventual na pressão seletiva de cepas microbianas resistentes.

Neste estudo, o diagnóstico clínico da faringotonsilite estreptocócica apresentou baixa sensibilidade e especificidade, o que já fora demonstrado em vários outros estudos. A PRE mostrou ser um bom exame de triagem para o diagnóstico de faringotonsilite estreptocócica, pois permitiu reduzir o uso de antibiótico e identificar um grupo de risco para as complicações da infecção estreptocócica. Portanto, o uso rotineiro da PRE permite um diagnóstico etiológico mais preciso. 
9. Gerber MA, Baltimore RS, Eaton CB, Gewitz M, Rowley AH, Shulman ST et al. Prevention of meumatic fever and diagnosis and treatment of acute streptococcal pharyngitis: a scientific statement from the American Heart Association Rheumatic Fever, Endocarditis and Kawasaki disease committee of the council on functional genomics and translational biology, and the interdisciplinary council on quality of care and outcomes research: endorsed by the American Academy of Pediatrics. Circulation 2009:119:1541-51.

10. Mclsaac WJ, White D, Tannenbaum D, Low DE. A clinical score to reduce unnecessary antibiotic use in patients with sore throat. CMAJ 1998:14:75-83.

11. Centor RM, Witherspoon JM. Dalton HP. Brody CE, Link K. The diagnosis of strep throat in adults in the emergency room. Med Decis Making 1981:1:239-46.

12. Breese BB. A simple scorecard for the tentative diagnosis of streptococcal pharyngitis. Am J Dis Child 1977:131:514-7.

13. Steinhoff MC, Abd el Khalek MK, Khallaf N, Hamza HS, el Ayadi A, Orabi A et al. Effectiveness of clinical guidelines for the presumptive treatment of streptococcal pharyngitis in Egyptian children. Lancet 1997;350:918-21.

14. Smeesters PR, Campos D Jr, Van Melderen L, de Aguiar E, Vanderpas J. Vergison A. Pharyngitis in low-resources settings: a pragmatic clinical approach to reduce unnecessary antibiotic use. Pediatrics 2006;118:e1607-11.

15. Rimoin AW, Hamza HS, Vince A, Kumar R, Walker CF. Chitale RA et al. Evaluation of the WHO clinical decision rule for streptococcal pharyngitis. Arch Dis Child 2005;90:1066-70.

16. Regoli M, Chiappini E, Bonsignori F, Galli L, de Martino M. Update on the management of acute pharyngitis in children. Ital J Pediatr 2011:37:10.

17. Bisno AL, Gerber MA, Gwaltney Jr JM, Kaplan EL, Schwartz RH. Practice guidelines for the diagnosis and management of group A streptococcal pharyngitis. Clin Infect Dis 2002;35:113-25.

18. American Academy of Pediatrics. Infecoposes estreptocócicas do grupo A. In: Pickering LK, ed. Red Book":2003. Report of Committee on Infectious Diseases. $26^{\text {th }}$ ed. Elk Groove Village: American Academy of Pediatrics; 2003. p. 419-30.

19. Tanz RR, Gerber MA, Kabat W, Rippe J, Seshadri R, Shulman ST. Performance of a rapid antigen-detection test and throat culture in community pediatric offices: implications for management of pharyngitis. Pediatrics $2009: 123: 437-44$
20. Nascimento-Carvalho CM, Marques HH. Recomendação do departamento de Infectologia da Sociedade Brasileira de Pediatria para conduta de crianças e adolescentes com faringoamigdalites agudas. J Pediatr (Rio J) 2006;82:79-80.

21. Gerber MA, Shulman ST. Rapid diagnosis of pharyngitis caused by group $A$ streptococci. Clin Microbiol Rev 2004:17:571-80.

22. Edmonson MB, Farwell KR. Relationship between the clinical likelihood of group a streptococcal pharyngitis and the sensitvity of a rapid antigen-detection test in a pediatric practice. Pediatrics 2005;115;280-5.

23. Rimoin AW, Walker CL, Hamza HS, Elminawi N, Ghafar HA, Vince A et al. The utility of rapid antigen detection testing for the diagnosis of streptococcal pharyngitis in low-resource settings. Int J Infect Dis 2010;14:e1048-53.

24. Fontes MJ, Bottrel FB, Fonseca MT, Lasmar LB, Diamante R, Camargos PA. Early diagnosis of streptococcal pharyngotonsillitis: assessment by latex particle agglutination test. J Pediatr (Rio J) 2007:83:465-70.

25. Armengol CE, Schlager TA, Hendley JO. Sensitivity of a rapid antigen detection test for group A streptococci in a private pediatric office setting: answering the red book's request for validation. Pediatrics 2004;113:924-6.

26. Morais S, Teles A, Ramalheira E, Roseta J. Streptococcal pharyngitis: clinical suspicion versus diagnosis. Acta Med Port 2009:22:773-8.

27. Woods WA, Carter CT, Schlager TA. Detection of group A streptococoi in children under 3 years of age with pharyngitis. Pediatr Emerg Care 1999;15:338-40.

28. Samore MH, Bateman K. Alder SC, Hannah E, Donnelly S, Stoddard GJ et al. Clinical decision support and appropriateness of antimicrobial prescribing: a randomized trial. JAMA 2005;294:2305-14.

29. World Heath Organization. WHO expert $\infty$ nsultation on rheumatic fever and rheumatic heart disease. Geneva: WHO; 2004.

30. Brasil. Ministério da Saúde. DATASUS [homepage on the Internet]. Assessoria técnica-gerencial [cited $2012 \mathrm{Feb}$ 06]. Available from: www.datasus.gov.br.

31. Ayanruoh S, Waseem M, Quee F. Humphrey A, Reynolds T. Impact of rapid streptococcal test on antibiotic use in a pediatric emergency department. Pediatr Emerg Care 2009:25:748-50.

32. Linder JA Bates DW, Lee GM, Finkelstein JA. Antibiotic treatment of children with sore throat. JAMA 2005:294:2315-22. 
11 REFERÊNCIAS 
Al-Najjar FYA, Uduman SA. Clinical utility of a new rapid test for the detection of group A Streptococcus and discriminate use of antibiotics for bacterial pharyngitis in an outpatient setting. Int J Infect Dis. 2008;12(3):308-11.

American Academy of Pediatrics. Group A streptococcal infections. In: Pickering LK, editor. Red Book 2000: Repport of the Committe on Infectious Disease. 25th ed. Elk Grove Village, IL: American Academy of Pediatrics; 2000. p.526-37.

Armengol CE, Schlager TA, Hendley JO. Sensitivity of a rapid antigen detection test for group A streptococci in a private pediatric office setting: answering the red book's request for validation. Pediatrics. 2004;113(4):924-6.

Atlas SJ, McDermott SM, Mannone C, Barry MJ. The role of point of care testing for patients with acute pharyngitis. J Gen Intern Med. 2005;20(8):759-61.

Attia MW, Zaoutis T, Klein JD, Meier FA. Performance of a predictive model for streptococcal pharyngitis in children. Arch Pediatr Adolesc Med. $2001 ; 155(6): 687-91$.

Ayanruoh S, Waseem M, Quee F, Humphrey A, Reynolds T. Impact of rapid streptococcal test on antibiotic use in a pediatric emergency department. Pediatr Emerg Care. 2009;25(11):748-50.

Bisno AL, Gerber MA, Gwaltney JM, Kaplan EL, Schwartz RH. Practice Guidelines for the diagnosis and management of Group A Streptococcal pharyngitis. Clin Infect Dis. 2002;35(2):113-25.

Bisno AL, Brito MO, Collins CM. Molecular basis of group A streptococcal virulence. Lancet. 2003;3(4):191-200.

Brasil. Ministério da Saúde. Sistema de Informações Hospitalares do SUS (SIH/SUS). Brasília, DF; 2008 [citado 25 nov. 2013]. Disponível em: 
http://www2.datasus.gov.br/DATASUS/index.php?area=0203\&VObj=http://tabn et.datasus.gov.br/cgi/deftohtm.exe?sih/cnv/ni

Breese BB. A simple scorecard for the tentative diagnosis of streptococcal pharyngitis. Am J Dis Child. 1977;131(5):514-7.

Bricks LF. Uso judicioso de medicamentos em crianças. J Pediatr (Rio J). 2003;79(Supl.1):107-14.

Buchbinder N, Benzdira A, Belgaïd A, Dufour D, Paon J-C, Morel A, et al. Streptococcal pharyngitis in the pediatric emergency department: value and impact of rapid antigen detection test. Arch Pediatr. 2007;14(9):1057-61.

Camurdan AD, Camurdan OM, Ok I, Sahin F, Ilhan MN, Beyazova U. Diagnostic value of rapid antigen detection test for streptococcal pharyngitis in a pediatric population. Int J Pediatr Otorhinolaryngol. 2008;72(8):1203-6.

Carapetis JR, Steer AC, Mulholland EK, Weber M. The global burden of group A streptococcal diseases. Lancet Infect Dis. 2005;5(11):685-94.

Cardoso DM, Sabino HM, Gilio AE, Marcondes B, Lotufo JPB, et al. Faringoamidalite estreptocócica: comparação entre diagnóstico clínico e microbiológico. Pediatria (São Paulo). 2009;31(2):94-9.

Cardoso, DM, Gilio AE, Hsin SH, Machado BM, De Paulis M, Lotufo JPB, Martinez MB GS. Impacto do uso da prova rápida para estreptococo betahemolítico do grupo A no diagnóstico e tratamento da faringotonsilite aguda em pronto-socorro de Pediatria. Rev Paul Pediatr. 2013;31(1):4-9.

Centor RM, Whiterspoon JM, Dalton HP, Brody CE, Link K. The diagnosis of strep throat in adults in the emergency room. Med Decis Making. $1981 ; 1(3): 239-46$.

Chiappini E, Regoli M, Bonsignori F, Sollai S, Parretti A, Galli L, et al. Analysis of different recommendations from international guidelines for the management of acute pharyngitis in adults and children. Clin Ther. 2011;33(1):48-58. 
Choby BA. Diagnosis and treatment of streptococcal pharyngitis. Am Fam Physician. 2009;79(5):383-90.

Cillo ACP, Macatti EF, Oliveira GDL, Neves GR, MartinsJ, Siqueira LF, et al. Avaliação de amigdalite estreptocócica em crianças. Rev Ciênc Med (Campinas). 1999;8(1):11-4.

Costa LP, Domiciano DS, Maria R, Pereira R. Características demográficas, clínicas, laboratoriais e radiológicas da febre reumática no Brasil: revisão sistemática. Rev Bras Reum. 2009;49(5):606-11.

Cohen JF, Chalumeau M, Levy C, Bidet P, Thollot F, Wollner A, et al. Spectrum and inoculum size effect of a rapid antigen detection test for group $A$ streptococcus in children with pharyngitis. PLoS One. 2012;7(6):e39085.

Deuster S, Roten I, Muehlebach S. Implementation of treatment guidelines to support judicious use of antibiotic therapy. J Clin Pharm Ther. 2010;35(1):71-8.

Dingle TC, Abbott AN, Fang FC. Reflexive culture in adolescents and adults with Group A Streptococcal Pharyngitis. Clin Infect Dis. 2014;59:643-50.

Ebell MH. Making decisions at the point of care: sore throat. Fam Pr Manag. 2003;10(8):68.

Edmonson MB, Farwell KR. Relationship between the clinical likelihood of group a streptococcal pharyngitis and the sensitivity of a rapid antigen-detection test in a pediatric practice. Pediatrics. 2005;115(2):280-5.

Fontes MJF, Bottrel FB, Fonseca MTM, Lasmar LB, Diamante R, Camargos PAM. Early diagnosis of streptococcal pharyngotonsillitis: assessment by latex particle agglutination test. J Pediatr (Rio J). 2007;83(5):465-70

Gerber MA, Shulman ST. Rapid diagnosis of pharyngitis caused by Group A Streptococci. Clin Microbiol Rev. 2004;17(3):571-80.

Gerber MA, Baltimore RS, Eaton CB, Gewitz M, Rowley AH, Shulman ST, et al. Prevention of rheumatic fever and diagnosis and treatment of acute 
Streptococcal pharyngitis: a scientific statement from the American Heart Association Rheumatic Fever, Endocarditis, and Kawasaki Disease Committee of the Council on Cardiovascular Disease. Circulation. 2009;119(11):1541-51.

Giesseker K, Mackenzie T, Roe MH TJ. Comparison of two rapid Streptococcus pyogenes diagnostic tests with a rigorous culture standard. Pediatr Infect Dis $\mathrm{J}$. 2002;21(10):922-7.

Giraldez-Garcia C, Rubio B, Gallegos-Braun JF, Imaz I, Gonzalez-Enriquez J, Sarria-Santamera A. Diagnosis and management of acute pharyngitis in a paediatric population: a cost-effectiveness analysis. Eur $J$ Pediatr. 2011;170(8):1059-67.

Gurol Y, Akan H, Izbirak G, Tekkanat ZT, Gunduz TS, Hayran O, et al. The sensitivity and the specifity of rapid antigen test in streptococcal upper respiratory tract infections. Int J Pediatr Otorhinolaryngol. 2010;74(6):591-3.

Henningham A. Pathogenesis of Group A Streptoccocal Infections. John Hopkins C Discov Med. 2012;13(72):329-42.

Ibia E, Sheridan M, Schwartz R. Knowledge of the principles of judicious antibiotic use for upper respiratory infections: a survey of senior medical students. South Med J. 2005;98(9):889-95.

Johansson L, Mansson NO. Rapid test, throat culture and clinical assessment in the diagnosis of tonsillitis. Fam Pract. 2003;20(2):108-11.

Lancefield RC. A serological differentiation of human and other groups of hemolytic streptococci. J Exp Med. 1933;57(4):571-95.

Lasseter GM, McNulty CAM, Richard Hobbs FD, Mant D, Little P. In vitro evaluation of five rapid antigen detection tests for group A beta-haemolytic streptococcal sore throat infections. Fam Pract. 2009;26(6):437-44.

Lean WL, Arnup S, Danchin M, Steer AC. Rapid diagnostic tests for Group A Streptococcal Pharyngitis: a meta-analysis. Pediatrics. 2014;134(4):771-8. 
Le Marechal F, Martinot A, Duhamel A, Pruvost I, Dubos F. Streptococcal pharyngitis in children: a meta-analysis of clinical decision rules and their clinical variables. BMJ Open. 2013;3(3):e001482.

Lieu TA, Fleisher GR, Schwartz JS, Lieu A, Fleisher R, Sanford J, et al. Costeffectiveness of rapid latex agglutination testing and throat culture for streptococcal pharyngitis. Pediatrics. 1990;85(3):246-56.

Linder JA, Bates DW, Lee GM, Finkelstein JA. Antibiotic treatment of children with sore throat. JAMA. 2005;294(18):2315-22.

Litvin CB, Ornstein SM, Wessell AM, Nemeth LS, Nietert PJ. Adoption of a clinical decision support system to promote judicious use of antibiotics for acute respiratory infections in primary care. Int J Med Inform. 2012;81(8):521-6.

Llor C, Madurell J, Balagué-Corbella M, Gómez M, Cots JM. Impact on antibiotic prescription of rapid antigen detection testing in acute pharyngitis in adults: a randomised clinical trial. Br J Gen Pract. 2011;61(586):e244-51.

Madurell J, Balagué M, Gómez M, Cots JM, Llor C. Impact of rapid antigen detection testing on antibiotic prescription in acute pharyngitis in adults. FARINGOCAT STUDY: a multicentric randomized controlled trial. BMC Fam Pract. 2010;11:25.

Maltezou HC, Tsagris V, Antoniadou A, Galani L, Douros C, Katsarolis I, et al. Evaluation of a rapid antigen detection test in the diagnosis of streptococcal pharyngitis in children and its impact on antibiotic prescription. $J$ Antimicrob Chemother. 2008;62(6):1407-12.

Martin JM, Green M, Barbadora KA, Wald ER. Group A streptococci among school-aged children: clinical characteristics and the carrier state. Pediatrics. $2004 ; 114(5): 1212-9$.

Mateo GF, Conejero J, Martinel EG, Baba Z, Aliaga A, Dicono S, et al. Atención Primaria diagnóstico precoz de faringitis estreptocócica en pediatria:validacion de una técnica antigénica rápida. Aten Primaria. 2010;42(7):356-61. 
Matthys J, De Meyere M, van Driel ML, De Sutter A. Differences Among International Pharyngitis Guidelines: not just academic. Ann Fam Med. 2007;5(5):436-43.

Mclsaac WJ, White D, Tannenbaum D, Low DE. A clinical score to reduce unnecessary antibiotic use in patients with sore throat. CMAJ. 1998;158(1):7583.

Mclsaac WJ, Goel V, To T, Low DE. The validity of a sore throat score in family practice. CMAJ. 2000;163(7):811-5.

Morais S, Teles A, Ramalheira E, Roseta J. Amigdalite estreptocócica presunção clínica versus diagnóstico. Acta Med Port. 2009;22(6):773-8.

Nascimento-Carvalho C, Marques $\mathrm{H}$. Uniformização das condutas. Recomendação do Departamento de Infectologia da Sociedade Brasileira de Pediatria para conduta de crianças e adolescentes com faringoamidalites agudas. J Pediatr (Rio J). 2006;82(1):79-82.

Needham CA, McPherson KA, Webb KH. Streptococcal pharyngitis: impact of a high-sensitivity antigen test on physician outcome. J Clin Microbiol. 1998;36(12):3468-73.

Pandey M, Batzloff MR, Good MF. Vaccination against rheumatic heart disease: a review of current research strategies and challenges. Curr Infect Dis Rep. 2012;14(4):381-90.

Peñalba Citores AC, Riaño Méndez B, Marañón Pardillo R, Míguez Navarro C, Vázquez López $\mathrm{P}$, Guerrero Soler $\mathrm{MM}$, et al. Incidencia de faringitis estreptocócica. An Pediatría (Barc). 2007;67(3):220-4.

Pichichero ME. Group A streptococcal tonsillopharyngitis: cost-effective diagnosis and treatment. Ann Emerg Med. 1995;25(3):390-403.

Piñeiro Pérez R, Hijano Bandera F, Alvez González F, Fernández Landaluce A, Silva Rico JC, Pérez Cánovas $C$, et al. Consensus document on the diagnosis 
and treatment of acute tonsillopharyngitis. An Pediatr (Barc). 2011;75(5):342.e1-13.

Pulcini C, Pauvif L, Paraponaris A, Verger P, Ventelou B. Perceptions and attitudes of French general practitioners towards rapid antigen diagnostic tests in acute pharyngitis using a randomized case vignette study. $J$ Antimicrob Chemother. 2012;67(6):1540-6.

Regoli M, Chiappini E, Bonsignori F, Galli L, de Martino M. Update on the management of acute pharyngitis in children. Ital J Pediatr. 2011;37(1):10.

Regueras De Lorenzo G, Santos Rodríguez PM, Villa Bajo L, Pérez Guirado A, Arbesú Fernández E, Barreiro Hurlé L, et al. Use of the rapid antigen technique in the diagnosis of Streptococcus pyogenes pharyngotonsillitis. An Pediatr (Barc). 2012;77(3):193-9.

Rimoin AW, Hamza HS, Vince A, Kumar R, Walker CF, Chitale RA, et al. Evaluation of the WHO clinical decision rule for streptococcal pharyngitis. Arch Dis Child. 2005;90(10):1066-70.

Roberts AL, Connolly KL, Kirse DJ, Evans AK, Poehling K a, Peters TR, et al. Detection of group A Streptococcus in tonsils from pediatric patients reveals high rate of asymptomatic streptococcal carriage. BMC Pediatr. 2012;12(1):3.

Rogo T, Schwartz RH, Ascher DP. Comparison of the Inverness Medical Acceava Strep A test with the Genzyme OSOM and Quidel QuickVue Strep A tests. Clin Pediatr (Phila). 2010;49(11):1050-2.

Rosenberg P, Mclsaac W, Macintosh D, Kroll M. Diagnosing streptococcal pharyngitis in the emergency department: Is a sore throat score approach better than rapid streptococcal antigen testing? CJEM. 2002;4(3):178-84.

Rubin LG, Mirkin GS. Apparent false positive detection of group a Streptococcus antigen resulting from pharyngeal infection with a nonhemolytic Streptococcus pyogenes. Pediatr Infect Dis. 2000;19(7):672-4. 
Ruiz-Aragón J, Rodríguez López R, Molina Linde JM. Evaluation of rapid methods for detecting Streptococcus pyogenes. Systematic review and metaanalysis. An Pediatr (Barc). 2010;72(6):391-402.

Sabuncu E, David J, Bernède-Bauduin C, Pépin S, Leroy M, Boëlle PY, et al. Significant reduction of antibiotic use in the community after a nationwide campaign in France, 2006-2007. PLoS Med. 2009;6(6):2002-7.

Samore MH, Bateman K, Alder SC, Hannah E, Donnelly S, Stoddard GJ, et al. Clinical decision support and appropriateness of antimicrobial prescribing. JAMA. 2005;294(18):2305-14.

Santos AGP, Berezin E. Comparação entre métodos clínicos e laboratoriais no diagnóstico das faringotonsilites estreptocócicas Comparative analysis of clinical and laboratory methods for diagnosing streptococcal sore throat. $J$ Pediatr (Rio J). 2005;81(1):23-8.

Sarikaya S, Aktaş C, Ay D, Cetin A, Celikmen F. Sensitivity and specificity of rapid antigen detection testing for diagnosing pharyngitis in the emergency department. Ear Nose Throat J. 2010;89(4):180-2.

Schwartz B, Marcy SM, Phillips WR, Gerber MA, Dowell SF. Pharyngitis principles of judicious use of antimicrobial agents. Pediatrics. 1998;101(171):171-4.

Shaikh N, Leonard E, Martin JM. Prevalence of streptococcal pharyngitis and streptococcal carriage in children: a meta-analysis. Pediatrics. 2010;126(3):e557-64.

Sheeler RD, Houston MS, Radke S, Dale JC, Adamson SC. Accuracy of rapid strep testing in patients who have had recent streptococcal pharyngitis. $J A m$ Board Fam Pract. 15(4):261-5.

Shulman ST, Bisno AL, Clegg HW, Gerber MA, Kaplan EL, Lee G, et al. Clinical practice guideline for the diagnosis and management of group $A$ streptococcal 
pharyngitis: 2012 update by the Infectious Diseases Society of America. Clin Infect Dis. 2012;55(10):e86-102.

Smeesters PR, Campos D, Van Melderen L, de Aguiar E, Vanderpas J, Vergison A. Pharyngitis in low-resources settings: a pragmatic clinical approach to reduce unnecessary antibiotic use. Pediatrics. 2006;118(6):e1607-11.

Steinhoff MC, Abd el Khalek MK, Khallaf N, Hamza HS, el Ayadi A, Orabi A, et al. Effectiveness of clinical guidelines for the presumptive treatment of streptococcal pharyngitis in Egyptian children. Lancet. 1997;350(9082):918-21.

Tanz RR, Gerber MA, Kabat W, Rippe J, Seshadri R, Shulman ST. Performance of a rapid antigen-detection test and throat culture in community pediatric offices: implications for management of pharyngitis. Pediatrics. 2009;123(2):437-44.

Tellechea AL, Salvo G, Cavagnari BM. Frecuencia del estreptococo betahemolítico del grupo $\mathrm{A}$ en las fauces de niños sintomáticos menores de 15 años según el grupo etario. Arch Argent Pediatr. 2012;110(6):516-9.

Van Brusselen D, Vlieghe E, Schelstraete P, De Meulder F, Vandeputte C, Garmyn K, et al. Streptococcal pharyngitis in children: to treat or not to treat? Eur J Pediatr. 2014;173(10):1275-83.

Wald ER, Green MD, Schwartz B BK. A streptococcal score card revisited. Pediatr Emerg Care. 1998;14(2):109-11.

Wald ER. Approach to acute pharyngitis in children and adolescents. Waltham: UpToDate; 2007. Available from: http://www.uptodate.com/contents/approachto-diagnosis-of-acute-infectious-pharyngitis-in-children-andadolescents?source=search_result\&search=pharyngitis+Wald\&selectedTitle $=1$ $\% 7 E 150$

Walker MJ, Barnett TC, McArthur JD, Cole JN, Gillen CM, Henningham A, et al. Disease manifestations and pathogenic mechanisms of group a Streptococcus. Clin Microbiol Rev. 2014;27(2):264-301. 
Walsh BT, Bookheim WW, Johnson RC, Tompkins RK. Recognition of streptococcal pharyngitis in adults. Arch Intern Med. 1975;135(11):1493-97.

Webb KH. Does culture confirmation of high-sensitivity rapid streptococcal tests make sense? A medical decision analysis. Pediatrics. 1998;101(2):e2-e2.

Weber R. Pharyngitis. Prim Care. 2014;41(1):91-8.

Werner K, Deasy J. Acute respiratory tract infections: When are antibiotics indicated. JAAPA. 2009;22(4):22-6.

Wessels MR. Streptococcal Pharyngitis. N Engl J Med. 2011;364(7):648-55.

Woods WA, Carter CT, Schlager TA. Detection of group A streptococci in children under 3 years of age with pharyngitis. Pediatr Emerg Care. 1999;15(5):338-40.

World Health Organization. Rheumatic fever and rheumatic heart disease. Geneve: WHO expert consultation; 2004. (WHO Technical Report Series 923). 